\title{
URANIUM SOILS INTEGRATED DEMONSTRATION: SOIL CHARACTERIZATION PROJECT REPORT
}

by

\author{
James C. Cunnane \\ Victor R. Gill \\ S. Y. Lee \\ David E. Morris \\ Mark D. Nickelson \\ Dale Lynn Perry \\ Vincent C. Tidwel
}

August 1993

PREPARED FOR THE

FERNALD ENVIRONMENTAL MANA GEMENT PROJECT

FERNALD ENVIRONMENTAL RESTORATION MANAGEMENT CORPORATION

P. O. BOX 398704

CINCINNATI, OHO 45239-8704

Under contract DE-ACOS-920R21972

U. S. Department of Energy

TERNALD FIELD OFTICE

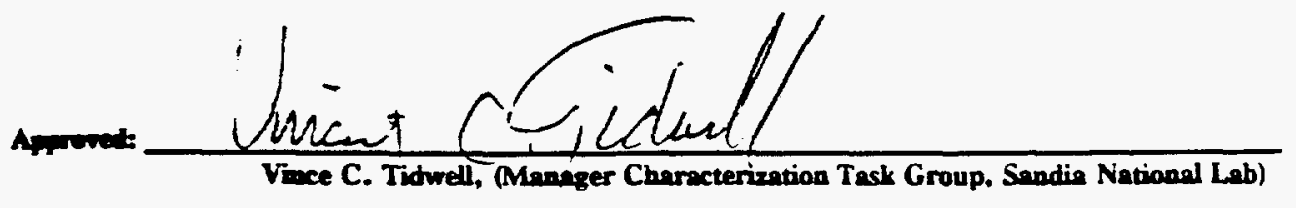

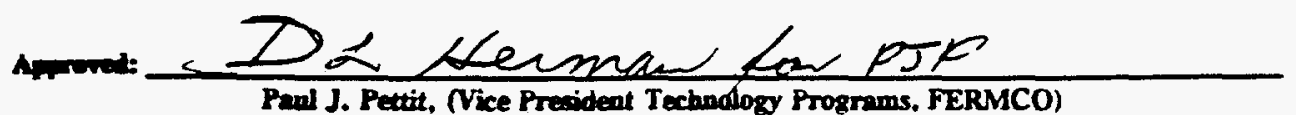

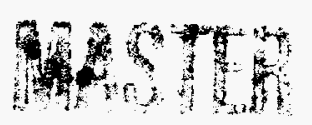




\section{PROJECT PARTICIPANTS LIST}

\section{Uranium in Soils Integrated Demonstration Coordinator:}

Kim Nuhfer

(ID Coordinator)
FERMCO/FEMP

Cincinnati, Ohio 45239-8704

(513) $648-6556$

\section{Uranium in Soils Integrated Demonstration Characterization Task Group:}

Vincent Tidwell

(Lead)

James Cunnane

Vic Gill

S. Y. Lee

Mark Nickelson

Dale Perry
Sandia National Laboratories

Albuquerque, New Mexico 87185

(505) $845-8956$

Argonne National Laboratory

Argonne, Illinois 60439

(708) $252-4541$

FERMCO/FEMP-Analytical

Cincinnati, Ohio 45239-8704

(513) 738-0003 (Extension-251)

Oak Ridge National Laboratory

Oak Ridge, Tennessee 37831-6038

(615) 574-6316

HAZWRAP

Oak Ridge, Tennessee 37831-7606

(615) 435-3236

Lawrence Berkeley Laboratory

Berkeley, California 94720

(510) 486-4819

\section{Other Project Participants:}

David Morris

Los Alamos National Laboratory

Los Alamos, New Mexico 87545

(505) 665-6487

Other participants whom we wish to acknowledge include: J. Marsh of Oak Ridge National Laboratory for his help with the initial analysis of the soil samples, E. Buck and N. Dietz of Argonne National Laboratory for their help with the microscopy studies, C. Carnahan from Lawrence Berkeley Laboratory for performing the bulk of the geochemical modeling, and S. Conradson, D. Tait, C. Brause, and J. Berg from Los Alamos National Laboratory for their assistance with the spectroscopy studies. 


\section{DISCLAIMER}

Portions of this document may be illegible in electronic image products. Images are produced from the best available original document. 


\begin{abstract}
An Integrated Demonstration Program, hosted by the Fernald Environmental Management Project (FEMP), has been established for investigating technologies applicable to the characterization and remediation of soils contaminated with uranium. Critical to the design of relevant treatment technologies is detailed information on the chemical and physical characteristics of the uranium waste-form. To address this need a soil sampling and characterization program was initiated which makes use of a variety of standard analytical techniques coupled with state-of-the-art microscopy and spectroscopy techniques. Sample representativeness is evaluated through the development of conceptual models in an effort to identify and understand those geochemical processes governing the behavior of uranium in FEMP soils. Many of the initial results have significant implications for the design of soil treatment technologies for application at the FEMP.
\end{abstract}

\title{
DISCLAIMER
}

This report was prepared as an account of work sponsored by an agency of the United States Government. Neither the United States Government nor any agency thereof, nor any of their employees, makes any warranty, express or implied, or assumes any legal liability or responsibility for the accuracy, completeness, or usefulness of any information, apparatus, product, or process disclosed, or represents that its use would not infringe privately owned rights. Reference herein to any specific commercial product, process, or service by trade name, trademark, manufacturer, or otherwise does not necessarily constitute or imply its endorsement, recommendation, or favoring by the United States Government or any agency thereof. The views and opinions of authors expressed herein do not necessarily state or reflect those of the United States Government or any agency thereof. 


\section{TABLE OF CONTENTS}

1. INTRODUCTION. ........................

1.1 Document Purpose....................... 1

1.2 Description of the Integrated Demonstration

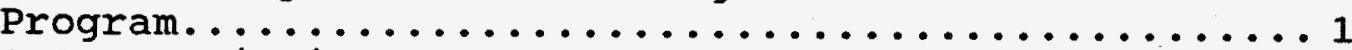

1.3 Description of ID Characterization Task Group... 2

1.4 Host site Description.................... 5

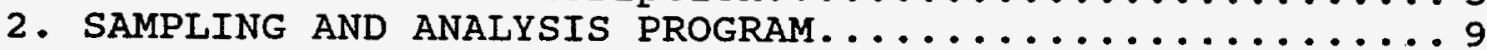

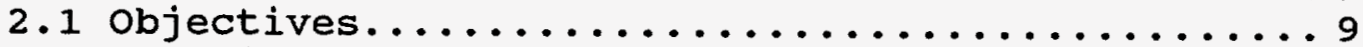

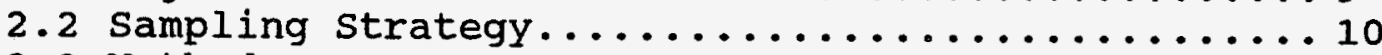

2.3 Methods............................ 14

3. PHYSICAL CHARACTERIZATION OF FEMP SOILS AND URANIUM

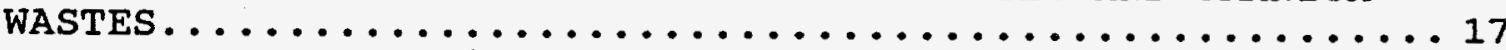

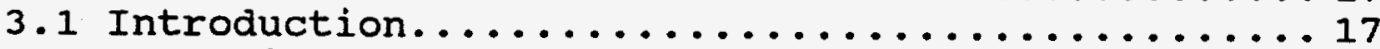

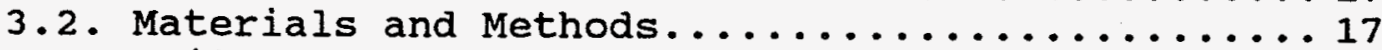

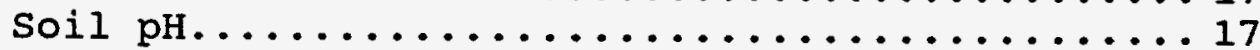

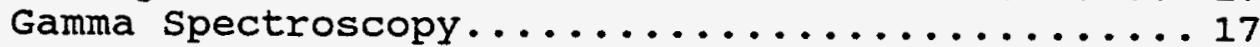

Particle Size Separation................. 18

Heavy Liquid Separation.................... 19

Neutron Activation Analysis............... 19

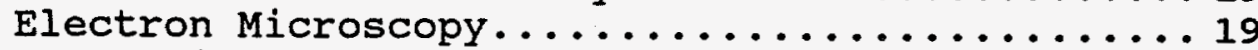

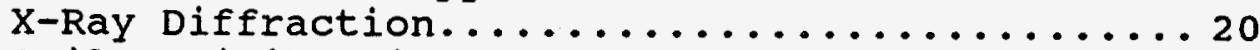

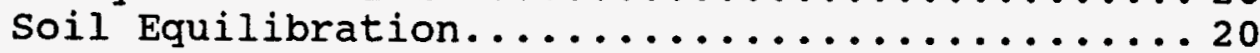

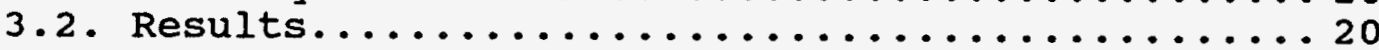

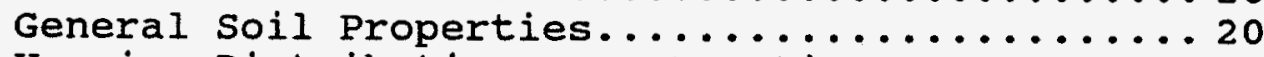

Uranium Distribution as a Function of

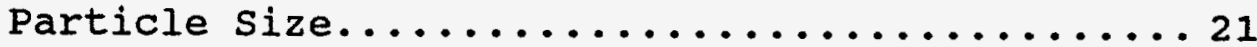

Uranium Distribution as a Function of

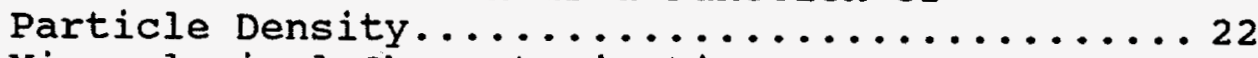

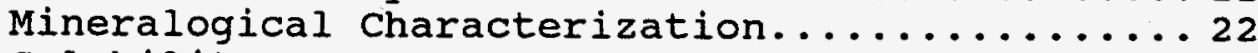

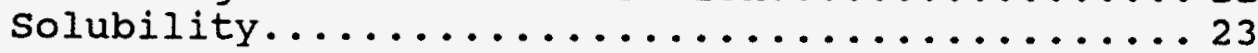

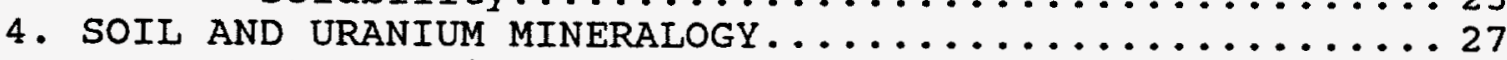

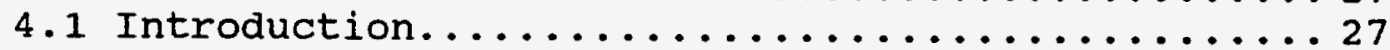

4.2 Approach............................ 27

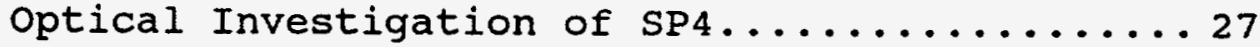

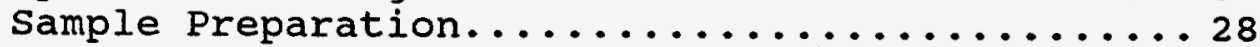

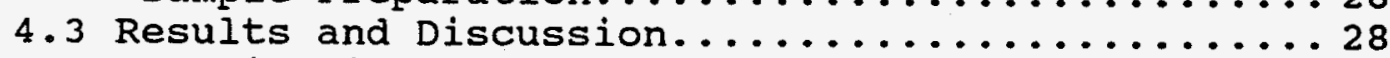

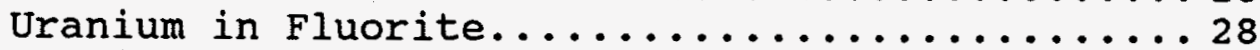

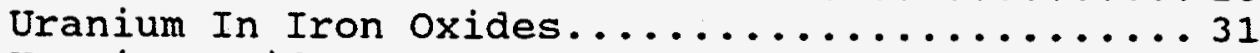

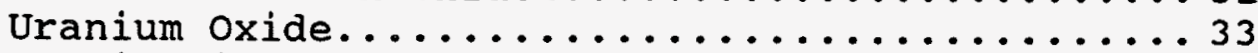

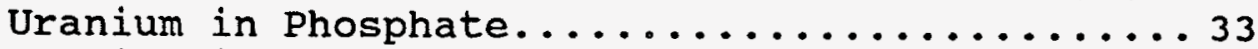

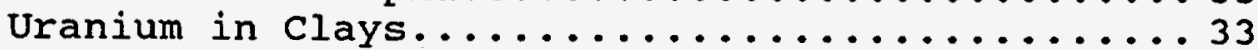

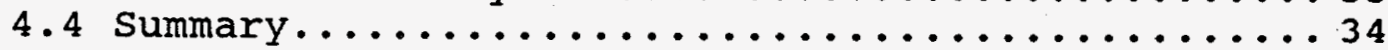




\section{TABLE OF CONTENTS (continued)}

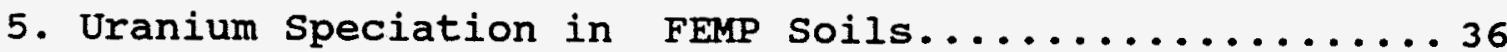

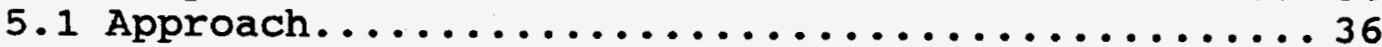

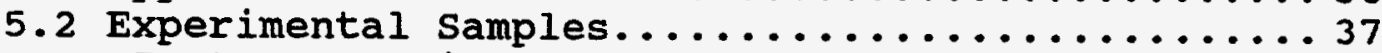

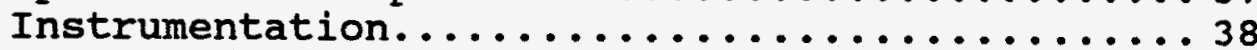

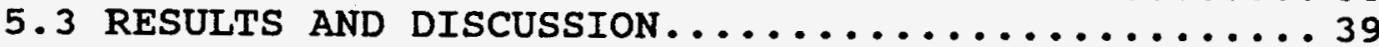

X-ray Absorption Spectroscopic Data......... 39

Luminescence Spectroscopy Data.............47

Fingerprinting of the Uranyl Luminescence

spectra........................... 52

Fingerprinting Using $\mathrm{x}$-ray Powder Diffraction

Data............................. 59

Preliminary Investigations of Treated Samples.. 59

5.4 Implications with Respect to Remediation....... 36

6. GEOCHEMICAL MODELLING.................... 63

6.1 Introduction........................63

6.2 Approach........................... 63

Data from FEMP site Wells..............6 63

Thermodynamic Data Base.................664

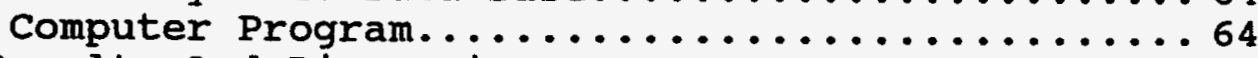

6.3 Results And Discussion................... 65

7. Summary of Results and Implications for the ID......69

7.1 Conclusions Regarding Innovative Application

of Technologies and Characterization Approach......69

7.2 Conclusions Regarding Physical Properties of

Contaminated soils.......................69

7.3 Conclusions Regarding Chemical Properties of

Contaminated soils........................ 70

7.4 Conclusions Regarding Modeling Predictions...... 71

7.5 Future Directions for Characterization Efforts.. 71

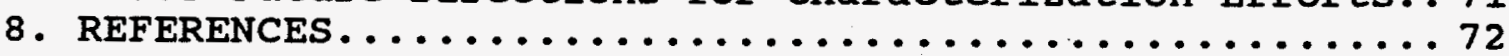




\section{GLOSSARY}

$\begin{array}{ll}\text { AEM } & \text { Analytical Electron Microscopy } \\ \text { CAA } & \text { Clean Air Act } \\ \text { CBED } & \text { Convergent Beam Electron Diffraction } \\ \text { CERCLA } & \text { Comprehensive Environmental Response, } \\ \text { DOE } & \text { Compensation, and Liability Act } \\ \text { DT\&E } & \text { Department of Energy } \\ \text { EDX } & \text { Demonstration, Testing and Evaluation } \\ \text { EELS } & \text { Energy Dispersive X-ray } \\ \text { EPA } & \text { Electron Energy Loss Spectrometer } \\ \text { EXAFS } & \text { Environmental Protection Agency } \\ \text { FEMP } & \text { Extended X-ray Absorption Fine-structure } \\ \text { FFCA } & \text { Fernald Environmental Management Project } \\ \text { FMPC } & \text { Federal Facilities Compliance Agreement } \\ \text { ID } & \text { Feed Materials Production Center } \\ \text { LMT } & \text { Integrated Demonstration } \\ \text { MDA } & \text { Lithium Metatungstate } \\ \text { mLU } & \text { Minimum Detectable Activity } \\ \text { NSLS } & \text { metric tons of uranium } \\ \text { ORNL } & \text { National Synchrotron Light Source } \\ \text { OTD } & \text { Oak Ridge National Laboratory } \\ \text { OU } & \text { Office of Technology Development } \\ \text { PCi/g } & \text { Operable Unit } \\ \text { RCRA } & \text { pico Curies per gram } \\ \text { RI/FS } & \text { Resource Conservation and Recovery Act } \\ \text { SAED } & \text { Remedial Investigation/Feasibility Study } \\ \text { SARA } & \text { Selected Area Electron Diffraction } \\ \text { SEM/BSE } & \text { Superfund Amendments and Reauthorization Act } \\ \text { SI } & \text { Scanning Electron Microscope Backscattered } \\ \text { SSRL } & \text { Detector } \\ \text { TEM } & \text { Saturation Index } \\ \text { XANES } & \text { Stanford Synchrotron Radiation Laboratory } \\ \text { XRD } & \text { Transmission Electron Micorscope } \\ & \text { X-ray Absorption Near Edge Structure } \\ \text { X-ray Diffraction }\end{array}$




\section{INTRODUCTION}

\subsection{Document Purpose}

One of the major problems facing the U.S. Department of Energy's (DOE) Environmental Restoration Program is the remediation of uranium-contaminated soils. In response to this problem the office of Technology Development (OTD) has initiated an Integrated Demonstration (ID) program to evaluate and compare the versatility, efficiency, and economics of various technologies that may be combined into systems for the characterization and remediation of uranium contaminated soils. The Fernald Environmental Management Project (FEMP) was selected as the host site for this ID program based on its past operating history and known environmental problems. In support of the ID, a task group has been appointed to design and administer a program to address site characterization issues relative to uranium-contaminated soils.

Because remedial technologies to be demonstrated are based on chemical and physical separation techniques, a key aspect of the characterization program is the description of the chemical and physical nature of the uranium wastes in the FEMP soils. As a first step in characterizing the contaminated soils a limited soil sampling and analysis program was conducted. This involved the collection of soil samples from various locations at the FEMP which represent different source terms and modes of deposition. These samples were subsequently analyzed by a host of standard analytical techniques and state-of-the-art microscopy and spectroscopy techniques. In an effort to gain a better understanding of the physical and chemical processes governing the distribution and transport potential of the uranium wastes, geochemical modeling was performed to predict the fate of a variety of uranium source terms in soils similar to that found at the FEMP.

The purpose of this report is to discuss the findings of the sampling and analysis program and to document the implications of these results relative to the design of soil treatment technologies and design of further soil characterization programs at the FEMP.

\subsection{Description of the Integrated Demonstration Program}

In order to help meet the cleanup goals of the DoE's nuclear waste sites such as the FEMP, the Director of Environmental Restoration and Waste Management initiated the OTD. One program initiated by OTD was the ID program. The ID program focuses on improving/validating technologies by demonstrating effectiveness, cost savings, risk reduction potential, site applicability, and regulatory and public acceptance. 
The results of the ID will be transferred for implementation throughout the DOE and the private sector. Technology transfer involves the transfer of technological information outside the DOE system (i.e., the private sector, Environmental Protection Agency [EPA], Department of Defense, etc.). The DOE strategy for technology transfer, as noted in SEN-30-91, is to increase DOE and industrial participation in an accelerated process. OTD headquarters (EM-55) will administer directives to ensure that technological data, reported in weekly and monthly internal reports, is distributed and disseminated outside the DOE system. Vehicles for the transfer of information include, but are not limited to, publications, presentations, and information exchange conferences.

As noted previously, the FEMP was selected to host an ID program. The FEMP, previously known as the Feed Materials Production Center (FMPC), is a contractor-operated federal facility for the remediation of a site which produced high purity uranium metal for the DOE. As such, this ID program will address the issues from "cradle to grave" surrounding the characterization and remediation of uranium contaminated soils, specifically soils of a high clay/silt content. Reduction of contaminated soil quantity, through the coupling of real time analysis and precise excavation, along with decontamination techniques applicable in high clay/silt soils will be the major technology areas. Secondary waste reduction, cost optimization, risk reduction, and user applicability are other important elements in this ID.

Innovative technologies and/or the innovative application of existing technologies for the characterization and remediation of uranium contaminated soils will be investigated throughout the DOE National Laboratory network, private industry, and universities. The ID program has a life expectancy of approximately three years with results feeding directly into the FEMP remediation program. Community relations activities shall be conducted as part of the ID in conjunction with the community relation activities currently ongoing under the FEMP Comprehensive Environmental Response, Compensation, and Liability Act (CERCLA) program. Information on treatability studies conducted within the ID will be conveyed to the public through community meetings and publications.

\subsection{Description of ID Characterization Task Group}

Issues facing the Uranium in soils ID program impinge on a wide range of disciplines. As such, the ID program has been divided into six working groups; characterization, decontamination, performance assessment, secondary waste, excavation, and regulation. Each group is made up of a group leader and four to five members, representing different DOE National Laboratories, who are experienced in the types of problems faced by the task group. The activities described in 
this report have been administered through the characterization task group. The mission of this task group is two-fold; 1) demonstrate innovative technologies and/or the innovative application of existing technologies for the characterization of soils contaminated with uranium wastes, and 2) provide sitecharacterization support to other task groups within the Uranium in Soils ID.

In efforts to fulfill this mission statement, two primary projects have been established by the characterization task group. The first of these addresses issues relative to the cost and time required to conduct site-characterization programs. one means of improving the efficiency of site characterization programs is through the infusion of new screening technologies. The benefits represented by employing screening technologies include a reduction in sampling requirements, reduction in sampling phases, and improved spatial resolution. For these reasons, testing and evaluation of four field screening technologies is being conducted in an effort to introduce such technologies into the site characterization phase of CERCLA and Resource Conservation and Recovery Act (RCRA) investigations. Those technologies to be tested include high-resolution gamma spectroscopy, a wide-area beta scintillation counter, inductively coupled plasma -- atomic emission spectroscopy, and a long range alpha detector system.

During August and September of 1992 , efforts were made to delineate the extent of uranium contamination at two hazardous waste sites at the FEMP by means of each of the field screening technologies. Efforts primarily concentrated on surficial surveys; however, a limited number of shallow boreholes were installed to demonstrate the downhole capabilities of selected technologies. These efforts were followed by the collection and analysis of soils samples to confirm or refute the finding of the field demonstration. Following the completion of the field demonstration, a cost-risk-benefits analysis was initiated to evaluate the potential advantages for employing these screening technologies. The interested reader is referred to the site Characterization Demonstration Plan (DOE 1993) for greater details. Results of the program will be available as an FEMP document in early 1993.

The other project of the characterization task group involves the work described in this report. As stated earlier, the intent of this project is the characterization of the physical and chemical nature of the uranium wastes found in the FEMP soils. This project addresses the first objective of our mission statement by demonstrating the utility of state-of-theart spectroscopy and microscopy techniques in hazardous waste site characterization. In this project we also demonstrate the role geochemical modeling can play in the interpretation of the collected soil characterization data. This project also plays an important role in meeting our second objective. Figure 1.1 


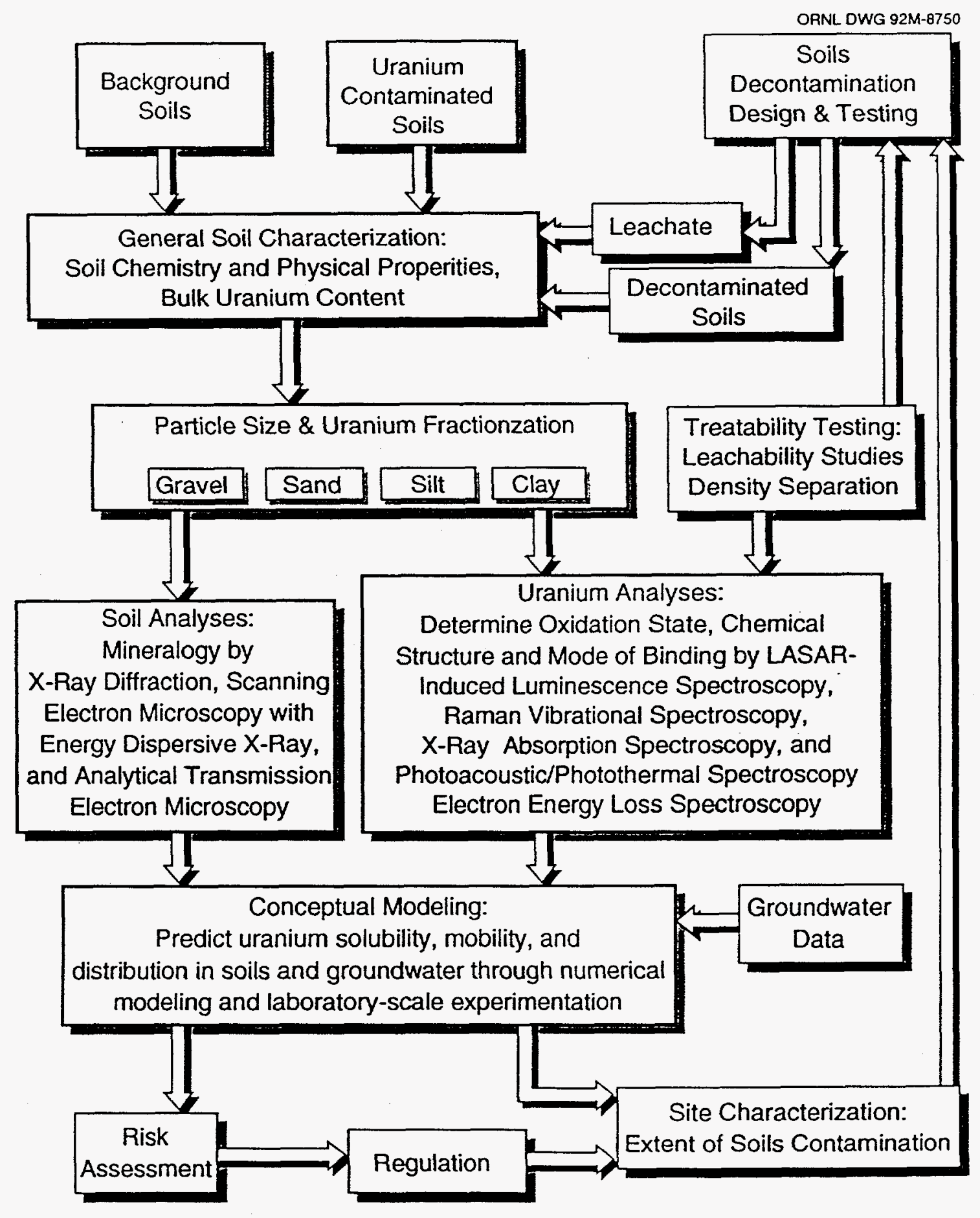

Figure 1.1. Flow chart outlining soils characterization project and interfaces with other ID participants. 
illustrates how data collected as part of this project will influence and support the efforts of other ID task groups. Preliminary data obtained as part of this program has previously been reported in two separate publications (Lee and Marsh 1992, Tidwell et al. 1992).

The two aforementioned projects are expected to continue to develop over the next few years. For instance, efforts will be made to assist in the technology transfer of field-screening methods demonstrated at the site. The feasibility of integrating these screening technologies with precise excavation equipment or with soil decontamination technologies (for real-time feedback on system performance) will be evaluated. Characterization of the uranium wastes in FEMP soils will continue to be performed as well as the characterization of soils treated by various decontamination strategies (again, to help evaluate the performance of decontamination strategies).

\subsection{Host Site Description}

The Atomic Energy Commission, predecessor to the U.S. DOE, established a production complex in the early 1950's for processing uranium and its compounds from natural uranium ore concentrates. This complex, presently known as the FEMP, is located on 1050 acres in a rural area approximately $18 \mathrm{miles}$ northwest of downtown Cincinnati, ohio (Figure 1.2). The villages of Fernald, New Baltimore, Ross, Shandon, and New Haven are all located within a few miles of the plant.

The FEMP consists of a large central production area as well as other surrounding storage and buffer zones. The production area covers approximately 136 acres near the center of the FEMP. The Pilot Plant was completed in 1951 and was the first operational facility at the FEMP. The Pilot plant was utilized to house many different processes including thorium metal production, uranium metal production, and uranium hexafluoride reduction. Following the completion of the Pilot plant the metals fabrication plant, Plant 6, began operations in 1952. The metal production plant, Plant 5; the greensalt plant, Plant 4; the recovery plant, Plant 8 ; the sampling plant, Plant 1 ; and the refinery (Plant 2/3) began operation in 1953. A uranium hexafluoride reduction plant, Plant 7 , and the special products plant, Plant 9, were operational in 1954.

Production peaked in 1960 at approximately 10,000 metric tons of uranium (mtu) per year. A product decline began in 1964, to a low in 1975 of about $1230 \mathrm{mtu}$. During the 1970's consideration was given to closing the FEMP, therefore capital improvements and staffing were minimized. In 1981, the FEMP began to accommodate increased production requirements. Production levels significantly increased and there was a rapid staff buildup for several years. Implementation of a major facilities restoration program followed. Production ceased in 


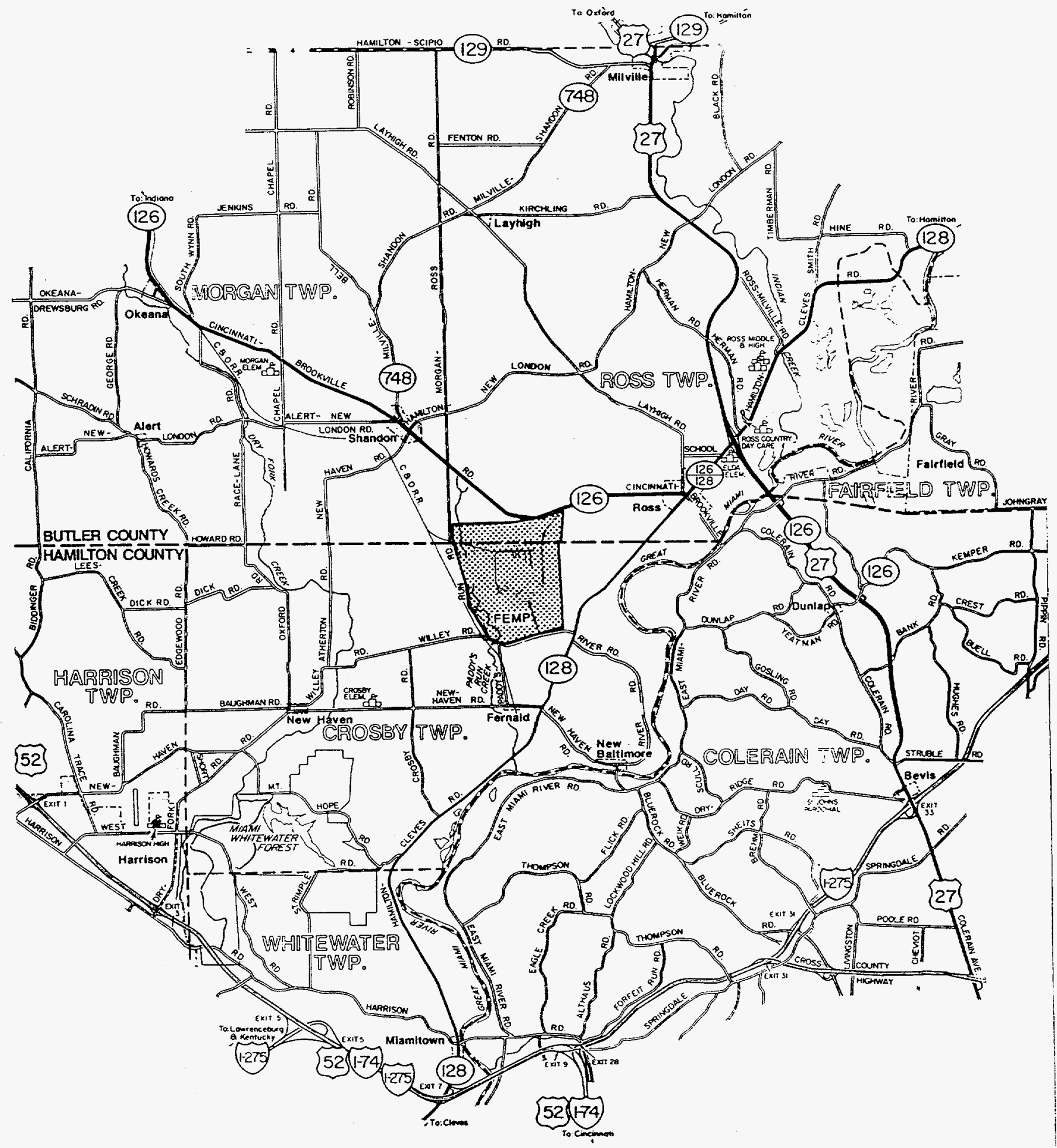

Figure 1.2. Map showing the location of the FEMP. 
the summer of 1989 to focus plant resources on the environmental restoration program.

On July 18, 1986, a Federal Facilities Compliance Agreement (FFCA) pertaining to environmental impacts associated with operation of the FEMP was jointly signed by DOE and the U.S. EPA. The FFCA was entered into pursuant to Executive order 12088 (43 CFR 47707) to ensure compliance with existing environmental statutes and implementing regulations such as the clean Air Act (CAA); RCRA; and CERCLA. In particular, the FFCA was intended to ensure that environmental impacts associated with past and present activities at the FEMP are thoroughly and adequately investigated so that appropriate remedial response actions can be formulated, assessed, and implemented. The 1986 FFCA was amended by a consent Agreement under sections 120 and 106 (a) of CERCLA. The consent Agreement became effective on June 29, 1990 and is currently being renegotiated.

In response to the FFCA, a Remedial Investigation / Feasibility study (RI/FS) is in progress pursuant to CERCLA, as amended by the superfund Amendments and Reauthorization Act (SARA). The technical strategy adopted by the CERCLA program divides the site into 5 distinct operable units. The components of the operable units (OU'S) are:

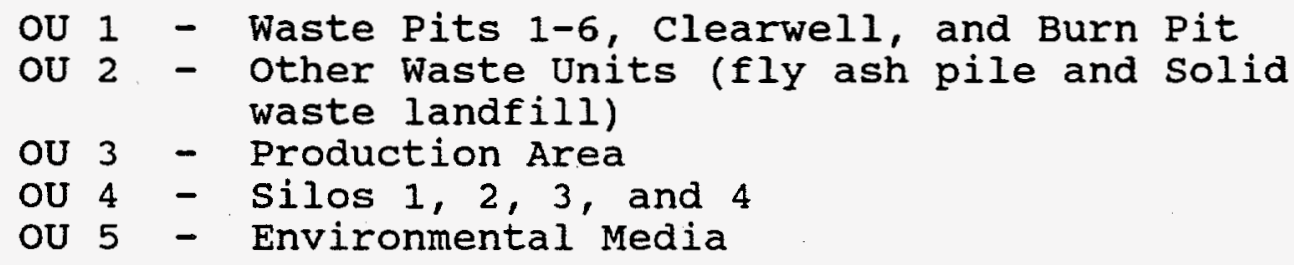

Contaminated soil exists to some degree in the majority of the operable Units. Operable Unit 1 has contaminated soil

surrounding the pits as well as lining the pits and operable Unit 4 has contaminated soil surrounding the silos. Operable Unit 2 has contaminated soil surrounding the fly ash pile and solid waste landfill. The bulk of the contaminated soil is located in the production area, operable Unit 3. Although contaminated soil is present in all the operable Units, all contaminated soil is being managed under Operable Unit 5 .

Soils in the region of the FEMP were formed from source materials that were deposited by the action of Wisconsin and Illinoisan glaciers. These materials consist mainly of glacial till but include sand, gravel, glacial lake clays, and silty clays.

Uranium is the principle contaminant of concern at the FEMP. The acceptable concentration level for uranium in soils has not been established. For planning purposes, the preliminary remedial action objective adopted under the FEMP RI/FS, $35 \mathrm{pCi} / \mathrm{g}$, will be utilized. The majority of soils containing uranium exceeding $35 \mathrm{pCi} / \mathrm{g}$ are located in the top $0.45 \mathrm{~m}$ of surficial 
material. With respect to surface area, approximately 50 percent of the production area soils contain contamination exceeding 35 $\mathrm{pci} / \mathrm{g}$. 
2. SAMPLING AND ANALYSIS PROGRAM

\subsection{Objectives}

Decontamination of soils or waters degraded by the introduction of hazardous pollutants requires detailed knowledge of the chemical and physical characteristics of the waste and environmental media. Generally, such information is not gathered due to the high costs and time required for the requisite analyses. However, without this information, the selection and optimization of treatment strategies is left to a trial-and-error approach. As such, an efficient approach to the problem is the establishment of a limited sampling and analysis program where information gained is maximized through the development of a conceptual understanding of the processes and events governing the behavior and distribution of the contaminant.

The Uranium in Soils ID faces similar problems, and hence a soil sampling and analysis program has been established. The objectives of this sampling program being the demonstration of the innovative application of technologies and approaches to the characterization of soils contaminated with uranium, and to provide needed characterization data to the other ID task groups.

Information needs for this ID program range from the actual speciation of the uranium waste form in the soil, to the size fractionation of the uranium, to the types of bonds formed between the uranium and the various soil fractions. Given the range of needs a host of techniques must be employed. In some cases standard analytical techniques provide adequate results; however, to define the uranium speciation and bonding mechanisms much more powerful techniques are required. As such, the capabilities of state-of-the-art microscopy and spectroscopy techniques are demonstrated (Table 2.1).

Another important component of this program is the approach that has been adopted to aid in the interpretation of the ensuing data. Because the requisite chemical characteristics require the employment of sophisticated equipment and/or time consuming analytical methods, achievement of a statistically defensible data set is unrealistic. How then does one evaluate the representativeness of the sparse data set? One option is to identify those processes that govern the behavior of uranium in FEMP soils, which incidentally are key to removing the uranium from the soil. Conceptual models are then developed that

describe the key processes. Sample representativeness may then be evaluated through qualitative comparison between sample data and the conceptual models. Through such models other parameters, which may be easier to measure, are identified that closely correlate with the chemical characteristic of interest. Sensitivity analyses can also be employed in an effort to reduce the set of perceived data requirements. 
TABLE 2.1. Physical And Chemical Characterization Techniques

\begin{tabular}{|l|l|}
\hline DATA NEED & ANALYTICAL METHOD \\
\hline $\begin{array}{l}\text { 1. Physical Analyses } \\
\text { Basic Soil Properties (physical } \\
\text { Und chemical) }\end{array}$ & ASTM Standards \\
\hline $\begin{array}{l}\text { Tranium Leachability } \\
\text { soil) Uranium (fractionated }\end{array}$ & Soil Leaching \\
\hline Soil Mineralogy & Gamma Spectroscopy \\
\hline $\begin{array}{l}\text { Microscopic Description of } \\
\text { Uranium }\end{array}$ & ICP Spectroscopy \\
\hline & X-ray Diffraction Analysis \\
\hline & $\begin{array}{l}\text { Energy Dispersive X-ray } \\
\text { Analysis }\end{array}$ \\
\hline $\begin{array}{l}\text { Uranium Speciation (oxidation } \\
\text { state chemical structure mode } \\
\text { of binding) }\end{array}$ & $\begin{array}{l}\text { Laser-Induced Luminescence } \\
\text { Spectroscopy }\end{array}$ \\
\hline & Raman Vibration Spectroscopy \\
\hline & X-ray Absorption Spectroscopy \\
\hline & $\begin{array}{l}\text { Photoacoustic/Photothermal } \\
\text { Spectroscopy }\end{array}$ \\
\hline & $\begin{array}{l}\text { Energy Dispersive X-ray } \\
\text { Analysis }\end{array}$ \\
\hline & $\begin{array}{l}\text { Transmission Electron } \\
\text { Microscopy }\end{array}$ \\
\hline & \\
\hline
\end{tabular}

One of the other factors influencing the establishment of this sampling and analysis program was the lack of information concerning the chemical and physical characteristics of the uranium waste form at the FEMP. As a result, our initial efforts have been focused on gaining a general understanding of how waste form characteristics vary across the site. The following section describes the strategy employed to address this need.

\subsection{Sampling Strategy}

The wide variety of uranium compounds utilized at the FEMP, as described in section 1.4, gives'rise to a number of potential sources which may generate unique uranium waste forms in the environment. Ideally, one would like to delineate potential source terms according to the various species of uranium released to the environment; however, such information is not available. For this reason source identification efforts have focused on the nature of the uranium waste as it was introduced into the environment. Three characteristic waste forms were adopted to guide the selection of sampling locations: 
- aqueous uranium wastes,

- solid uranium product (as released through spills), and

- air borne uranium wastes (dust, aerosols).

Site selection relied heavily on information provided in the RI/FS Report for Operable Unit 3 (DOE 1990). Information of particular interest consisted of total uranium content of soils and perched groundwaters, and background information on past facility operations. This information allowed inferences to be drawn concerning relationships between potential source terms and areas of known soils contamination.

In selecting locations for sampling, efforts were made to choose sites representing one of the three release types noted above, and where contamination was believed to be well above background. The number of samples collected and analyzed was predicated on the level of effort established for the project. Based on these criteria two sites were selected which are believed to be representative of soils contaminated by aqueous uranium wastes (Figure 2.1). One site is located north of Plant $2 / 3$ while the other site is associated with the Decontamination Pad/Drum Baling area. Plant $2 / 3$, the refinery, was a large-scale chemical operations plant in which the following processes occurred: digestion of enriched uranium scrap residues in nitric acid to produce a uranyl nitrate feed solution, solvent extraction and purification using kerosene-tributyl phosphate (PUREX process), concentration of the purified uranyl nitrate solution by evaporation, and thermal denitration to uranium trioxide. The decontamination and decommissioning building and pad areas were used primarily for decontamination and disposal activities. Materials were cleaned and reused, salvaged if possible, or placed on the metal scrap pile.

A single site was selected for the characterization of soils contaminated by uranium product spills (Figure 2.1). The site selected is associated with the Plant 1 Drum Storage Pad. Activities that were conducted at Plant 1 and the storage pad included shipping, receiving, storing, milling, and classifying depleted, normal, and enriched uranium materials, the sampling and analysis of incoming materials, and the storage of residues and other materials awaiting off-site shipment.

For the preliminary characterization of soils contaminated by uranium dusts released from plant processing and waste disposal practices, two sites have been selected; one located northeast\$of Plant 6 (Figure 2.1) and the other near the Incinerator site (Figure 2.2). The most probable source for the soils contamination in these areas is air borne releases from Plants 5 and 6 , and the Incinerator site. These plants housed the uranium milling and machining operations for the FEMP while the incinerator was used to dispose of combustible materials contaminated with uranium. Furthermore, meteorological data contained in the RI/FS Report (DOE 1990) suggest that the prevailing winds are from the southwest and west-southwest. 


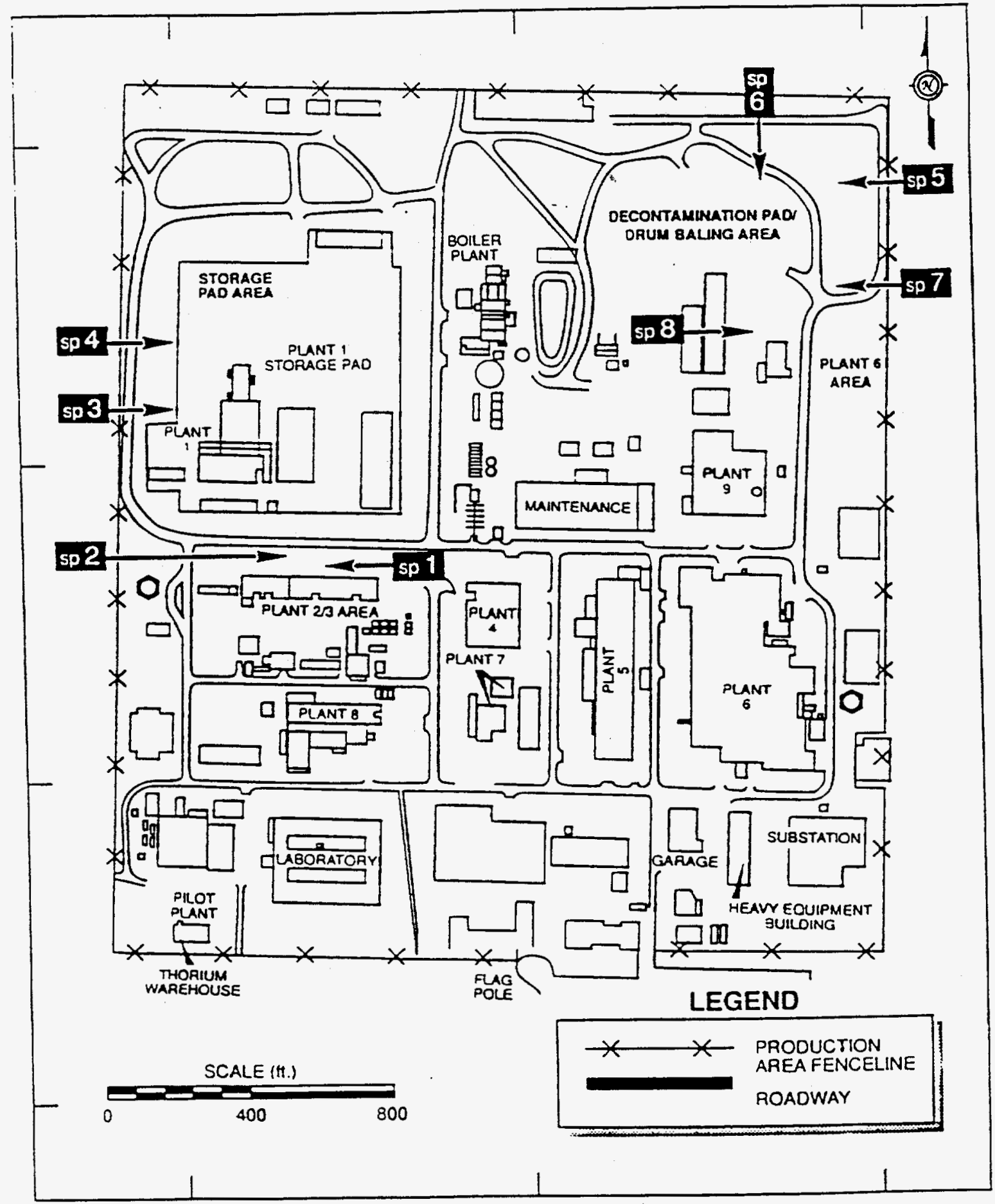

Figure 2.1. Sample Sites in Production Area 


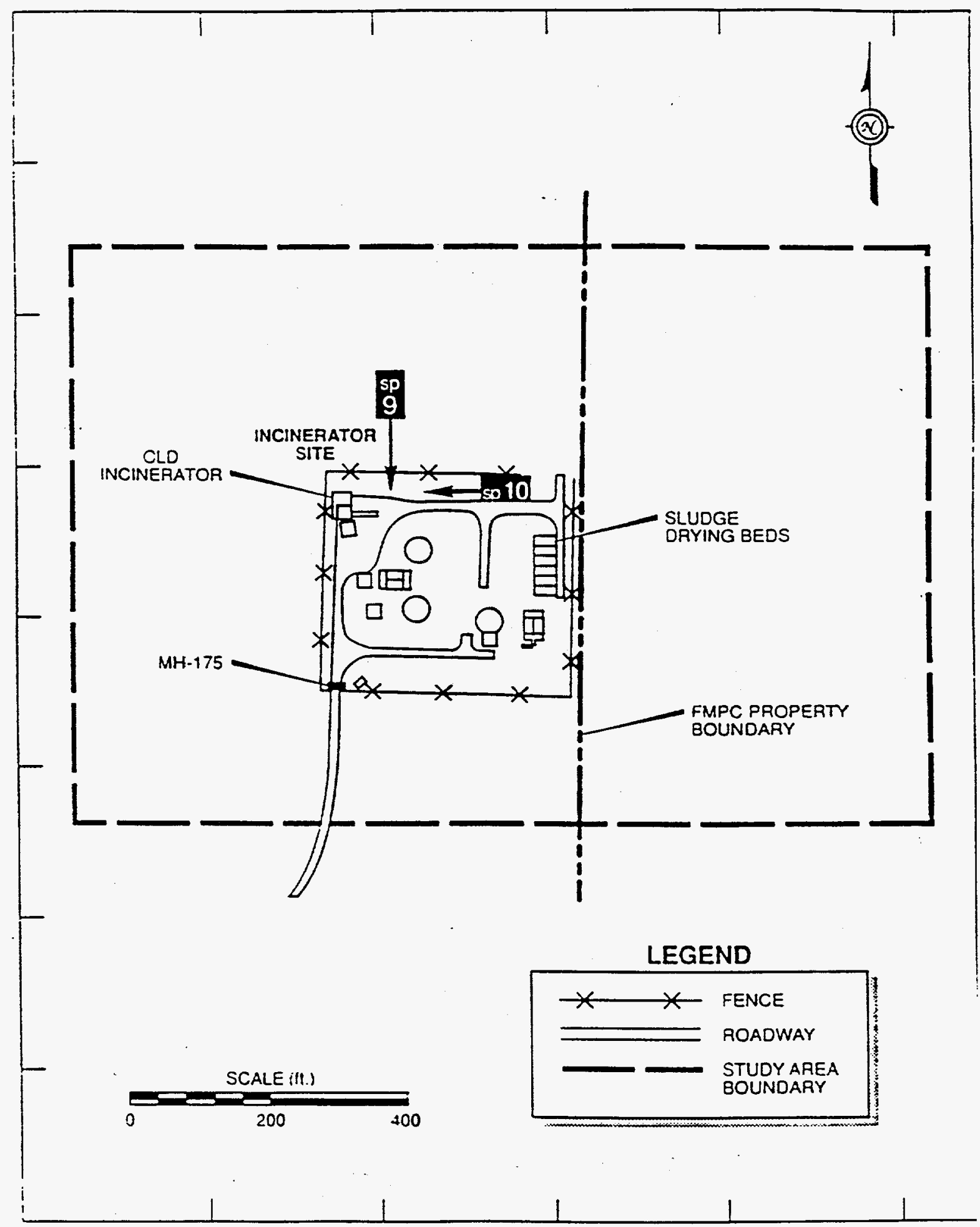

Figure 2.2. Sample Sites near Incinerator Area 
Two background soil samples were also collected and analyzed. These samples were collected off-site in areas characterized by the same soil series and geomorphologic setting as that found at the FEMP. Two such soil series were selected for characterization; one of a lacustrine origin and the other of a glacial till. Sampling locations can be found on Figure 2.3.

\subsection{Methods}

Collection of soil core samples was performed according to the protocols and procedures established for the FI/FS operable Unit 3 program, the RI/FS Quality Assurance Project Plan, and the Project Specific Health and Safety Plan (DOE 1990).

Characterization task group representatives, with the aid of FEMP personnel, performed the soil core sampling. Sampling was initiated with a survey of the area by means of a sodium-iodide detector. The site surveys were used to help locate areas of high surface activity in an effort to bias sampling (so as to assure sufficient contamination levels for detailed characterization). Prior to collecting a sample, the gravel or grass cover was removed before setting up a hand-driven auger. A stainless steel auger with one to three $30.5-\mathrm{cm}-1$ ong polybutyrate sleeve(s) (5 cm dia.) was used for sample collection. After retrieval of the auger by a hydraulic jack, soil cores were cut at the joints of sleeves and capped for shipment. Supplemental undisturbed samples were collected by pushing down a 8.5-cm-dia by 3.5-cm-deep plastic dish and cutting the bottom of the soil block with a knife for microscopic analyses. Samples were shipped to the Oak Ridge National Laboratory (ORNL) for preliminary analysis and distribution to other analysts.

The soil cores were described according to the standard soils description methodology (Soil survey staff, 1975) and then cut into 5- to $10-\mathrm{cm}$ segments. Each soil core segment was given an identification number in the following way; SP\#-1-A, where "SP\#" designates the sampling site (site descriptors are given in Figures 2.1 and 2.2), "-1" identifies the sleeve number collected from a particular sampling site, and "-A" designates the sample segment cut from the sleeve, starting from the top of each sleeve.

A short time after the initial phase of sampling, two additional samples were collected from soils which were to be used in treatability studies conducted by the Decontamination Task Group of the Uranium in Soils ID (Kneff et al., 1992). Treatability samples were excavated from two separate areas within the FEMP. Each area was about 25 by $20 \mathrm{ft}$, with an excavation depth of 6 to 8 inches. Once the treatability samples were collected they were homogenized and stored in 55 galion drums. Soil samples for use by the Characterization Task Group were collected from Drum 6 associated with the Plant 1 storage 


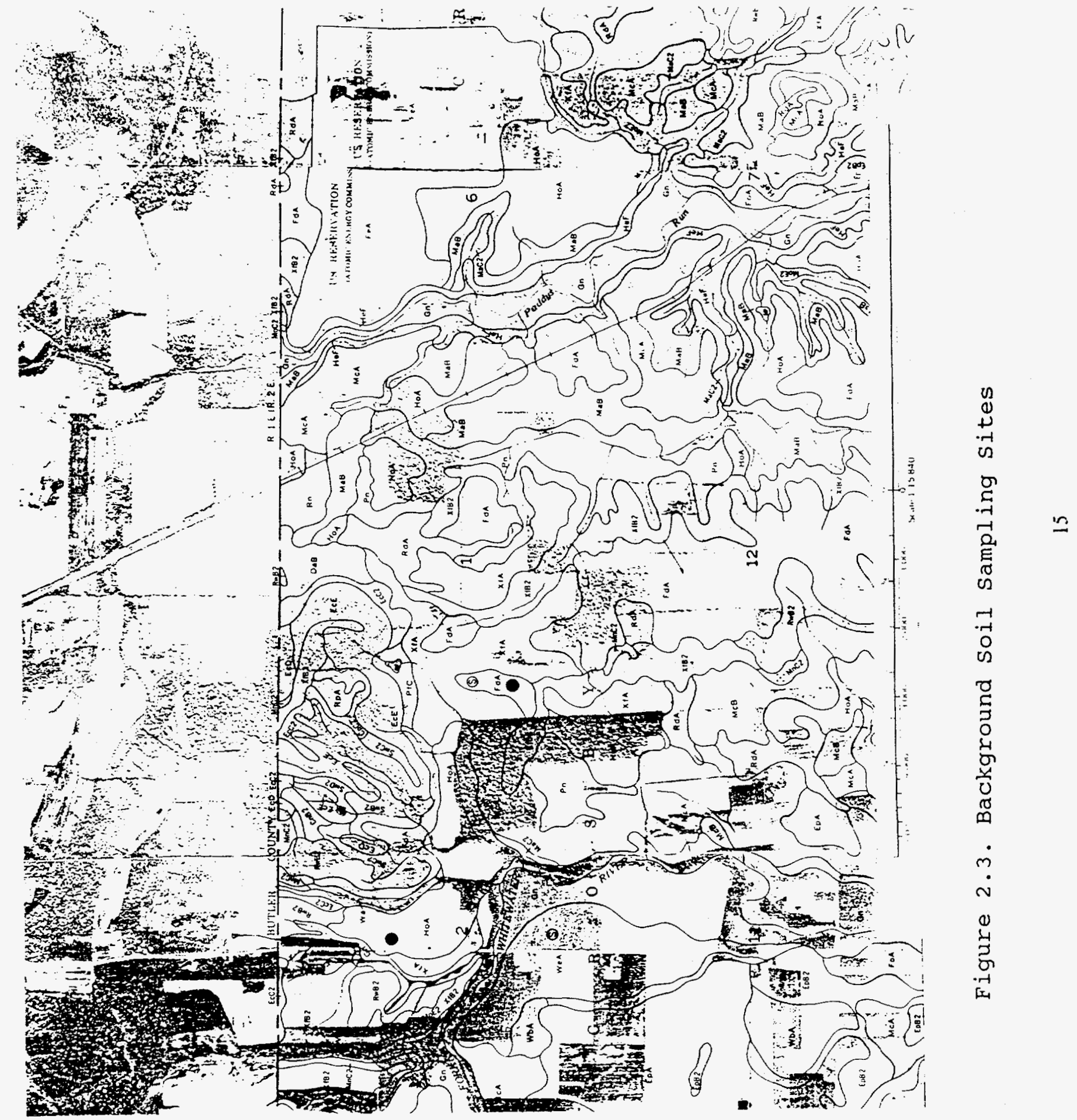


Pad Area excavation (designated sample B-16) and from Drum 12 associated with the Incinerator Site excavation (designated sample $A-14)$. The A-14 sample was taken from within the same area where the Characterization Task Group had taken cores SP-9 and SP-10 (Lee and Marsh, 1992). Likewise, the B-16 sample came from the area near $\mathrm{SP}-3$ and $\mathrm{SP}-4$ core sampling sites. 


\section{PHYSICAL CHARACTERIZATION OF FEMP SOILS AND URANIUM WASTES}

\subsection{Introduction}

The objective of the physical/mineralogical/morphological characterization task is to understand the nature of uranium contamination in the FEMP site soils. This task provides vital characteristic data for site Characterization, Treatability, Waste Disposal, Risk/Performance Analysis Task groups, and other private industries participating in the Uranium in Soils ID program and the FEMP Environmental Restoration programs. The preliminary investigation was completed earlier this year (Lee and Marsh 1992). The results of the investigation have been used by many ID participants for planning field demonstration studies and selecting candidate soils for treatability investigations.

This task extended the previous characterization investigation study to the two treatability study soil samples collected from the Plant 1 storage Pad Area and the Incinerator Area. We are investigating (1) uranium distribution in relation to soil particle size fractionation, (2) physiochemical properties of the contaminated soils, (3) mineralogical, micromorphological, and compositional analyses of soils and uranium-bearing particles, and (4) the soil-solution chemistry and uranium partitioning during selective geochemical

dissolution. Mineralogical analyses include density separation of uranium-bearing particles, high resolution scanning electron microscopy, and $x$-ray powder diffraction. Soil physiochemical characterization includes measurement of soil buffer capacity, organic matter content, texture, cation exchange capacity, base saturation, and soil dewatering tests under different leaching protocols. Redistribution of uranium dissolved or desorbed during leaching treatments under different $\mathrm{pH}$ and ionic strengths will also be examined in order to understand leaching behavior of uranium in these contaminated soils.

\subsection{Materials and Methods}

\section{Soil pH}

Soil pH measurements were made using a Horizon pH meter with a combination electrode. Triplicate soil samples were prepared for $\mathrm{pH}$ measurement by adding $5 \mathrm{~mL}$ of distilled water to $5 \mathrm{~g}$ of soil, stirring, and allowing equilibration for one hour before beginning $\mathrm{pH}$ measurements.

\section{Gamma Spectroscopy}

Representative portions of both soils were transferred to $8.5-\mathrm{cm}$ dia. by $3-\mathrm{cm}$ high plastic containers for uranium 
quantification by gamma spectroscopy. Gamma spectroscopy was performed on each sample prior to particle size separation and on particle density fractions. These samples were counted on a high resolution, solid state, coaxial, intrinsic, germanium detector coupled to a ND6700 multichannel analyzer with 4096 channels. The gamma system had previously been calibrated with an Amersham QCY44 certified mixed gamma standard with traceability to the National Institute of Standards and Technology in the identical geometry used to contain the soil samples. In addition, weekly and daily sources were counted to verify detector calibration and precision. The samples were counted down the soil column from 1 $h$ to overnight, depending upon the activity level of each sample. The $238 \mathrm{U}$ concentration was determined using the $1001-\mathrm{keV}$ line for $234 \mathrm{~Pa}$, which is a daughter of $238 \mathrm{U}$ that is assumed to be in secular equilibrium with the parent uranium isotope. At equilibrium, the activities of the two nuclides should be identical and the measurement of one determines the activity of the other. The $235 \mathrm{U}$ isotope was determined using its $143-\mathrm{keV}$ peak. The activity ratio of $235 \mathrm{U} / 238 \mathrm{U}$ for natural uranium is 4.6. For those samples having activities below detectable limits, a minimum detectable activity (MDA) is reported. MDA is defined as the minimum activity of the radionuclide which must be present $95 \%$ of the time to be detected in the presence of the sample compton continuum.

\section{Particle Size Separation}

Particle size separations were performed on both FEMP soils in order to determine the uranium partitioning among the various size fractions. Particle size separations were performed by field moist sieving using $4-$ and $2-\mathrm{mm}$ stainless steel sieves. size fractions larger than $2 \mathrm{~mm}$ were designated as gravel. The $<2-\mathrm{mm}$ fractions were further separated into 2 to $0.053 \mathrm{~mm}$ (sand), 0.053 to $0.002 \mathrm{~mm}$ (silt), and <0.002 $\mathrm{mm}$ (clay) by wet sieving and centrifugation (Jackson, 1975). These size-fractionated samples, as well as the whole soil, were then analyzed by neutron activation analysis for uranium quantification. Water samples produced during the particle size separation were analyzed for a) total uranium by mass spectroscopy, b) isotopic uranium by alpha spectroscopy, c) trace element analysis by inductively coupled plasma atomic emission spectroscopy, d) anions by ion chromatography, and e) alkalinity by acid titration to $\mathrm{pH} 4.5$. Due to the sensitivity of the alpha spectroscopy method for uranium, only those soils and leachates with very low levels of uranium (< $10 \mathrm{pCi} / \mathrm{g}$ for solid and < $100 \mathrm{pCi} / \mathrm{L}$ for liquid) could be analyzed by this method. For this reason, the high-level uranium samples were done by mass spectroscopy. Prior to the uranium and metal analyses, 1 to $3 \mathrm{~g}$ of soil was digested at 90 to $95^{\circ} \mathrm{C}$ with $\mathrm{HNO}_{3}$ and $30 \% \mathrm{H}_{2} \mathrm{O}_{2}$, centrifuged, and filtered. The filtrates were diluted before spectroscopic analyses. 


\section{Heavy Liquid Separation}

Heavy liquid separations were performed on the sand and silt fractions of both soils in an attempt to isolate an uraniumenriched fraction for later mineralogical analysis. Lithium metatungstate ( $\mathrm{LMT}, \rho=3.0 \mathrm{~g} / \mathrm{cm}^{3}$ ) was the medium used in all density separations. Ten to fifteen grams of each fraction were placed in a Pyrex glass centrifuge tube. Approximately $100 \mathrm{~mL}$ of LMT was poured into the tube. The tube was then shaken for 30 minutes. The soil adhering to the tube above the level of the IMT was then washed down with LMT. The tube was then centrifuged at $2000 \mathrm{rpm}$ for 30 minutes to help separate the density fractions. Following centrifugation, the bottom of the tube was placed in liquid nitrogen in order to freeze the heavy fraction. This is done to provide additional protection from loss of heavy particles during the isolation of the light fraction. Once the bottom of the tube is sufficiently frozen, the unfrozen light fraction was quantitatively transferred into a filtration apparatus. The filtrate was then rinsed with warm $\left(60-80^{\circ} \mathrm{C}\right)$ distilled deionized water in order to solubilize any remaining LMT. The filtered suspension was centrifuged at $2000 \mathrm{rpm}$ for 30 minutes only if any material was suspected of passing through the filter. The light fraction was then be quantitatively transferred from the filter paper, dried, and weighed. Identical procedures were followed for the heavy fraction.

\section{Neutron Activation Analysis}

Uranium quantification of the whole soil and sizefractionated samples for both $A-14$ and $B-16$ was performed by the comparative neutron activation analysis method. In this method, count rates determined for the soil samples were compared to count rates for standards that contain known quantities of uranium. Irradiations having a neutron flux of approximately $5 \mathrm{x}$ $1013 \mathrm{n} / \mathrm{cm}^{2} / \mathrm{sec}$ were performed for one minute in pneumatic tube number 2 in the Neutron Activation Analysis Laboratory at the ORNL High Flux Isotopes Reactor. Gamma spectra of the activated samples were analyzed using the Nuclear Data ACCUSPEC system software and two programs developed at ORNL. Complete detailed procedures on this method are given in wade et al. (1992).

\section{Electron Microscopy}

Scanning electron microscopy (SEM), utilizing both secondary and backscattered electron imaging coupled with energy dispersive $X$-ray analysis (EDX), was used for morphological analysis and particle size/elemental distributions. A small amount of dry whole soil and size-fractionated samples of both soils was embedded in epoxy resin under vacuum. Vacuum removal of the soil air allows complete resin migration into the soil micropores.

After resin polymerization, microscopic specimens that have approximately 1 to $4 \mathrm{~cm}^{2}$ cross-sectional areas were prepared by 
sanding the soil resin blocks and later polishing these blocks with very fine diamond powder.

\section{X-Ray Diffraction}

Uranium-enriched size and density fractions of both soils were examined by $x$-ray diffraction (XRD) to determine the nature of the uranium phases occurring in these soils. A scintag XDS 2000 diffractometer equipped with $\mathrm{CuK} \alpha$ radiation was used for all XRD analyses. Scans were run on the fractions from 2 to $60^{\circ} 2$ $\theta$ in order to encompass the range of major peak locations for the probable uranium phases. Phase identification was determined by comparing the diffraction data of each fraction to that of known mineral standards.

\section{Soil Equilibration}

An equilibration study involving the two soils was initiated to determine their soluble ionic speciation. This study should provide valuable information by enabling the treatability task group to predict the baseline solubility behavior of uranium and other ionic species of interest in all leaching experiments of these soils. For each soil duplicate, $2500 \mathrm{~mL}$ of deionized water was added to a Nalgene carboy containing $200 \mathrm{~g}$ of field moist soil. An experimental bland was prepared in the same manner but without the addition of contaminated soils. This mixture was shaken manually 2-3 times daily for 30 seconds each time and allowed to rest in between these shakings. On each sampling episode, the samples were allowed to rest for one hour following the first shaking before a $50-\mathrm{mL}$ aliquot was taken from each duplicate. These aliquots were then filtered using $0.4 \mu \mathrm{m}$ millipore membrane paper to remove all particulates from the aliquot. The aliquots were immediately transferred to the lab for rapid (< 5 days) analysis. Concentrations of water-soluble radionuclides, inorganic cations and anions, and carbonate species, as well as pH will be analyzed at ten different times throughout a 10-week period. Radionuclide concentrations (235U and $238 \mathrm{U}$ ) will be determined using a mass spectrometer. Inorganic cation concentrations ( $\mathrm{K}, \mathrm{Na}, \mathrm{Ca}, \mathrm{Mg}, \mathrm{Al}, \mathrm{Si}, \mathrm{Fe}$, and Mn) will be determined using an ICP while those of the inorganic anions ( $\mathrm{F}, \mathrm{Cl}, \mathrm{NO}_{3}, \mathrm{SO}_{4}$, and phosphate species) will be determined by ion chromatography measurement. Carbonate speciation will also be determined by acid titration.

\subsection{Results}

\section{General Soil Properties}

The A-14 soil taken from the Incinerator Area was covered by fescue grass. Soils near the concrete curb of the driveway were 
highly disturbed but the soils away from the curb were less disturbed. This soil had a well developed Ap horizon with a dark grayish brown (7.5YR 4/2) color, 5\% gravel content, high organic matter content, $\mathrm{pH} 7.2$, and a silt loam texture (Table 3.1).

The B-16 soil which was taken near the storage Pad was also covered by fescue grass. In general, the soils near the storage Pad were highly disturbed but the soils away from the storage Pad were less disturbed. The $\mathrm{B}-16$ soil was taken from a relatively less disturbed area. This soil had a dark brown (7.5YR 3/3) color, 5\% gravel content, possible plant roots, $\mathrm{pH} 7.5$, and a silt loam texture (Table 3.1). These soil properties suggest that the B-16 soil may be similar to the Ap horizon of the Henshaw soil series.

Even though the texture of $A-14$ and $B-16$ are within the same class, differences in the actual percentages for each fraction are evident. The A-14 soil has a greater silt percentage and lesser sand and clay percentages than the spatially adjacent B-16 soil. The increased silt percentage associated with soil A-14 may be a response to the incorporation of particulate matter ejected from the nearby incinerator in this soil.

\section{Uranium Distribution as a Function of Particle Size}

Results of the uranium partitioning among the sand, silt, and clay fractions for both FEMP soils show the highest contribution to the total uranium levels was the silt fraction for $\mathrm{A}-14$ and the clay fraction for B-16 (Table 3.2). Even though higher uranium concentrations were commonly observed in the other size fractions of both soils, their contributions to the overall

Table 3.1. General Soil Properties of Soils A-14 and B-16.

\begin{tabular}{|c|c|c|c|}
\hline Soil & Series & Color & pH \\
\hline A-14 & Fincastle $^{b}$ & 7.5 YR 4/2 & 7.2 \\
\hline B-16 & Henshaw $^{b}$ & 7.5 YR 3/3 & 7.5 \\
\hline
\end{tabular}

$a_{G R=g r a v e l, ~} s=s a n d, s i=s i l t$, and $c=c l a y$. burban land.

contamination level is dampened by the lower abundances of these particle size fractions (i.e. $12 \%$ sand and $13 \%$ clay in $\mathrm{A}-14$ ). This difference in the uranium partitioning between these two soils likely reflects their differing modes of contamination. Particulates (mainly of silt size) ejected from the nearby incinerator contaminated the soils represented by A-14. Leakage of aqueous uranium waste and subsequent adsorption of uranium species onto colloidal surfaces contaminated the soils represented by $\mathrm{B}-16$. 
Table 3.2. Uranium Distribution as a Function of Particle Size.

\begin{tabular}{|l|l|l|l|l|l|}
\hline Sample & Size Fraction & $\begin{array}{l}\text { Size Distri- } \\
\text { bution }\end{array}$ & $\begin{array}{l}\text { Uranium } \\
\text { Concentra-tion }\end{array}$ & \multicolumn{2}{l|}{$\begin{array}{l}\text { Uranium Contribution by Size } \\
\text { Fraction }\end{array}$} \\
\hline & $\mathrm{mm}$ & $\%$ & $\begin{array}{l}\text { micrograms } \\
\text { /gram }\end{array}$ & $\begin{array}{l}\text { micrograms } \\
\text { /gram }\end{array}$ & $\%$ \\
\hline A-14 & $>2$ & 5 & ND & ND & ND \\
\hline & $2-0.053$ & 12 & 1043 & 125 & 27 \\
\hline & $0.053-0.002$ & 70 & 288 & 203 & 44 \\
\hline & $<0.002$ & 13 & 1026 & 133 & 29 \\
\hline & $>2$ & 5 & ND & ND & ND \\
\hline & $2-0.053$ & 21 & 117 & 25 & 7 \\
\hline & $0.053-0.002$ & 54 & 240 & 129 & 37 \\
\hline & $<0.002$ & 20 & 989 & 195 & 56 \\
\hline
\end{tabular}

ND Not Detected

Even though a predominance of the uranium contamination is seen in the silt fraction of $A-14$, sizable contributions to the overall contamination were still observed for the sand (27\%) and clay (29\%) fraction. Likewise for $B-16$, the silt fraction still contributes $37 \%$ to the overall contamination level for this soil. Because of both the differing modes of contamination and uranium partitioning among the particle sizes of these soils, a mere physical separation and removal of a particular size fraction would not be greatly beneficial for reclamation purposes.

\section{Uranium Distribution as a Function of Particle Density}

Results of the heavy liquid separations for both soils show a predominance of light $(\rho<3.0 \mathrm{~g} / \mathrm{cm} 3$ ) minerals over heavy ( $\rho>$ $3.0 \mathrm{~g} / \mathrm{cm} 3$ ) minerals (Table 3.3 ). For both $\mathrm{A}-14$ silt and sand, greater than $96 \%$ of the total sample occurred in the light fraction. For B-16 silt, greater than $75 \%$ of the sample occurred in the light fraction. For B-16 sand, this same figure rose to $95 \%$

Results of the uranium partitioning among the particle density fractions show the expected predominance of uranium phases, on an equivalent weight basis, within the heavy fraction. These enriched fractions will be later examined by x-ray diffraction to determine their uranium mineralogy.

\section{Mineralogical Characterization}

SEM micrographs of the A-14 sand fraction show a wide variety of sizes and shapes of minerals (Plate 3.1). Some minerals occur as a stable, large-sized aggregate. The unusually high stability of the aggregates is expected to develop during 
the incinerating process. The aggregates contained uranium particles as well as other heavy minerals. Uranium occurred also as a microfracture-filling mineral in the aggregate. Uraniumcontaining particles were typically composed of calcium, silicon, or phosphorus. A cerium phosphate mineral was also found in this sample. Quartz was the dominant mineral in the sand fraction.

In the B-16 silt fraction (Plate 3.2), uranium particles were either composed entirely of uranium or coexisted with calcium and/or silicon. In future analytical determinations, detailed microscopic analyses will be performed after heavy liquid separation in order to examine concentrated uraniumbearing fractions.

\section{Solubility}

Results from the first two sampling episodes (the first sampling performed one hour after initiating the experiment; the second sample performed one day after initiating the experiment) have shown total uranium values to range from 0.12 to $0.74 \mathrm{mg} / \mathrm{g}$ soil in duplicate samples of A-14. A much higher total uranium range (2.75 to $32.59 \mathrm{mg} / \mathrm{g}$ soil) was found in the duplicate samples of $B-16$, thereby indicating a greater amount of watersoluble uranium phases in this soil than in A-14. Calcium and magnesium are the two most abundant cations in both soils, but this combination is much higher in B-16 than in A-14. The higher concentration of Ca2+ plus Mg2+ apparently causes the observed self flocculation of this suspension during the settling periods

Table 3.3. Uranium Distribution as a Function of Particle Density

\begin{tabular}{|l|l|l|l|l|l|l|l|}
\hline Sample & Recovery & \multicolumn{2}{l}{ Weight Distri-bution } & U-238 & & \multicolumn{2}{l|}{ U-238 } \\
\hline & & Heavy & Light & Heavy & Light & Heavy & Light \\
\hline & $\%$ & $\%$ & $\%$ & cpm & cpm & cpm/g & cpm/g \\
\hline A-14 Silt & 86.00 & 2.33 & 97.67 & 3.54 & 4.32 & 10.1 & 0.3 \\
\hline A-14 Silt & & 2.47 & 97.53 & & & & \\
\hline $\begin{array}{l}\text { A-14 } \\
\text { Sand }\end{array}$ & 93.50 & 4.00 & 96.00 & 2.35 & 8.24 & 29.4 & 4.6 \\
\hline $\begin{array}{l}\text { A-14 } \\
\text { Sand }\end{array}$ & 97.47 & 3.67 & 96.33 & & & & \\
\hline B-16 Silt & & 17.27 & 82.73 & ND & ND & ND & ND \\
\hline B-16 Silt & & 24.40 & 75.60 & & & & \\
\hline $\begin{array}{l}\text { B-16 } \\
\text { Sand }\end{array}$ & 98.40 & 5.00 & 95.00 & 0.33 & 2.89 & 1.3 & 0.6 \\
\hline $\begin{array}{l}\text { B-16 } \\
\text { Sand }\end{array}$ & 98.27 & 3.60 & 96.40 & & & & \\
\hline
\end{tabular}

a Not Detected 
between their thrice-daily mixings. The $\mathrm{pH}$ of each suspension rapidly increased (in many cases $>1 \mathrm{pH}$ unit) from the first to the second sampling episode with the second $\mathrm{pH}$ near neutrality. In terms of soluble cationic species, only minor amounts of sodium were found in the experimental blank during both sampling episodes.

Nitrate and total alkalinity were the two most abundant anionic species in both the FEMP soils in these first two sampling episodes. While nitrate levels were similar between these two soils (approximately 100 to $150 \mathrm{mg} / \mathrm{g}$ soil), the concentration of total alkalinity was much higher in B-16 (250.0 to $490.0 \mathrm{mg} / \mathrm{g}$ soil) than in A-14 (62.5 to $171.5 \mathrm{mg} / \mathrm{g}$ soil). Minimal levels of nitrate and alkalinity were observed in the experimental blank. The soil values therefore represent actual dissolution products. The nitrate and alkalinity data of $\mathrm{B}-16$, coupled with its higher calcium and magnesium levels, infer dolomite and/or calcite dissolution in this soil. 

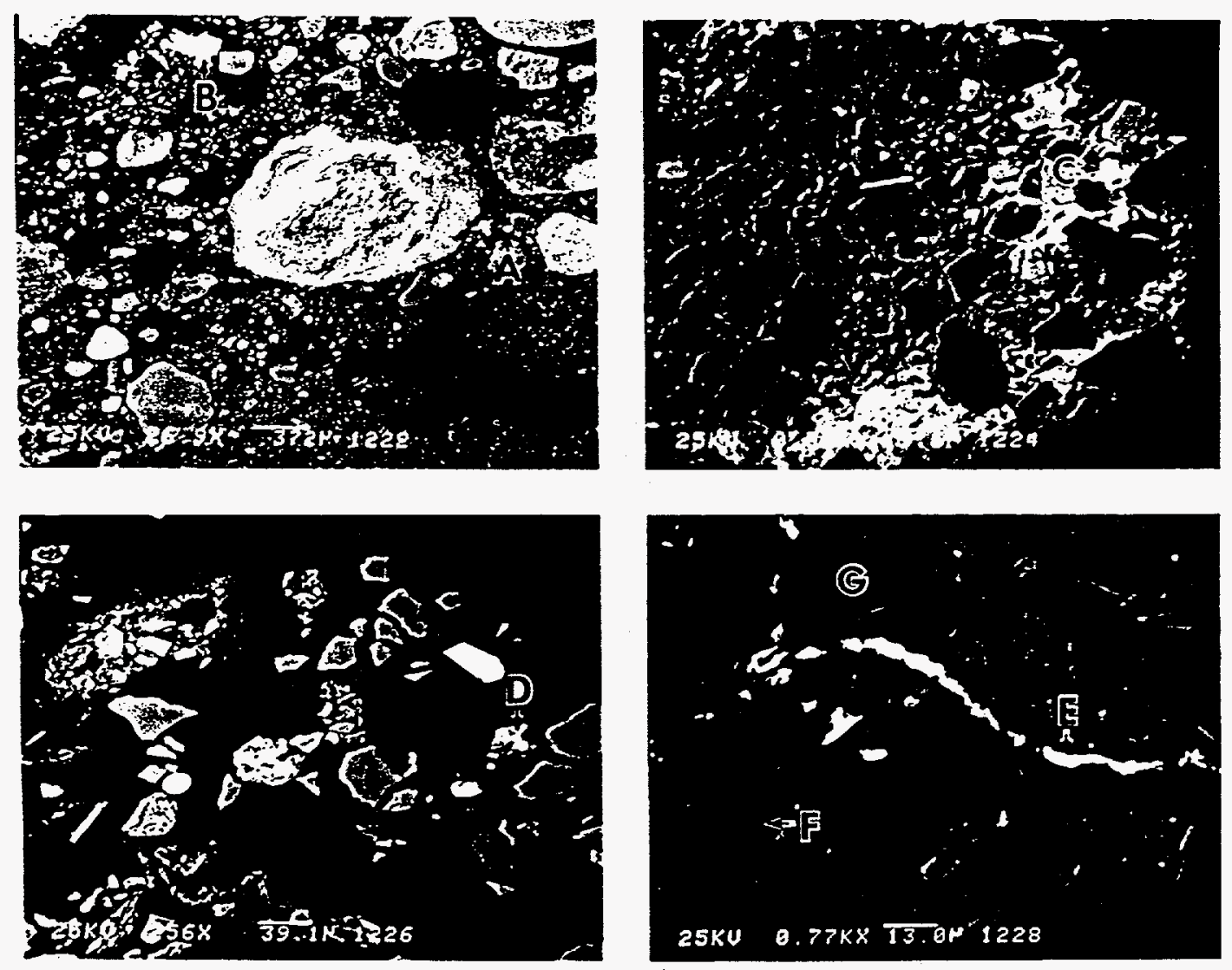

Plate 3.1. Four SEM micrographs were taken from the sand fraction of FEMP A-14 sample. Particle $A$ has uranium as a major component with a very small amount of oxygen. Particles $B$ and $D$ have uranium and a lesser amount of calcium, phosphorus, and oxygen. Particle $C$ has phosphorus, cerium, neodymium, and a lesser amount of thorium and oxygen. The microfracture-filling mineral (marked E) has uranium and silicon with a smaller amount of calcium and phosphorus. The matrix of the aggregate is aluminosilicate clays (marked F) and silt-size quartz (marked G). 

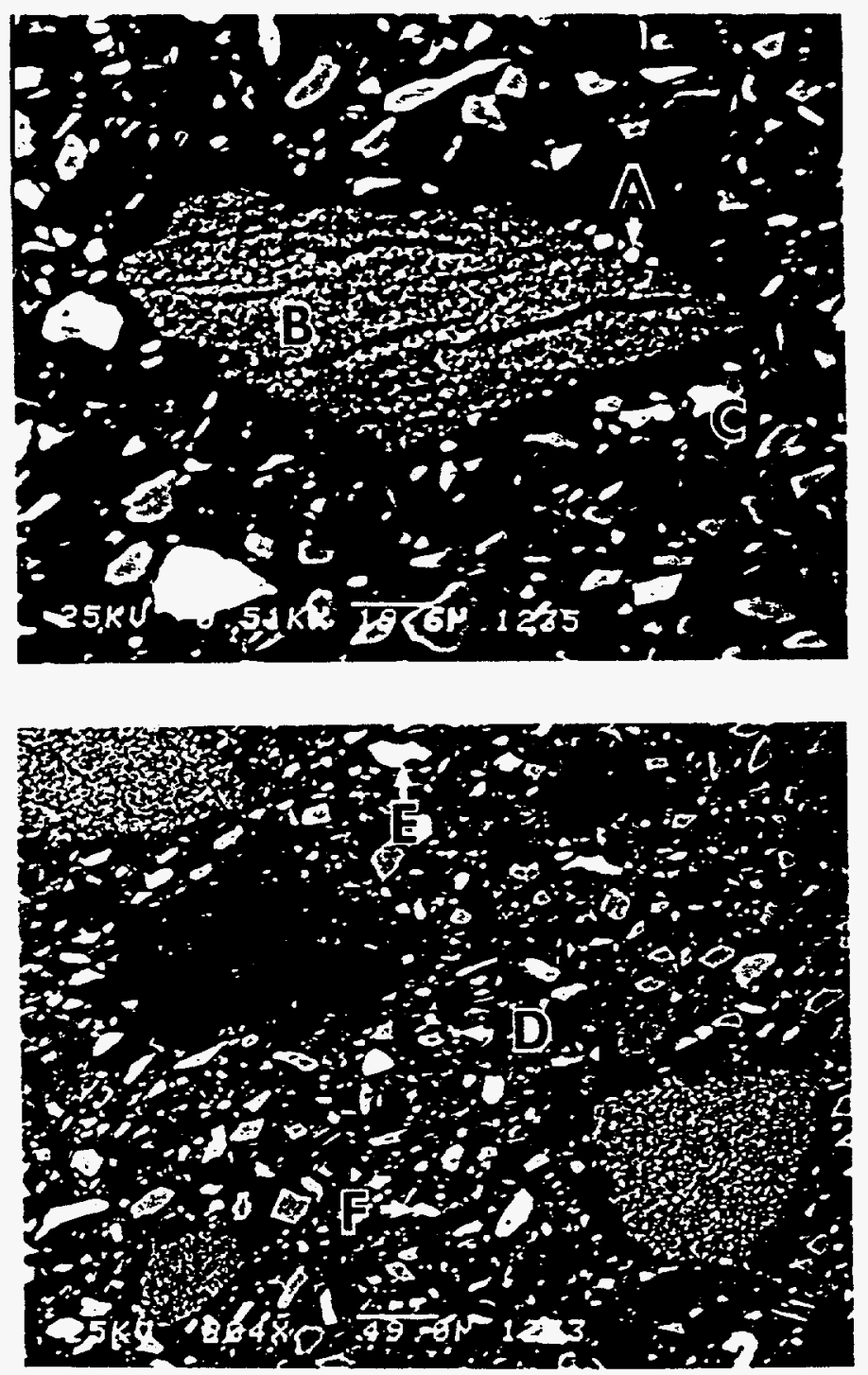

Plate 3.2. Two SEM micrographs were taken from the silt fraction of FEMP B-16 sample. The uranium particle $A$ also contains calcium, silicon, and aluminum. The fine silty aggregate is an aluminosilicate mineral (marked B). Particle $C$ is an iron oxide mineral and particle D is a phosphate mineral that contains cerium, neodymium, and lanthanum (monazite). Particles $\mathrm{E}$ and $\mathrm{F}$ are an iron-titanium oxide (ilmenite) mineral. other silt particles are quartz, dolomite (marked G), and feldspars. 


\section{SOIL AND URANIUM MINERALOGY}

The objective of this study has been to demonstrate the identification of uranium phases in the contaminated soils by Analytical Electron Microscopy (AEM). Data on the relative amounts of different phases and the physical characteristics of the phases; including composition, morphology and size, is being collected and the results of the investigation to date are described in this section. One soil sample, SP4 (Plant 1/ Storage pad Area), has been examined in detail.

\subsection{Introduction}

To provide a representative characterization of uranium phases distributed in soil, a relatively large number of unaltered particles must be examined. This is achieved by examining the soil in an optical microscope and segregating individual particles for examination or by mounting a collection of particles in epoxy and examining a polished cross-section with a scanning electron microscope using a backscattered detector (SEM/BSE). Sample SP4 was chosen for the initial AEM investigations because $\mathrm{mt}$ has a high contamination and variety of uranium-containing particles (Lee \& Marsh, 1991).

\subsection{Approach}

Uranium containing regions of the contaminated soils were identified by optical microscopy and SEM/BSE, isolated, embedded in epoxy and sectioned by ultramicrotome. The samples were analyzed by Analytical Electron Microscopy (AEM) using a JEOL 2000FXII Transmission Electron Microscope (TEM) fitted with analytical instruments. Facilities include two Noran Instruments energy dispersive X-ray detectors (EDX) and a Gatan Parallel Electron Energy Loss spectrometer (EELS). EELS was used in thiw study because of its higher spatial resolution compared to EDX. This section discusses the combined techniques of optical microscopy, SEM/BSE and AEM for the characterization of uraniumbearing phases in soils.

\section{Optical Investigation of SP4}

Soil sample SP4 was examined using an optical microscope, in an effort to correlate uranium phases with specific optical characteristics. The refractive index of uranium phases are characteristic for identification and the method is under investigation for locating uranium rich regions within the soil. Fluorite, zircon and a few uranium oxides were identified but the images were not clear because the uranium phases were probably too small or not well formed. Discrete uranium mineral phases can usually be identified easily in the optical microscope 
(Ewing, 1992). The fact that such phases were not observed, suggests weathering of the soil with the subsequent

redistribution of uranium into secondary minerals has not

occurred in this sample. Uranium phases also produce

characteristic yellow-green luminescence when exposed to UV

light. This can be used to isolate uranium rich regions; the procedure is described elsewhere in this document (see section. 5 "Uranium speciation in FEMP Soils").

\section{Sample Preparation}

Efforts concentrated on obtaining good resin infiltration as this allowed a smoother flat surface to be produced during polishing of intact large particles. The spatial relationship of uranium phases within particles was preserved in such samples, so allowing more uranium containing areas in a given field of view. A small amount of each sample was infiltrated with an epoxy resin commonly used in the preparation of TEM samples, particles were polished and then sliced into TEM thin sections by ultramicrotome. Some of the uranium-associated morphologies looked similar to those documented by Lee and Marsh (1991), but most of the regions were considerably smaller $(\leq 50 \mu \mathrm{m})$. Procedures were carried out to improve infiltration of clay components of the soil with the embedding resin. Section integrity was improved so that it was possible to correlate the uranium phases identified in the TEM with the corresponding area in the SEM/BSE image. In Figure $4.1 \mathrm{a}$ and $4.1 \mathrm{~b}$ it is possible to see similar features in both the SEM and TEM micrographs. Good infiltration of the resin provided intact samples (Figure $4.1 \mathrm{c}$ ).

Analysis of phases involved the use of the EDX, EELS, selected area electron diffraction (SAED) and convergent beam electron diffraction (CBED) which are techniques which can be carried out with AEM.

\subsection{Results and Discussion}

The following presentation of results is a summary of the phases observed in SP4 soil samples. AEM analysis showed that there were at least three major types of phases that contained uranium; a calcium phase, an iron oxide phase and as uranium oxide particles. Uranium was also located in a phosphate phase and minor amounts were found associated with clay. Phases were investigated using the full range of AEM techniques available.

\section{Oranium in Fluorite}

Calcium and uranium were detected together in a number of SEM analyses which suggests that this phase is an important contributor to uranium contamination in the sample SP4. Figure 4.2a shows a micrograph of a uranium bearing calcium phase. SAED analysis (Figure $4.2 \mathrm{~b}$ ) matched with fluorite and CBED symmetry 

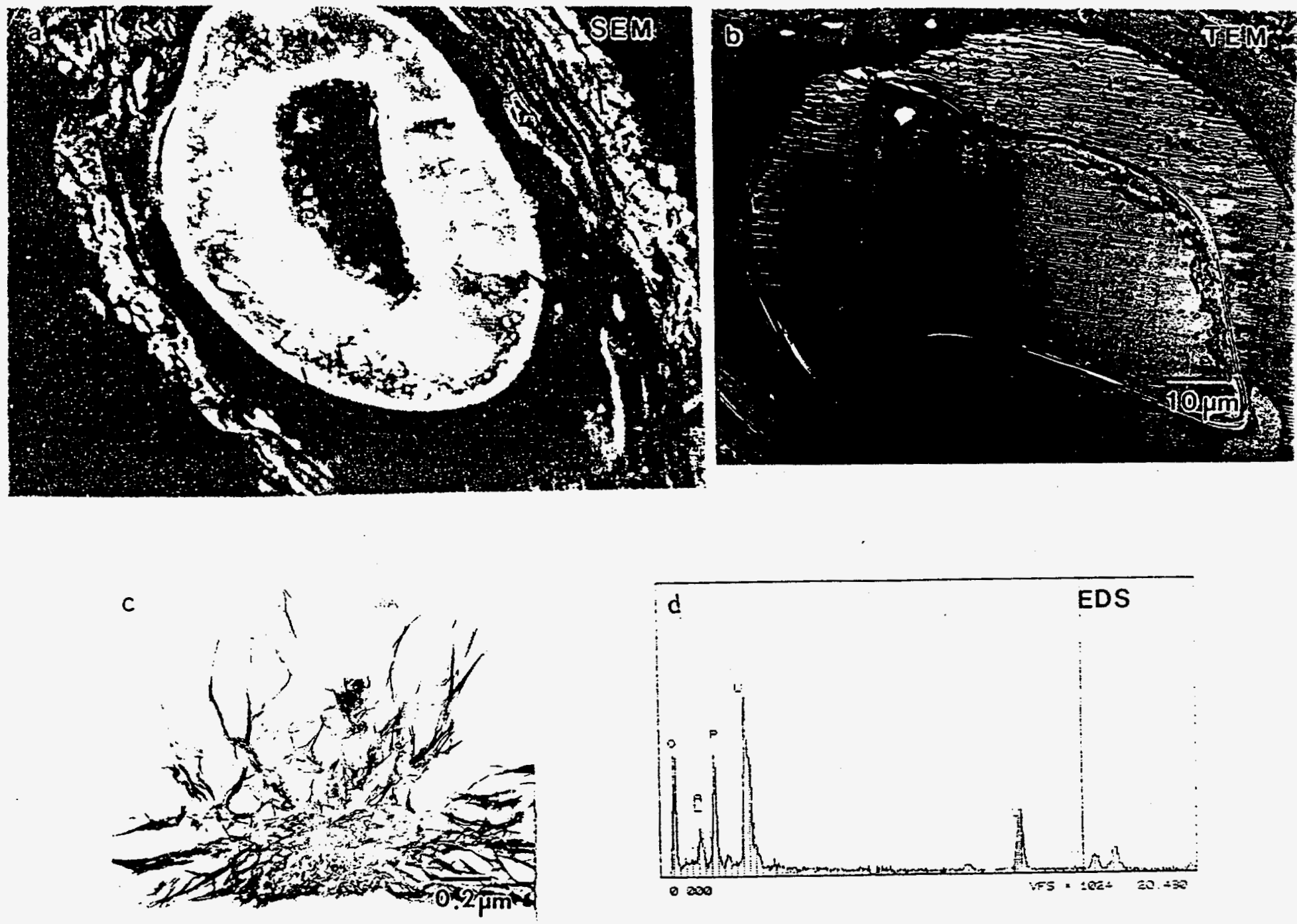

Figure 4.1. (a) SEM/BSE micrographs showing three crescent shaped uranium contaminated regions (light contrast), which can also been seen in the TEM image (b). The arrows in (a) and (b) point to the same regions in the SEM and TEM images. The copper grid can be seen in (b) which results in a $\mathrm{Cu}-\mathrm{K}_{\mathrm{ab}}$ peak in all EDX analyses. In (c) good infiltration of the resin into the soil has occurred which permits intact thin sections to be produced. 


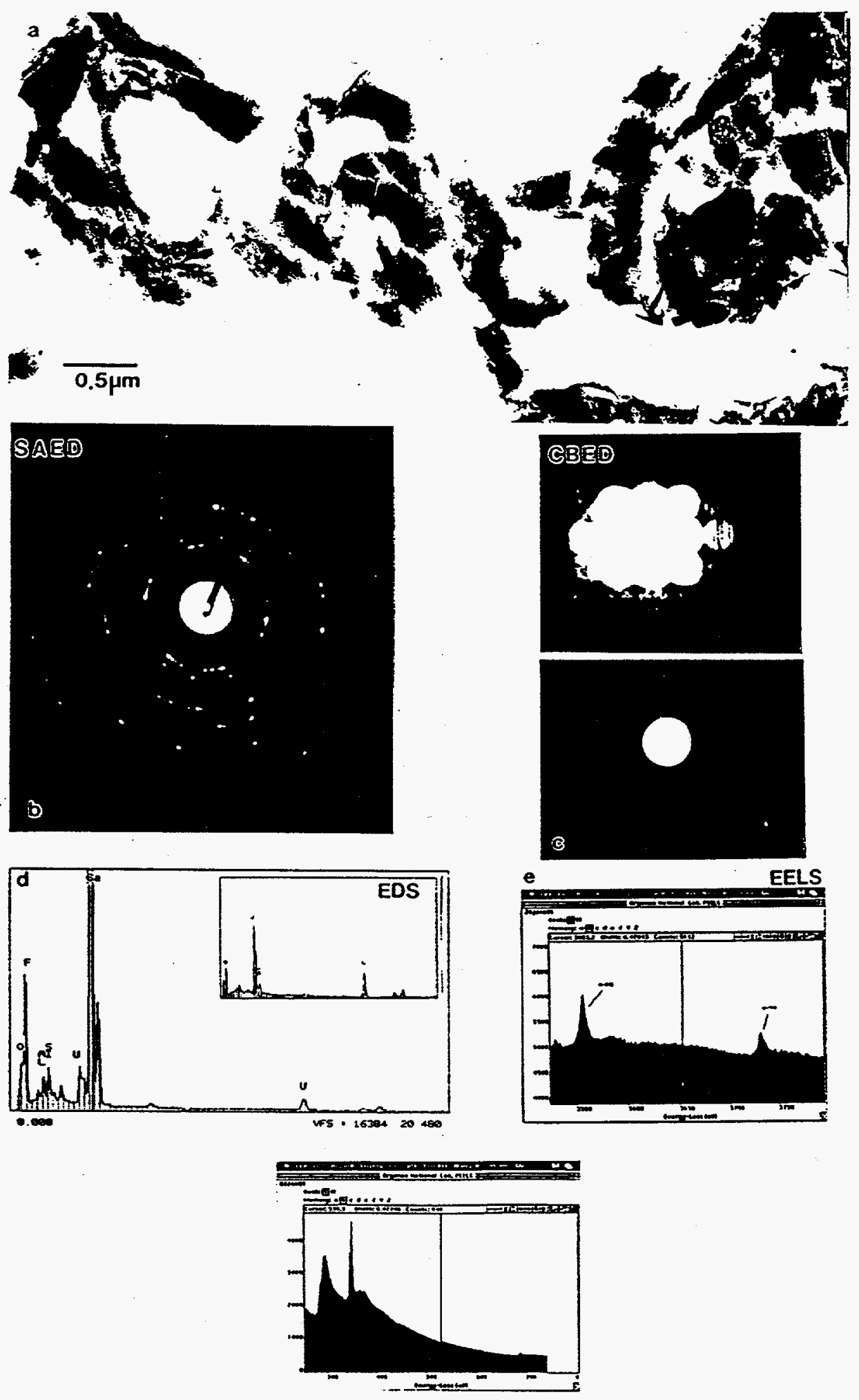

Figure 4.2. A bright field micrograph of a uranium bearing phase (a) was identified as calcium fluorite by SAED (b), symmetry analysis with CBED (c) and compositional analysis by EDX (d) and EELS (e). 
analysis (c) was consistent with fluorite. EDX analysis (d) indicated the phase was calcium fluoride $\left(\mathrm{CaF}_{2}\right)$. This was confirmed using the higher spatial resolution of EELS (e), which showed that oxygen was not a major component of this phase. In the first EEL spectrum, the uranium $M_{4}, 5$ edges can be seen at $3552 \mathrm{eV}$ and $3728 \mathrm{eV}$, and in the spectrum below, the $\mathrm{L}_{2}, 3$ (346 eV and $350 \mathrm{eV}$ ) edges of calcium and the fluorine K-edge at $685 \mathrm{eV}$ are visible. The minerals of the fluorite group can incorporate uranium into their structures. Oxygen is also taken up for charge compensation (Perry, 1992). If uranium is contained within the calcium fluoride phase it may well be ordered within this structure so forming a superlattice. A superlattice should be readily identifiable, especially one with uranium atoms. So far it has not been possible to observe such an effect.

The table below shows some uranium concentrations in element weight percent taken from calcium phases found in these sections.

\begin{tabular}{|l|l|l|}
\hline Element & $\mathrm{U}$ & $\mathrm{Ca}$ \\
\hline wt: & 22.25 & 72.68 \\
\hline & 22.05 & 67.23 \\
\hline & 20.51 & 74.58 \\
\hline & 20.08 & 74.35 \\
\hline & 21.5 & 74.16 \\
\hline & 5.66 & 91.08 \\
\hline
\end{tabular}

The uranium concentration remained fairly constant with respect to calcium, except in a few instances. Probes were placed at all regions over the calcium particles. The results suggest that uranium is unlikely to be adsorbed on the surface of the particles but contained within the $\mathrm{CaF}_{2}$ structure.

\section{Uranium In Iron oxides}

Amorphous uranium bearing iron oxide phases were observed in many particles. This type of uranium phase had a different morphology compared to that of the calcium phase. It consisted of small (100 nm diameter) particles which often appeared to be strung together into a much larger agglomerate. On occasions both calcium and iron uranium phases were observed in close proximity (i.e., not more than $1-2 \mu \mathrm{m}$ separated them). In Figure 4.3a SEM/BSE image (a) of a uranium containing particle is shown along with its complimentary TEM image (b). Iron phases were found throughout this sample (c) and an EDX analysis of one such phase is shown in Figure $4.3 \mathrm{~d}$.

Silicon was also found during the analysis of the iron oxide phases. It was not clear whether the silicon was part of the phase or not. EELS will be used to check this. Generally, a higher concentration of uranium was found in these phases than in the calcium phases. The uranium concentration varied considerably from around 10 to $60 \mathrm{wt} \%$, probably due to interference from uranium oxide regions. 

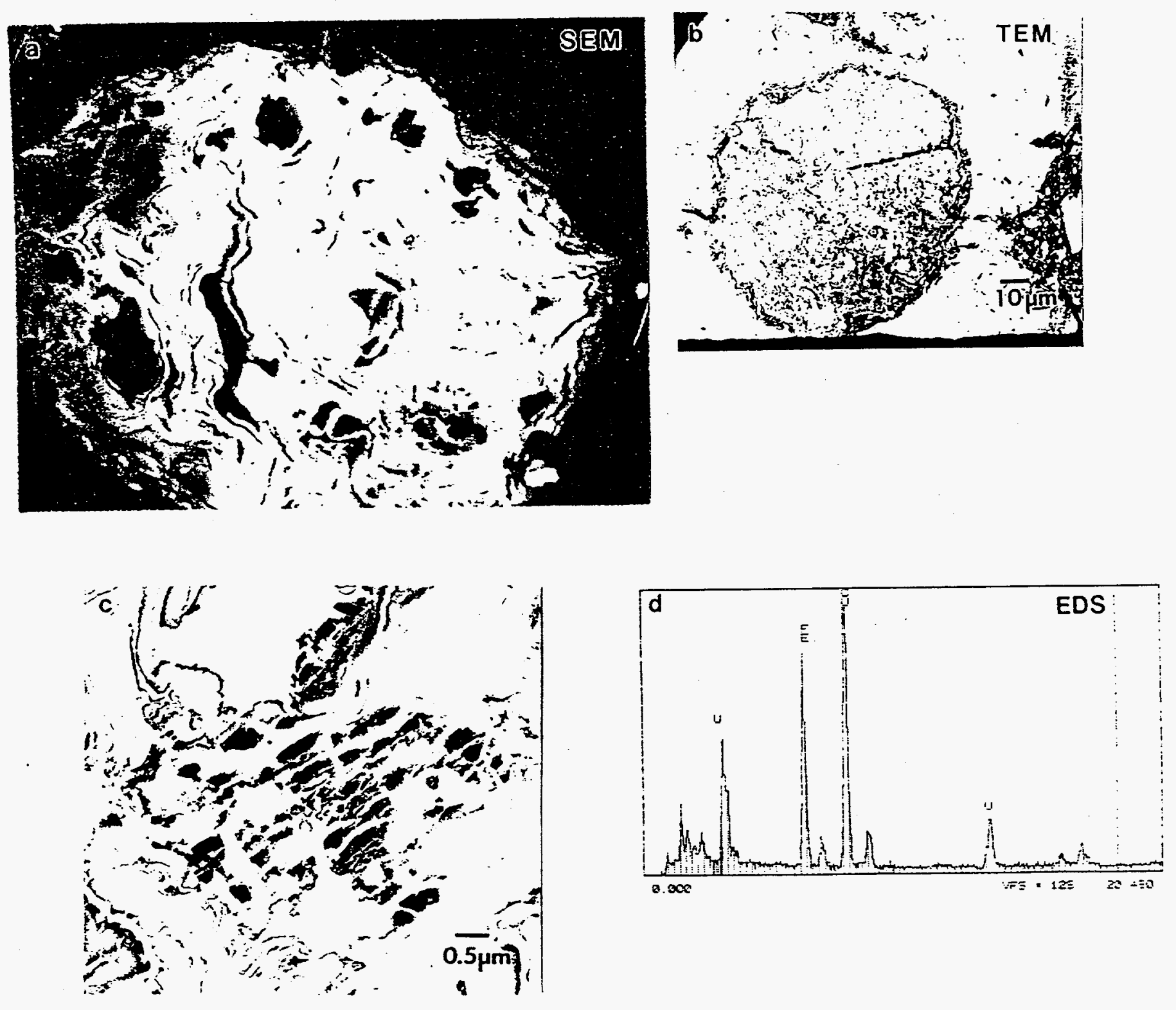

Figure 4.3. Another major uranium bearing phase found in SP4 was an amorphous iron oxide phase. A particle containing uranium was found during SEM analysis (a) was characterized in the TEM (b) and shown to contain mainly small clumps of particles (c) identified as uranium iron oxide phases (d). 


\begin{tabular}{|l|l|l|l|}
\hline El wt\% & U & Fe & Si \\
\hline & 29.23 & 66.35 & 2.73 \\
\hline & 18.78 & 74.87 & 4.96 \\
\hline & 29.24 & 58.67 & 7.23 \\
\hline & 62.54 & 29.55 & 2.39 \\
\hline & 27.59 & 56.11 & 8.94 \\
\hline & 75.01 & 10.85 & 10.40 \\
\hline & 36.69 & 52.46 & 6.35 \\
\hline
\end{tabular}

\section{Uranium oxide}

Uranium oxide particles were also found in the soil samples. The SEM has shown the existence of such uranium particles, but it appears that these are relatively difficult to section, as they are so hard. These uranium particles were crystalline and large enough for single crystal patterns to be generated. Most of the uranium oxides have similar unit cell parameters which means that in order to distinguish between uranium oxides, diffraction data must be collected extremely carefully.

The SAED of a uranium oxide phase shown in Figure 4.4 was located close to the calcium fluoride phase described earlier; the spacings match with the fluorite uranium oxide $\left(\mathrm{UO}_{2}\right)$. EDX analysis of this phase is shown in Figure $4.4 \mathrm{~b}$. Another uranium oxide phase was found containing small quantities of silicon, potassium and iron. The phase exhibited spacings that suggested a unit cell larger than most simple uranium oxides. Uranium phases found have tended to be radiation stable and are still under investigation.

\section{Uranium in Phosphate}

A uranium phosphate phase was found in one group of particles in SP4. The phase is crystalline owing to the morphology (Figure 4.5d), however, SAED analysis failed to detect any signs of crystallinity. The uranium phosphate particles are elongated and micrographs appear to display lattice fringes. These did undergo some change during observation which supports the contention that these are crystalline. There are a range of possible uranium phosphate phases (see section 6 "Geochemical Modeling"). These phases may be so beam sensitive that they become amorphous immediately during observation. Investigation of this phase by AEM will continue to try determine the structure.

\section{Uranium in clays}

Clay minerals are known to have an affinity for uranyl species and take up uranium either by adsorption onto the surface of the clay or within interlayer sites. Nevertheless, in spite of the fact that clays are a major component of FEMP soils, very 
few examples of uranium associated with clays have been found. A magnesium containing clay which was found to contain no uranium was identified as belonging to the chlorite group. Another type of clay (mica group) was found to contain uranium on one occasion.

\subsection{Summary}

Selected soil particles from SP4 were examined using optical microscopy combined with SEM and AEM. With these methods of analysis it was possible to isolate and characterize discrete uranium bearing phases. With optical microscopy no large uranium bearing secondary minerals were observed. With SEM, however, clumps of uranium rich regions were identified. Upon further examination with AEM these regions were found to be composites of finely dispersed phases which were both crystalline and amorphous. Iittle uranium was associated with the clay substrate itself. While it is necessary to show the relationship of these results to larger soil samples, the utility of the use of integrated microscopy techniques for uranium phase identification and characterization has been demonstrated.
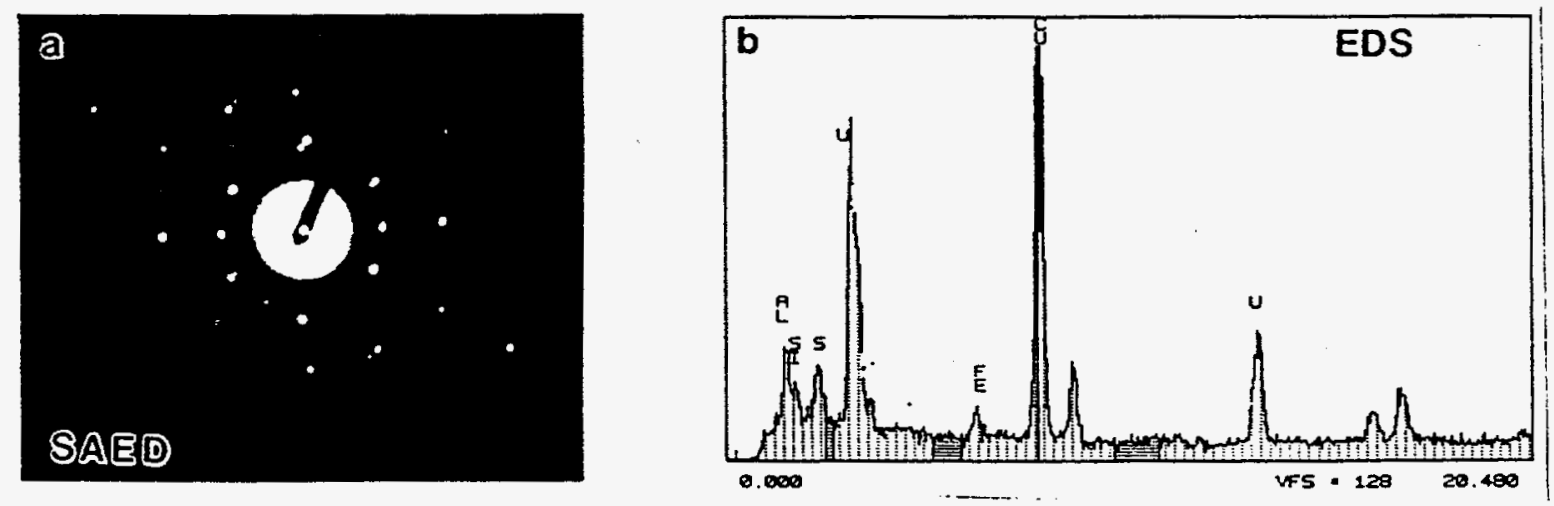

Figure 4.4. Uranium oxide particles were found on a number of occasions. SAED of the uranium oxide was consistent with a fluorite type structure. EDX is shown in figure $4 \mathrm{~b}$. 

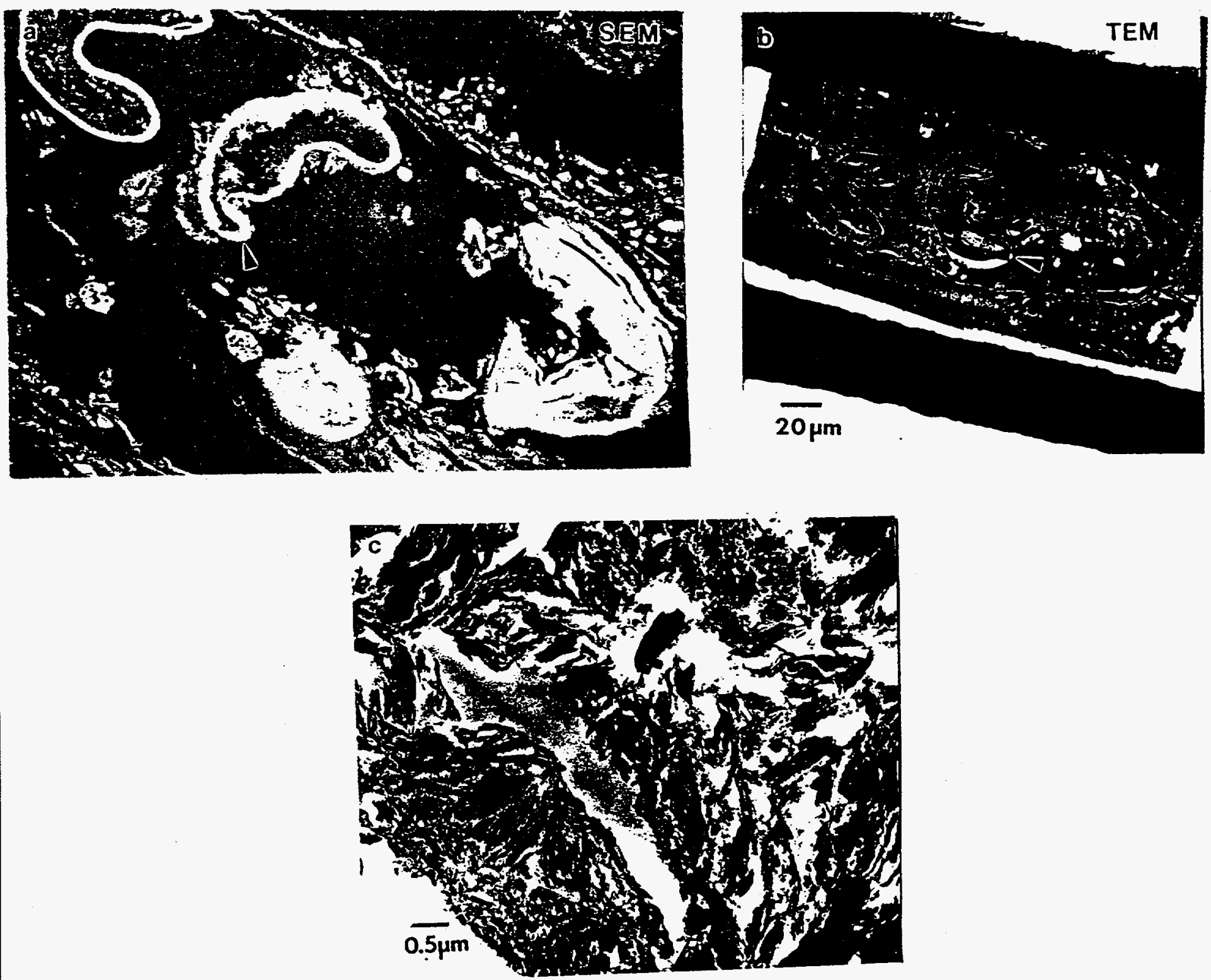

Figure 4.5. Shows another example of the technique which allows comparison between SEM/BSE (a) and TEM (b) images, which displays a oval shaped particle. Two uranium bearing phases were found in these particles; a uranium iron oxide phase and a uranium phosphate phase (c) with the accompanying EDX (d). 


\section{Uranium Speciation in FEMP Soils}

\subsection{Approach}

The objective of the uranium speciation task is to characterize the important chemical characteristics (oxidation state, chemical structure, mode of binding) and properties (surface precipitates, mineral coatings, clay adsorbates) of uranium and uranium / organic mixtures in soils at the FEMP. providing this type of information $(\mathrm{e} . \mathrm{g}$. , the dominant species in the shallow subsurface near plant $2 / 3$ might be found to be the uranium mineral schoepite), we help the Decontamination Task Team to devise and test remediation schemes more effectively, and we provide solid evidence to use as a benchmark in developing and validating the conceptual model for uranium transport at the. To adequately specify uranium speciation, techniques that probe structure at the molecular level are required. Elemental specificity, while important, is insufficient by itself. We also need techniques that are applicable to solid samples (e.g., clays and minerals), because these frequently possess challenging optical properties. To achieve this molecular-level sensitivity, we employ a combination of four spectroscopic techniques that we have shown to be sufficient for actinide speciation studies in subsurface matrices. These methods (1) are complementary in the information they provide, and (2) span an analyte concentration range from - 1 \% to 100 parts-per-trillion and below (i.e., the relevant regime for the FEMP).

The first two techniques, $x$-ray absorption and Raman vibrational spectroscopies, provide molecular structure information explicitly. That is, one need not make assumptions or resort to models to deduce structural information. However, these methods have modest analytical sensitivity. X-ray absorption spectroscopy is the most incisive tool because it provides a "snapshot" of the local coordination environment about the target (uranium) ion. Thus, the identity and number of coordinating atoms (from ligands and/or surfaces) and their bond lengths can be quantitated. X-ray absorption spectroscopy also provides oxidation state information [e.g., U(IV) vs U(VI)] directly. Raman vibrational spectroscopy provides explicit coordination sphere structure via the number, energy, and intensity of the observed vibrational transitions. The other two methods, luminescence and photoacoustic spectroscopies, provide molecular-level information implicitly based on the encoding of structure on electronic transition bands. However, these methods possess exquisite (ppt and below) analytical sensitivity. In addition, luminescence spectroscopy for hexavalent uranium species can provide a method for "fingerprinting" many uranyl species because of the unique, highly structured nature of the emission seen for these uranyl species. Conversely, photoacoustic spectroscopy is expected to be very useful for determining the speciation of tetravalent uranium species, because these species have weak $f-f$ electronic absorption 
transitions that are sensitive to the U(IV) coordination environment. By using these four techniques in concert, uranium speciation can be delineated over order-of-magnitude changes in concentration, both in solution and on a wide variety of solid matrices.

An important element in many of these spectroscopies is the ability to couple them to microprobe systems to spatially resolve the uranium species in the soils at the micron resolution level, and the ability to use pulsed excitation sources and gated detection schemes to temporally resolve the signals to achieve better distinction of the various uranium species. All of the methods outlined above except $x$-ray absorption can easily be implemented in spatially-resolved and temporally-resolved modes. $X$-ray absorption can be implemented in these modes in principle, but temporal resolution would be of little value.

We also employ several ancillary techniques to assist in characterization and absolute identification of the uranium speciation. The principal ancillary method is x-ray diffraction. since much of the uranium in the soils has been found to be particulate in nature, x-ray diffraction provides a powerful means of rapidly identifying these particulate uranium species. other methods include inductively-coupled plasma emission spectroscopy and delayed neutron activation analysis for quantitation of bulk uranium concentration.

\subsection{Experimental Samples}

Most of the speciation characterization work that we have carried out to date has been on core samples that were provided to us by Dr. S. Y. Lee of Oak Ridge National Laboratory. A summary of these samples is provided in Table 5.1. Dr. Lee provided us with portions of samples from five different sites. We have further focused our efforts on the samples from three of these sites. Two of these sites, the Plant 1 / storage Pad Area and the Incinerator Area, have been chosen as the locations for sample collection and homogenization for treatability studies. Therefore, we opted to look in detail at the samples collected by Lee at these sites to provide information to the Decontamination Task team to assist them in their efforts with the treatability samples. The third site on which we have focused is the Plant 2 $/ 3$ site. The reason for focusing on samples from this site is that the site has a high level of uranium contamination, and the source term ( the PUREX process) is fairly well understood. In general, based on information contained in the RI/FS report of the main operable unit (OU-3) at the FEMP, the uranium source term and therefore the contaminant speciation may be different for each of the sites at the plant. 
Table 5.1. Summary of FEMP Soil Samples obtained for Characterization Work from ORNL

\begin{tabular}{|l|l|l|}
\hline Sample ID $^{\text {a }}$ & Designator & Site Descriptor \\
\hline SP2-2-ABC & SP2-2 & Plant 2 / 3 Area \\
\hline SP2-3-ABC & SP2-3 & Plant 2 / 3 Area \\
\hline SP4-1A/2A & SP4-1 & $\begin{array}{l}\text { Plant 1 / Storage } \\
\text { Pad Area }\end{array}$ \\
\hline SP5-1AB & SP5-1 & $\begin{array}{l}\text { Decontamination } \\
\text { Pad / Drum Bailing } \\
\text { Area }\end{array}$ \\
\hline SP8-1A/2A/3A & SP8-1 & Plant 6 Area \\
\hline SP9-1A/3A & SP9-1 & Incinerator Area \\
\hline
\end{tabular}

a The sample identification scheme of Lee and Marsh (1992) has been preserved here.

b These are the abbreviated designators that will be referenced in the remainder of the report.

$C$ This sample was collected from the 10-20 in. horizon.

d This sample was collected from the 20-31 in. horizon.

The samples obtained from Lee contained a wide range of particle sizes from large sand and gravel chunks $(-2-3 \mathrm{~mm}$ diameter) to fine clay-sized particles. The only sample preparation undertaken by us on these materials was homogenization by grinding portions of all samples for the initial x-ray absorption spectroscopy investigations. We also performed a crude size fractionation, based on gravimetry, for several luminescence spectroscopy investigations. Finally, for $x-r a y$ diffraction determinations of the particulate uranium in the sample from the Plant $2 / 3$ area (SP2-3), the particulate uranium was isolated and concentrated by hand under a microscope while illuminating the sample with ultraviolet light. Particles that appeared to possess the characteristic green emission of uranyl species were isolated by this procedure.

Samples were also collected for treatability studies by the Decontamination Task Team as noted above. These samples were homogenized by mechanical means and analyzed (Kneff et al., ETEC/GEN-ZR-0018) prior to shipment. The analyses indicated that the Plant 1 samples were sufficiently homogenized whereas the Incinerator Area samples were poorly homogenized. Portions of these samples were examined by us in the same form in which they were received. Some of the samples were also examined following air-drying.

\section{Instrumentation}

Uranium LIII $\mathrm{x}$-ray absorption spectral data were obtained on powdered samples at both the National synchrotron Light source (NSLS) at Brookhaven National Laboratory and the stanford Synchrotron Radiation Laboratory (SSRL) at Stanford University. All data were collected under ambient temperature and pressure. 
Absorption was detected in either transmission mode or fluorescence mode. Calibrations of the U LIII edge were obtained either simultaneously or between sample runs. Additional experimental and data reduction details will be presented in a forthcoming manuscript.

Luminescence data were collected using either continuous wave argon-ion laser excitation (Spectra-Physics Model 2040) or monochromatized light from a xenon arc lamp. For the laserexcited experiments, data were collected on a SPEX Industries Model 1403 Double Monochromator. For the arc-lamp experiments, data were collected on a SPEX Industries Fluorolog system. In all cases the emitted light was detected using a photomultiplier tube. In the laser-excited experiments the near ultraviolet lasing lines at 336,351 , and $364 \mathrm{~nm}$ were used. The focus of the beam was varied from $~ 50$ microns to 2 millimeters to change the spatial resolution of the probe on the sample. The samples were contained in glass vials in their heterogeneous form and were manually rastered with respect to the excitation beam to probe different sites and features within the samples. In the arc-lamp experiments the exciting light was focused to illuminate large portions of the sample, and no spatial resolution was obtained. The excitation wavelength was chosen to optimize the emission intensity. In some cases, the arc-lamp experiments were conducted with the samples (in sealed capillary tubes) in a liquid helium cryostat $(\sim 10 \mathrm{~K})$ in an attempt to mitigate the quenching of the uranium luminescence and to sharpen the spectral features.

$\mathrm{X}$-ray powder diffraction patterns were collected on a Philips computer-controlled X-ray Diffractometer using $\mathrm{Cu} \mathrm{K} \alpha$ radiation. Data points were collected at 0.02 steps / degree $2 \phi$ with an integration time of $150 \mathrm{~s} /$ step. Crushed powder samples were contained in aluminum sample holders.

\subsection{RESULTS AND DISCUSSION}

\section{X-ray Absorption Spectroscopic Data}

X-ray absorption spectral data have been obtained for all samples. (Note that sample IDs for the samples obtained from ORNL will henceforth be abbreviated as indicated in Table 5.1.) Portions of all of these samples were ground to a homogeneous fine powder using an agate mortar and pestle for use in the $x-r a y$ absorption experiment. Several of the samples have been run at both NSLS and SSRL with excellent reproducibility of results in all cases. Figure 5.1 shows the $x$-ray absorption spectrum in the region of the U LIII edge for sample SP2-2, superimposed on the spectra for an aqueous $\mathrm{UO}_{2}{ }^{2+}$ solution and solid $\mathrm{UO}_{2}$. The position of the absorption edge (Section A in Fig. 5.1) is a very sensitive indicator of the oxidation state of the absorber 


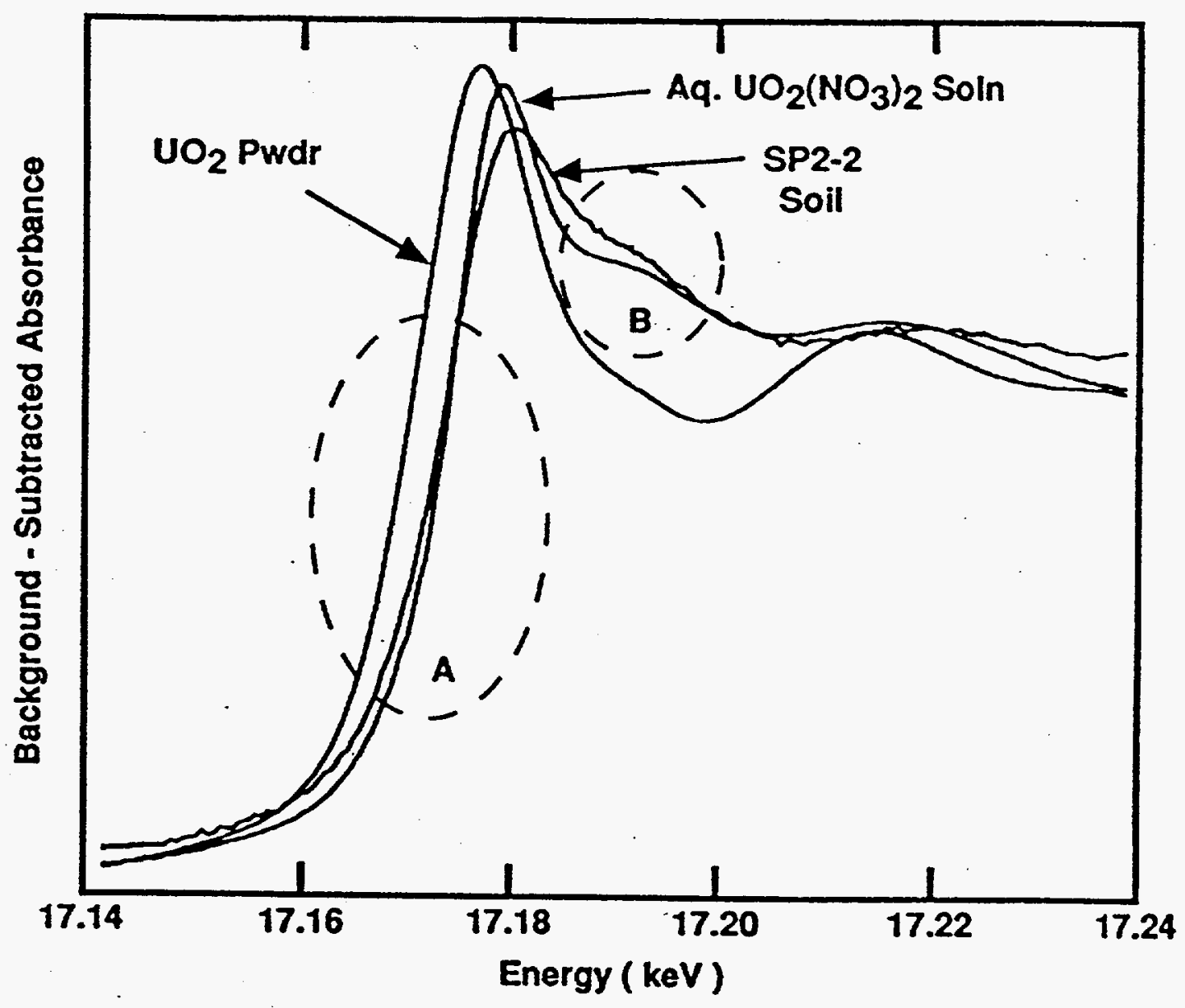

Figure 5.1. Background-corrected $x$-ray absorption spectra for the FEMP Sample SP2-3 compared to a tetravalent uranium species $\left(\mathrm{UO}_{2}\right.$ powder) and a hexavalent uranyl species $\left(50 \mathrm{mM} \mathrm{UO} \mathrm{UO}_{2}\left(\mathrm{NO}_{3}\right)_{2}\right.$ in $\left.\mathrm{H}_{2} \mathrm{O}\right)$. The edge position (Region $\mathrm{A}$ ) and the XANES feature (Region B) are characteristic of speciation and demonstrate that the FEMP sample consists predominantly $\mathrm{UO}_{2}{ }^{2+}$ species. 
(uranium) atom. Since the absorption edge energy increases with increasing charge on the uranium atom, it can be seen that the oxidation state of the FEMP sample is significantly higher than the one for $\mathrm{UO}_{2}$ (i.e., a tetravalent uranium species), and the same as that for aqueous $\mathrm{UO}_{2}{ }^{2+}$ (i.e., a hexavalent uranium species). The XANES ( $x$-ray absorption near edge structure) feature on the high energy side of the main absorption feature near $17192 \mathrm{eV}$ (Section B in Fig. 5.1) is also diagnostic of $\mathrm{UO}_{2}{ }^{2+}$. Note that this feature is present in the FEMP sample and the aqueous solution of $\mathrm{UO}_{2}{ }^{2+}$, but is absent in the spectrum of $\mathrm{UO}_{2}$. $\mathrm{X}$-ray absorption spectroscopic signals are a populationweighted average of the spectra from all uranium species in the sample. Therefore, if the FEMP sample were a mixture of uranyl species and uranium species in other lower oxidation states (4t and/or 5+), the absorption edge would have been shifted to lower energy, and the shoulder near $17192 \mathrm{eV}$ would have been diminished. Consequently, we estimate that greater than $80-90 \%$ of the uranium in this sample exists as uranyl moieties.

In Figure 5.2 the $x$-ray absorption spectrum of the samples provided by ORNL from three different sites at the FEMP in the region of the U LIII edge are compared. Note that these spectra are all very similar from the position of the edge feature into the first extended $x-r a y$ absorption fine-structure (EXAFS) feature $(-17220 \mathrm{eV})$. Thus, the majority of the uranium in the soil samples from these three different sites must be present as hexavalent uranium species. Close inspection reveals that Sample SP4-1 has slight differences in both the XANES feature and the first EXAFS feature. This is manifested as a shift in the peak position to lower energy and a change in intensity. These differences are borne out in the EXAFS analysis (vide infra).

Additional information concerning the structure and the speciation of these hexavalent uranium species can be obtained from analysis of the EXAFs region of the spectra. To facilitate the following discussion, a cartoon representation of the basic structural motif for the uranyl moiety is presented in Fig. 5.3. This moiety is characterized by two axial or "yl" oxygen atoms typically at distances varying from 1.7 to 1.9 angstroms. This structural feature is essentially invariant and is the defining feature in terms of both spectroscopy and chemistry of the uranyl moiety. In contrast, the number and types of atoms constituting the "equatorial" shell can vary substantially from one uranyl species to another. These atoms introduce perturbations to both the chemistry and the spectroscopy of the uranyl species, and are primarily responsible for the changes seen in the spectroscopic data. For this reason, spectroscopic techniques serve as useful probes for uranyl speciation.

Analysis of the EXAFS portion of the $x$-ray absorption spectrum in general provides direct information concerning the 


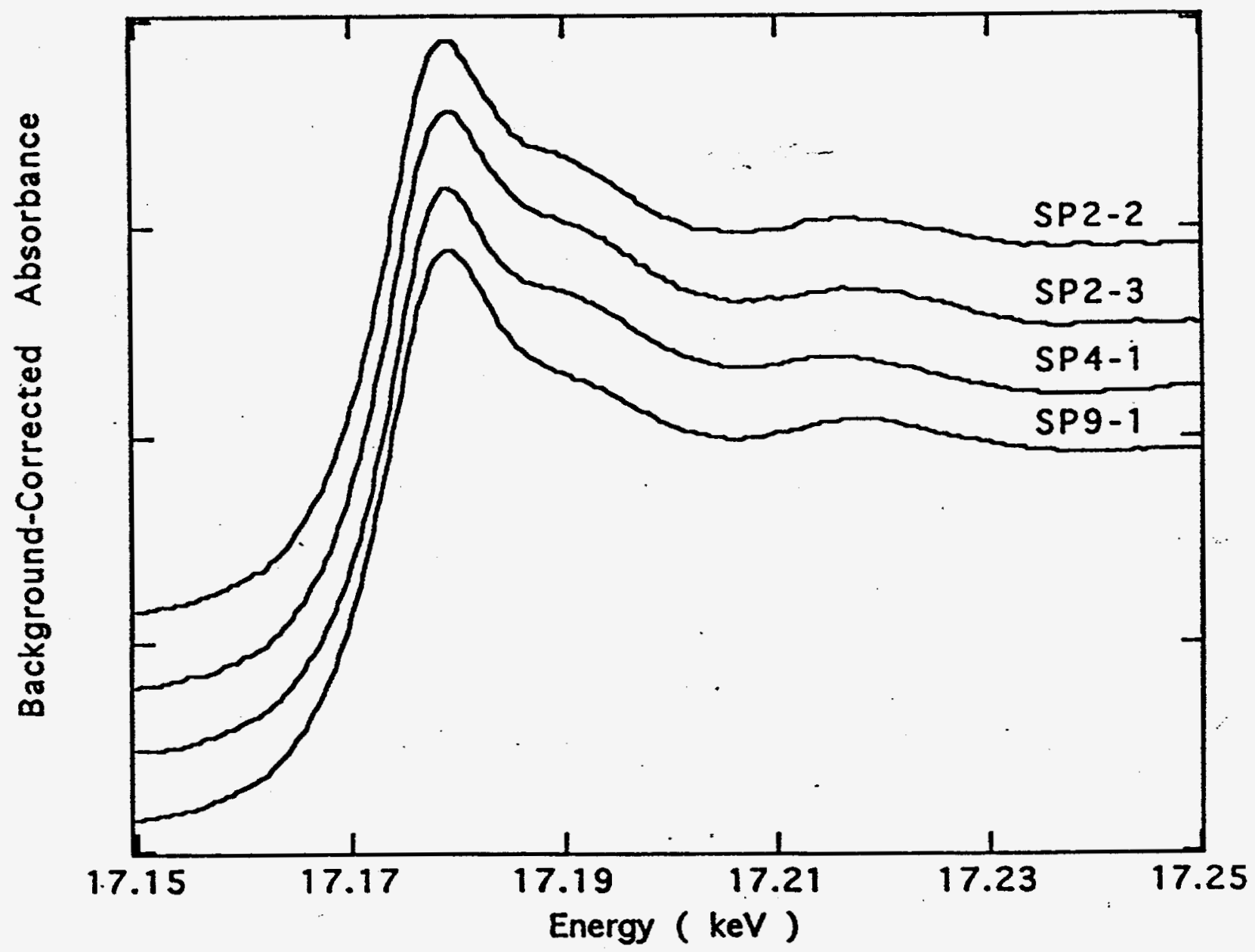

Figure 5.2. Background-corrected $x$-ray absorption spectra for the FEMP soil samples from two horizons within the plant $2 / 3$ Area; $10-20$ inches (SP2-2), and $20-31$ inches (SP2-3), and from the Plant 1 / Storage Pad Area (SP4), and the Incinerator Area (SP9). 


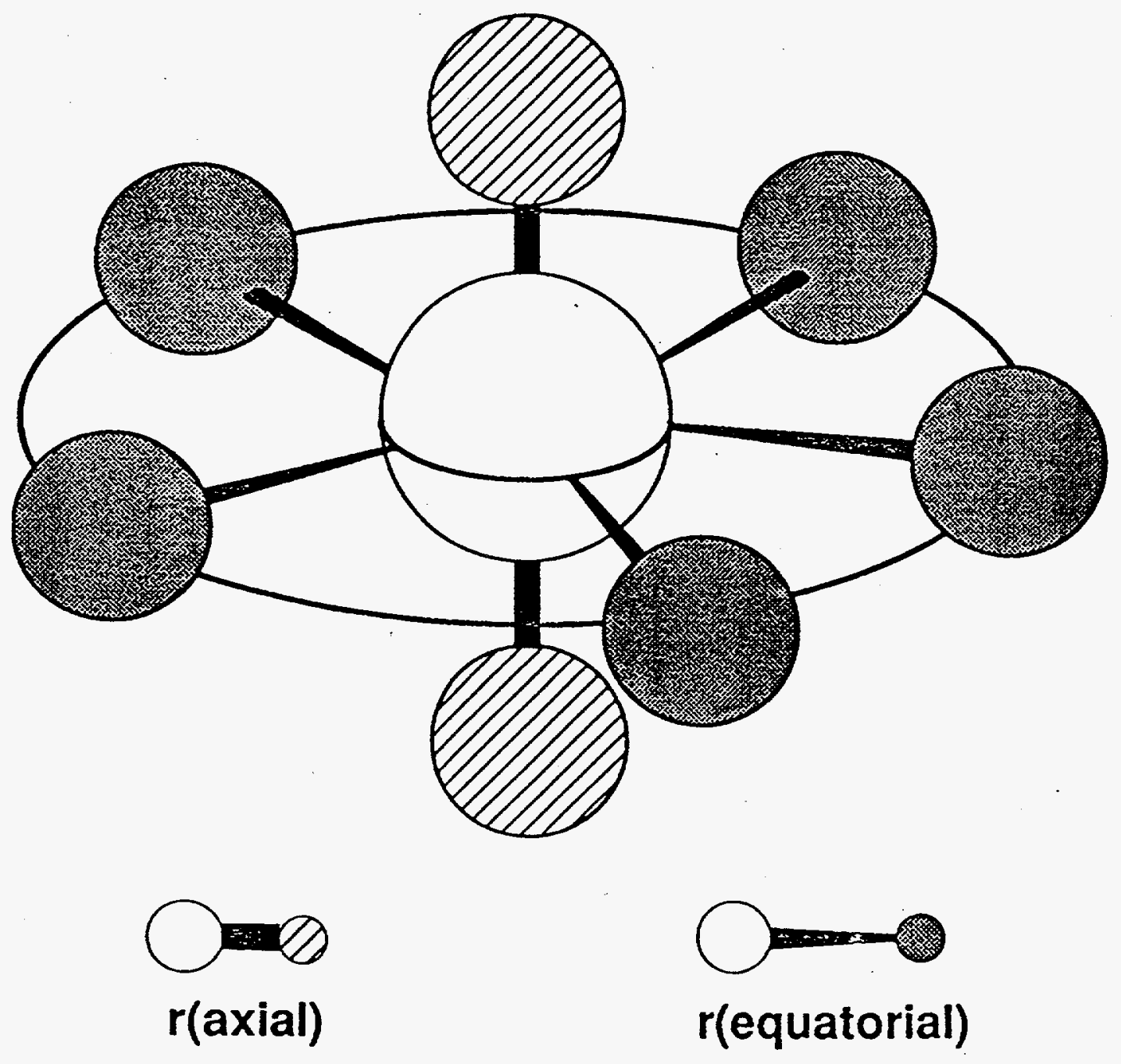

Figure 5.3. Cartoon representation of the structural motif of $\mathrm{UO}_{2}{ }^{2+}$ species. The typical axial U-O bond length is 1.7 to 1.9 angstroms. The equatorial bond lengths can vary from $\sim 2.2$ to 2.5 angstroms and the number of coordinating atoms can vary from $\sim 4$ to 6 . 
bond distances, the numbers of bound atoms, and the identities of the bound atoms about the sorber (i.e., uranium). Because the "yl" oxygen atoms remain essentially invariant, their contribution can be mathematically filtered from the EXAFS spectrum to focus on the contributions from the more speciationsensitive equatorial atoms. A comparison of these filtered EXAFS spectra for samples SP2-2, SP4-1, and SP9-1 is shown in Fig. 5.4. The large amplitude feature at a distance of -2 angstroms (uncorrected for phase shift) is due to the equatorial atoms. The position of this band is about the same for all three samples indicating that the average bond distance between uranium and the equatorial atoms is approximately the same for the uranyl species in all these samples. Furthermore, because the amplitude is approximately the same in this feature for samples SP2-2 and SP91 , the number of equatorial atoms is about the same. However, the amplitude for Sample SP4-1 is significantly reduced relative to the others. This suggests that the number of equatorially coordinated oxygens is lower for the uranyl species in this sample and/or the disorder (for example, from having several different uranium-oxygen bond distances) is greater. In either case, these results show that, while the average uranyl speciation is comparable for samples SP2-2 and SP9-1, it is different in sample SP4-1. Interestingly, Sample SP4-1 is also the only sample in the suite SP2-2, SP2-3, SP4-1, and SP9-1 for which no structured optical luminescence is observed (vide infra). A summary of the structural parameters that have been extracted from the EXAFS analysis for these samples is provided in Table 5.2 .

Table 5.2. Structural Parameters for Average Uranyl species in the FEMP soil samples

\begin{tabular}{|l|l|l|l|l|}
\hline \multicolumn{2}{|c|}{ Axial Oxygens } & \multicolumn{2}{c|}{ Equatorial Oxygens } \\
\hline Sample & $\begin{array}{l}\text { Bond } \\
\text { Distance } \\
\text { (Angstroms) }\end{array}$ & $\begin{array}{l}\text { No. of } \\
\text { Atoms }\end{array}$ & $\begin{array}{l}\text { Bond } \\
\text { Distance } \\
\text { (Angstroms) }\end{array}$ & $\begin{array}{l}\text { Amplitude Relative } \\
\text { to SP2-2a }\end{array}$ \\
\hline SP2-2 & 1.81 & 1.9 & 2.34 & 1.00 \\
\hline SP2-3 & 1.82 & 2.2 & 2.34 & 0.97 \\
\hline SP2-3 & 1.81 & 2.0 & 2.35 & 1.07 \\
\hline SP4-1 & 1.81 & 2.1 & 2.39 & 0.68 \\
\hline SP9-1 & 1.81 & 1.8 & 2.35 & 0.96 \\
\hline
\end{tabular}

a The absolute number of coordinated atoms cannot be determined from the existing data. However, relative amplitudes demonstrate the near invariance for these samples with the exception of the SP4-1 Sample.

b This was a replicate determination at NSLS to the one preceding it in the table (from SSRL) to demonstrate the excellent reproducibility obtained in these studies. 


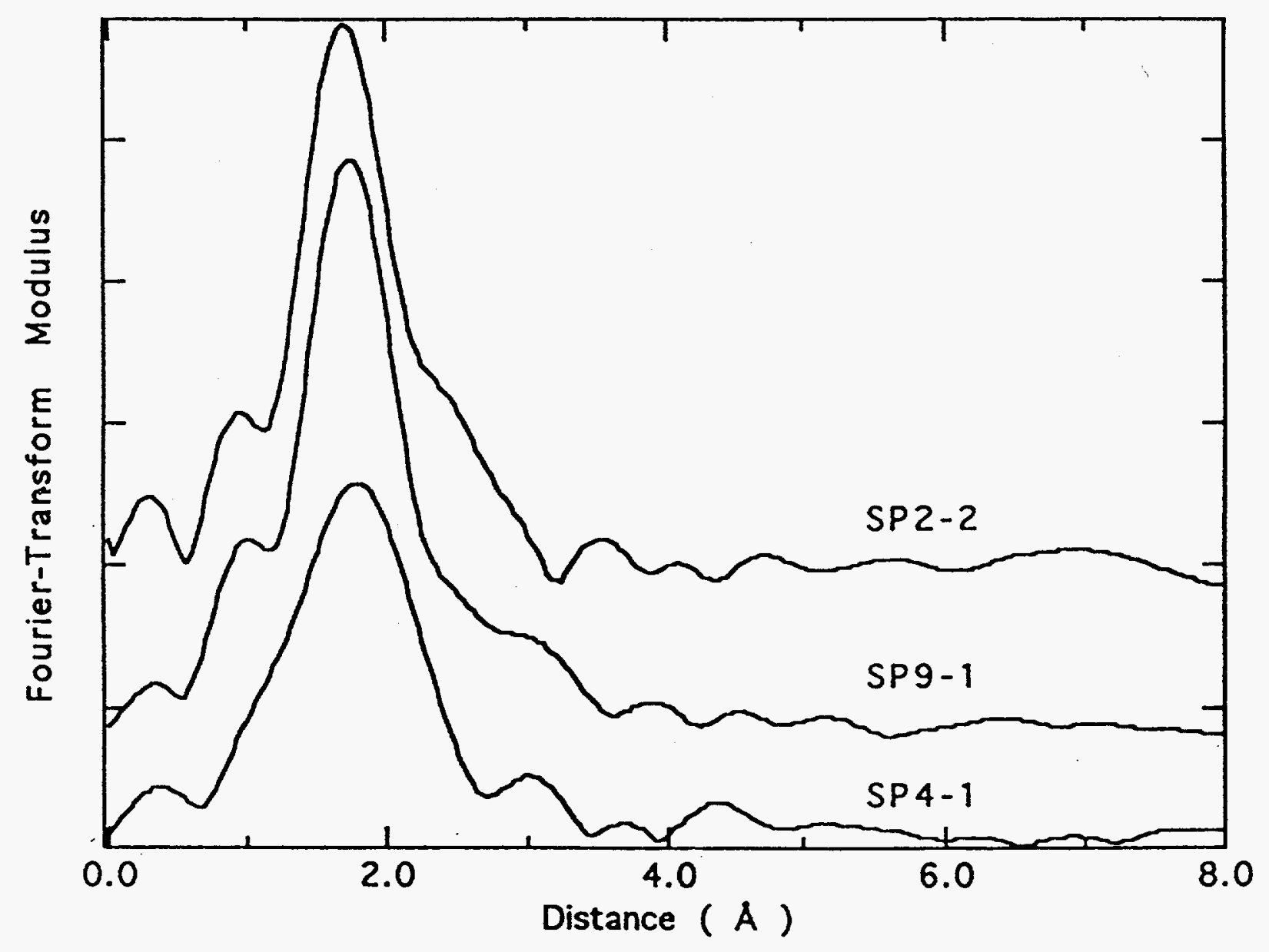

Figure 5.4. Fourier-Transform representations of the extended $x-$ ray absorption fine structure spectra of uranyl contaminated the FEMP soils from three different sites. Plant $2 / 3$ Area (SP2-3). Incinerator Plant Area (SP9-1). Plant 1 / Storage Pad Area (SP41). The contribution from the axial oxygen atoms has been filtered out of these spectra to facilitate comparison of the equatorial features. 


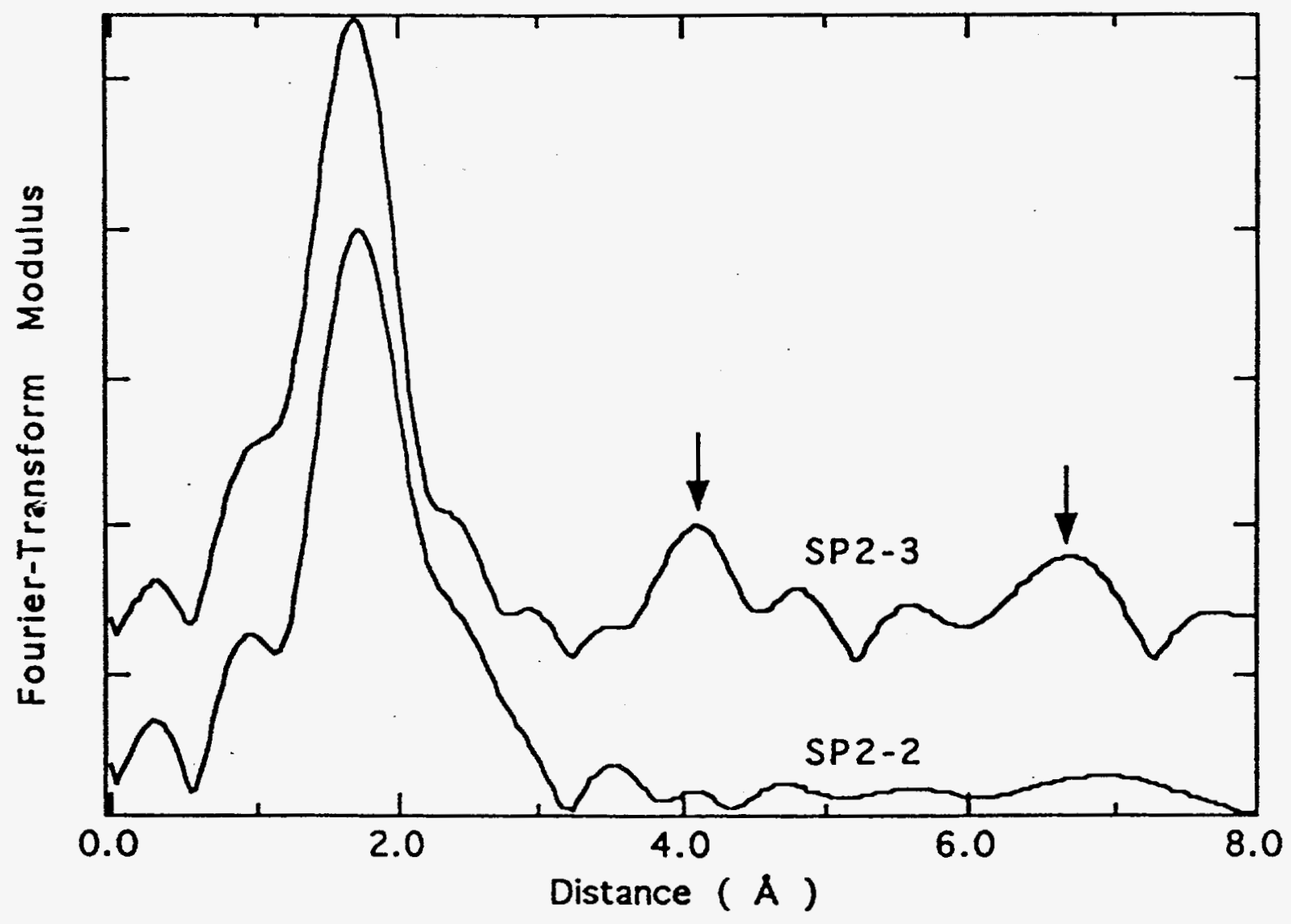

Figure 5.5 Fourier-Transform representations of the extended $x-$ ray absorption fine structure spectra of uranyl contaminated the FEMP soils from two different horizons within the Plant $2 / 3$ Area. SP2-2 is the $10-20$ inch horizon. SP2-3 is the $20-31$ inch horizon. The contribution from the axial oxygen atoms has been filtered out of these spectra to facilitate comparison of the equatorial features. The new features (marked by arrows) in the spectrum of SP2-3 arise from scattering off atoms more distant than the equatorial coordination shell. 
Another important observation from the EXAFS analysis can be seen in the comparison of the spectra of Samples SP2-2 and SP2-3 (Fig. 5.5). For Sample SP2-3, several additional features (indicated by the arrows) are seen at longer distances ( 4 and 7 angstroms) than the uranium-equatorial oxygen feature. These new features are most probably due to scattering off atoms at farther distances than the equatorial oxygens. Their obvious presence in this spectrum suggests that the uranyl species in this sample has longer-range order than those in the other samples. A possible origin for the higher order would be a more crystalline environment for the uranyl species. In fact, as discussed below, the optical luminescence for sample SP2-3 also suggests that the uranyl species are in a more highly crystalline environment.

The $x$-ray absorption data for the Treatability samples has only recently been acquired and is still undergoing analysis. However, for both samples the position of the absorption edge (c.f., Figs 5.1 and 5.2) is entirely consistent with a dominance of hexavalent uranyl species. Additional details will be provided in a forthcoming manuscript.

\section{Iuminescence spectroscopy Data}

The initial luminescence determination for the samples identified in Table 5.1 was a simple visual screening using broadband ultraviolet light from a Mineralight UVS-54 lamp (Ultraviolet Products, Inc.). The samples were dispersed over an area of $-50 \mathrm{~cm}^{2}$ and the test was conducted while examining them under $\times 20$ magnification on a spencer binocular microscope. Samples SP2-2, SP2-3, and SP5-1 all appeared to yield the greenyellow tint characteristic of uranium as a $\mathrm{UO}_{2}{ }^{2}+$ (uranyl) moiety. Note that some of the luminescence was clearly identified with small aggregates. We have confirmed this for sample SP2-2 by obtaining a photomicrograph under visible versus ultraviolet illumination. The ultraviolet photograph clearly shows localized regions of green luminescence that correlates with

microcrystalline encrustations in the visible photograph. This is consistent with previous conclusions by Lee et al. (1992) that much of the uranium exists as particulate matter. However, sample SP2-3-ABC did appear to have a dispersed luminescence that may be due to $\mathrm{UO}_{2}{ }^{2+}$ associated with the clay fraction. The absence of detectable luminescence by this simple screening method does not preclude the existence of $\mathrm{UO}_{2}{ }^{27}$ moieties in the sample.

Optical luminescence spectroscopy data have been obtained for all samples listed in Table 5.1 and for the Treatability Samples from the Incinerator Area and the Plant 1 / storage Pad Area. Typical uncorrected spectra are shown in Figure 5.6 for Samples SP2-3 and SP4-1. All samples show the broad, unstructured emission band with a maximum at $-22,500 \mathrm{~cm}^{-1}$. While we do not know the specific source of this emission, it is probable that it derives either from natural organic materials or 


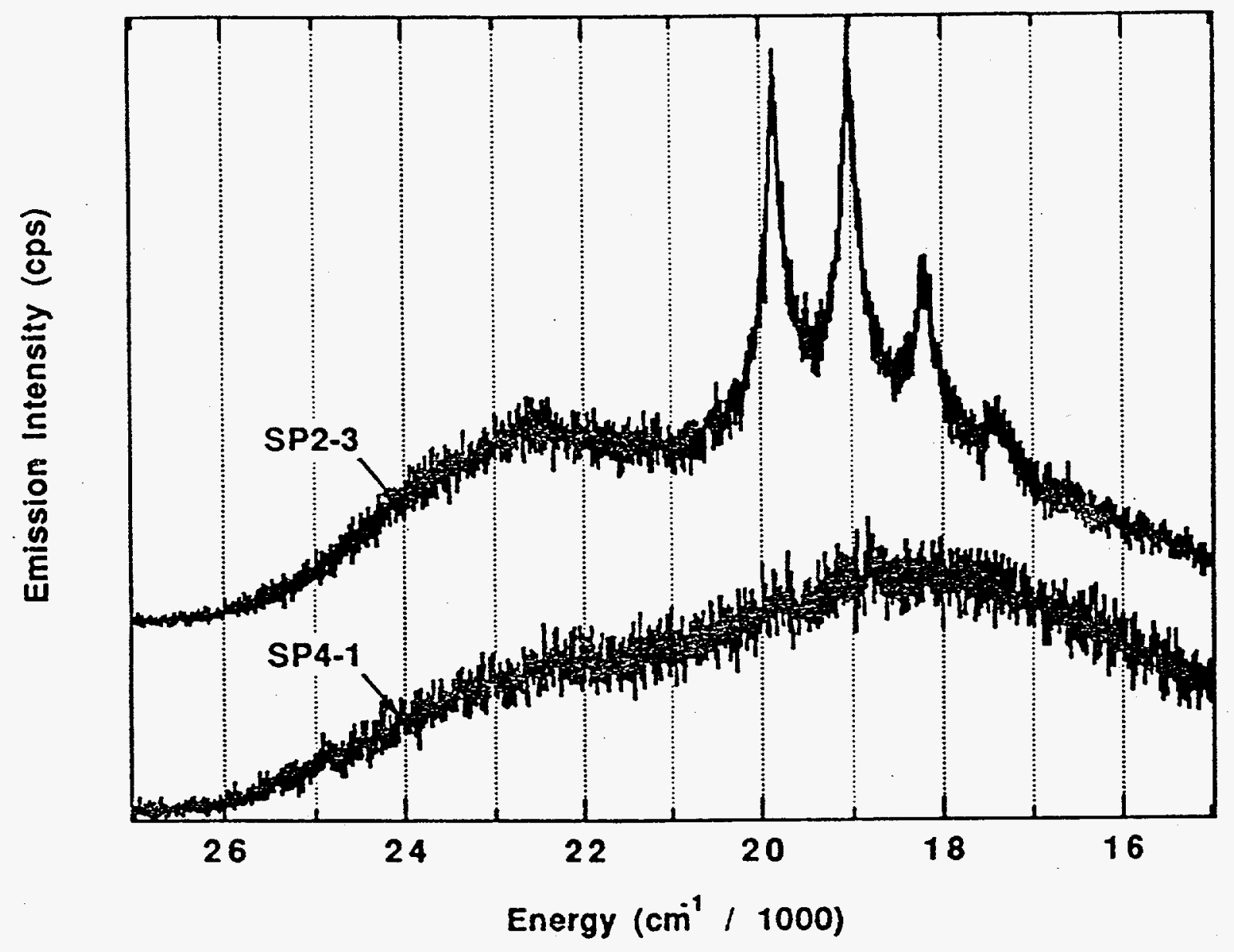

Figure 5.6. Emission spectra obtained from bulk samples of the FEMP soils obtained from the Plant $2 / 3$ Area (SP2-3) and the Plant 1 / Storage Pad Area (SP4-1). Spectra were obtained at ambient temperature using defocused ( $2 \mathrm{~mm}$ beam waist) $364 \mathrm{~nm}$ excitation from a continuous-wave Art laser. The structured emission centered about $19,000 \mathrm{~cm}^{-1}$ in SP2-3 is characteristic of uranyl luminescence. The broad, unstructured band centered about $22,500 \mathrm{~cm}^{-1}$ is intrinsic to the FEMP soils. 
natural iron-bearing minerals in the soils. Only sample SP8-1 (Plant 6 Area) appears to be devoid of luminescence from a uranyl moiety. However, the absence of a characteristic emission from a uranium-bearing sample is not positive evidence for the absence of uranyl moieties, as many naturally-occurring agents (organics and heavy metals) are capable of quenching the uranyl emission effectively. Sample SP4-1 is unique in that it shows an additional broad, unstructured emission centered at $-18,000 \mathrm{~cm}^{-1}$ (Fig. 5.6). Samples SP2-2, SP2-3, SP5-1, and SP9-1 and the Treatability Sample from the Incinerator Area contain one or more regions within the samples that show the characteristic structured yellow-green emission spectra typical of uranyl species (Fig. 5.6, top).

This highly structured emission spectrum, even at room temperature, is one of the unique aspects of the spectroscopic behavior of the uranyl moiety. This structure provides a wealth of information that can be used to help deduce speciation and, in many cases, serves as a fingerprint for the uranyl species. The speciation diagnostics that can be extracted from these structured emission spectra are illustrated in the simulated spectrum shown in Figure 5.7. Note that four distinct, independent parameters can be readily extracted from these spectra, and each will be influenced to some degree by the speciation and changes therein of the uranyl moiety. (see, for example, Figs. 5.12 and 5.13.)

Structured uranyl emission spectra have been obtained from many seemingly different domains within the bulk portions of the two samples from the Plant $2 / 3$ Area (SP2-2 and SP2-3). For example, most emission appears to come from particulates or from microcrystals coating the edges of the larger sand particles, but some emission also appears to originate from a more dispersed source. However, the spectra from these domains seem to be the same within either bulk sample. In contrast to this similarity within bulk samples, there is a marked difference in the spectra for the samples from the two different horizons at the Plant $2 / 3$ Area as shown in Figure 5.8. Note that the spectrum for the SP23 sample has much more well-resolved vibronic bands than that of SP2-2, and the positions of these bands are different in the two spectra. An increase in the resolution of vibronic bands may be attributable to an increase in the degree of crystallinity of the sample. This interpretation is consistent with the appearance of the more distant EXAFs features in the $x-r a y$ absorption spectrum of this sample (vide supra). In fact, we have found such highly resolved uranyl emission spectra only for well-crystallized uranyl minerals and salts, some of which are illustrated below.

Another pronounced difference in the structured spectra occurs on going from the uranyl associated with the sand / gravel fraction to that associated with the clay / silt fraction. (These size fraction distinctions are only qualitative, as no rigorous effort to fractionate the soils was made. Furthermore, the sand / gravel fraction may include aggregates containing 


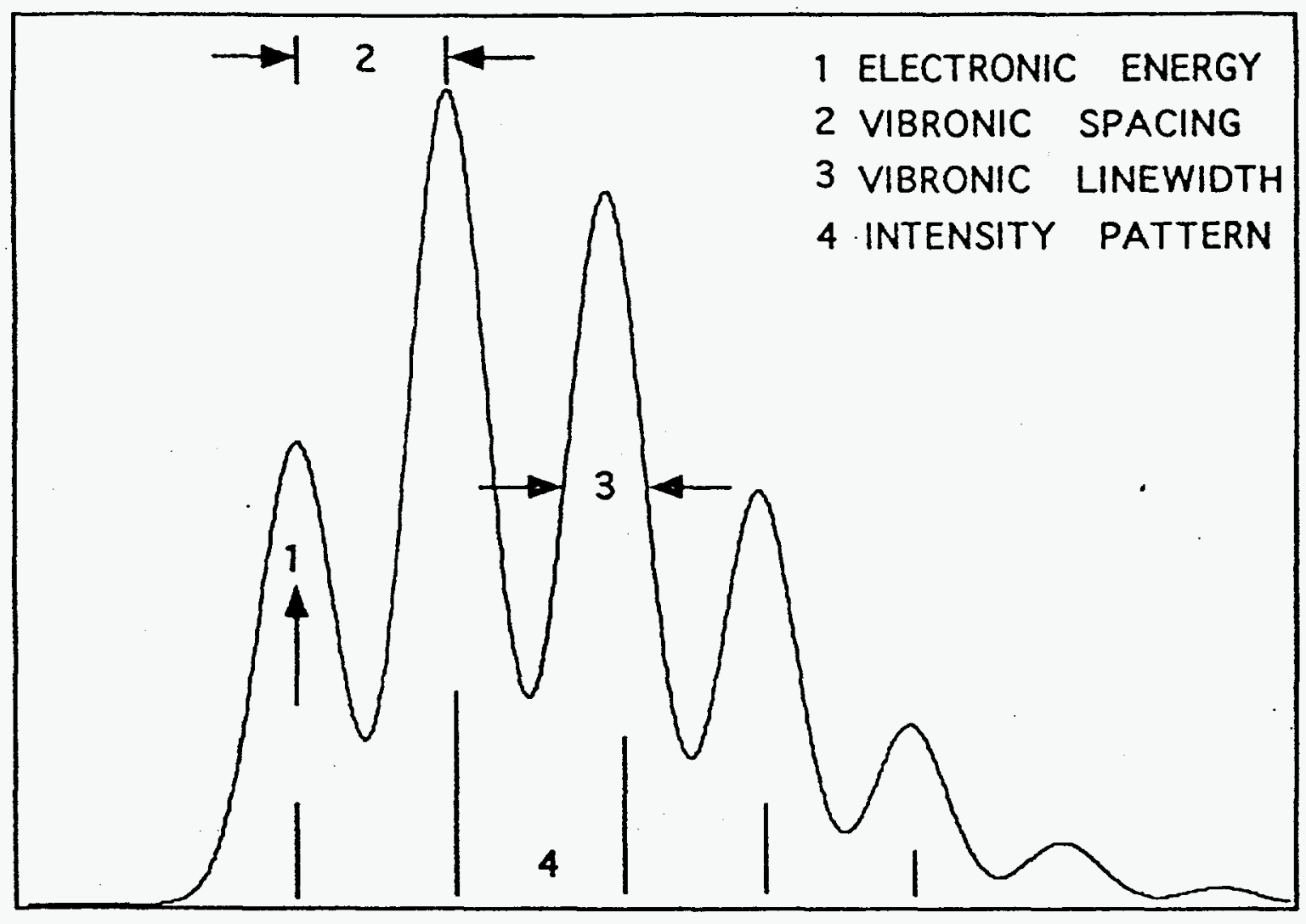

Figure 5.7. Model of a vibronically structured emission spectrum illustrating the four main features that can be used as diagnostics in characterizing uranyl speciation. 


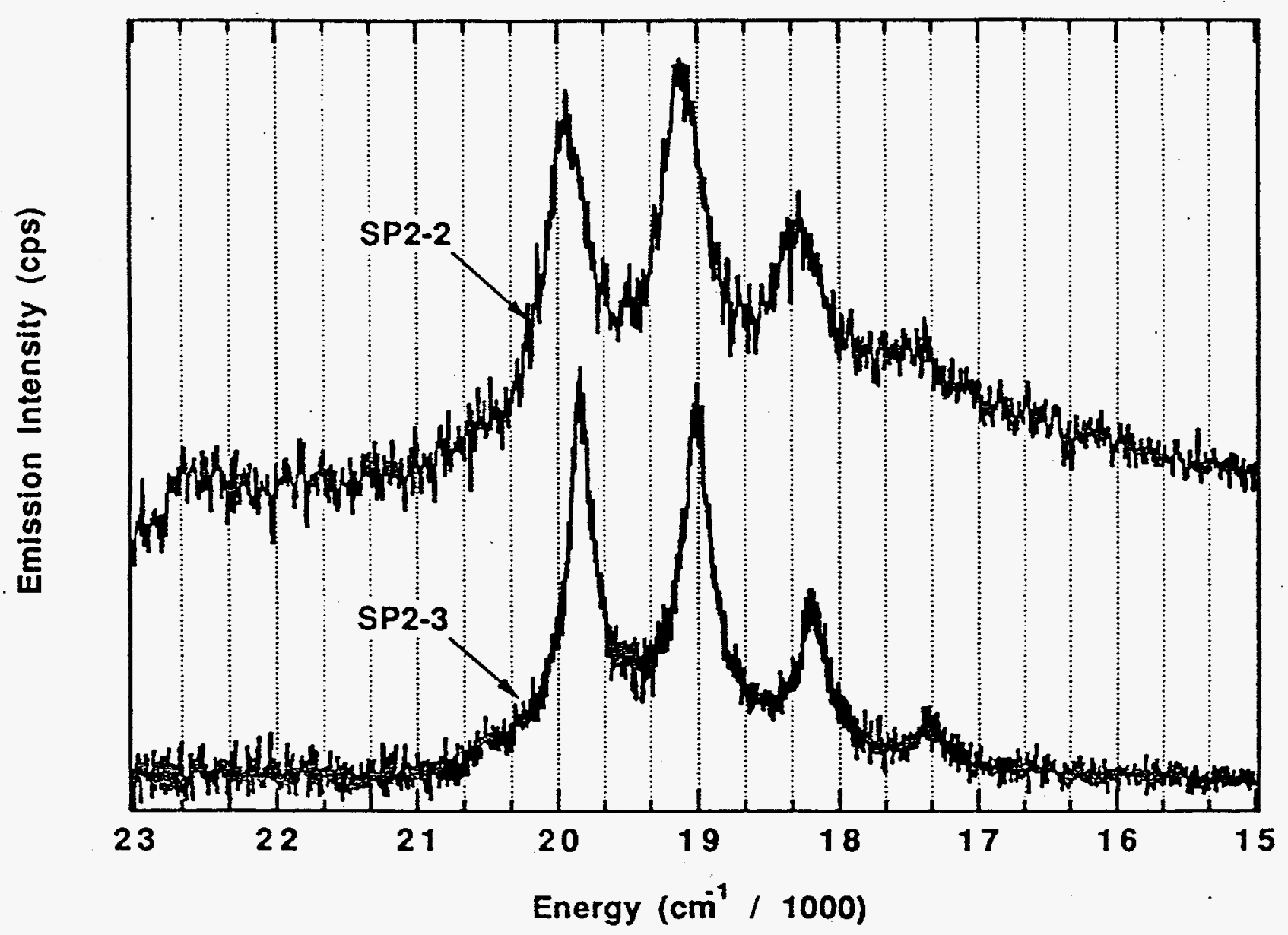

Figure 5.8. Background-corrected emission spectra of uranyl contaminated the FEMP soils from two different horizons within the Plant $2 / 3$ Area. SP2-2 is the $10-20$ inch horizon. SP2-3 is the $20-31$ inch horizon. Spectra were obtained at ambient temperature using defocused ( $2 \mathrm{~mm}$ beam waist) $364 \mathrm{~nm}$ excitation from a continuous-wave Ar+ laser. In both cases the emission was clearly emanating from a particulate source in the sample. 
clay-sized particles.) This is true for both the SP2-3 sample Figure 5.9) and the SP9-1 sample (Figure 5.10), although the nature of the difference is not the same for both samples. For example, in SP2-3 the spectrum from the clay / silt fraction appears to have broader vibronic bands than that from the sand / gravel fraction and is possibly composed of two different spectra from distinct uranyl species. For SP9-1 the spectrum from the clay / silt fraction has narrower vibronic bands than that from the sand / gravel fraction and appears to be composed of only a single spectrum. Other samples have not been investigated for this effect yet.

The emission data that have been obtained from the Incinerator Area Treatability Sample are shown in Figure 5.11 . For comparison, the spectrum obtained from the sand / gravel fraction of SP9-1 (i.e., from the same site) is included in Fig. 5.11. Note that there is a significant diminution in the intensity of the structured emission on going from the (as received) wet sample to an air-dried sample. In addition, there seems to be a shift in the band positions in these two spectra that would suggest a change in speciation associated with drying, rather than a simple loss of intensity. The nature of the apparent change in speciation for the Treatability sample on drying is unknown. It is unlikely that the change is associated with a redox transformation for uranium, because aerobic conditions were maintained in the drying process. It is also possible that the drying process per se is not responsible for the observed differences. Overall, the spectrum of the wet sample looks quite similar to that obtained from the SP9-1 fraction, but with a greater component of broadband background emission.

\section{Fingerprinting of the Uranyl Luminescence spectra}

Because the uranyl emission spectra in many cases are quite distinct, it should be possible to use these data as fingerprints for the uranyl species in the soil samples. This will be particularly true if some information concerning the contaminant source term, the groundwater composition, and the soil mineralogy is available, because deductions concerning possible species can be made while other species can be eliminated from consideration. An example of the procedure is presented in Figures 5.12 and 5.13 for the highly structured spectrum obtained from the sand / gravel fraction of Sample SP2-3. In Fig. 5.12 (top) the spectrum of the uranyl hydroxide mineral schoepite is shown. It might be expected that any time an aqueous uranyl solution encounters a basic soil (such as exists in the vicinity of the plant $2 / 3$ area) the uranyl will promptly hydrolyze to insoluble hydroxide precipitates. However, schoepite and all other uranyl hydroxide precipitates that we have examined show a weak, broad, and essentially structureless emission comparable to that of schoepite. Thus, the species giving rise to the SP2-3 spectrum cannot be a simple uranyl hydroxide. Note, however, that the additional emission feature observed from SP4-1 (Fig. 5.6, 


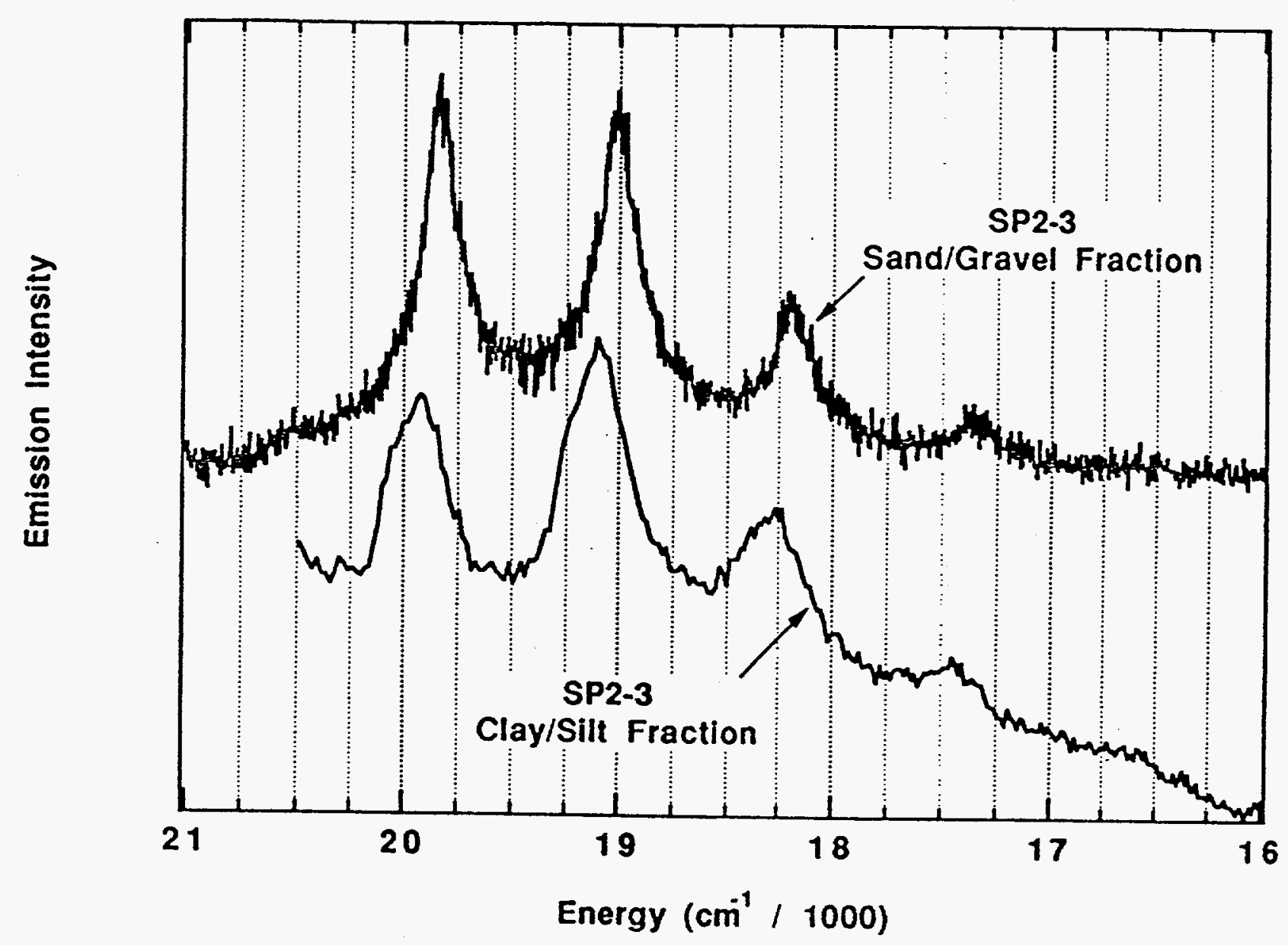

Figure 5.9. Comparison of the uranyl luminescence spectra versus size fraction for the FEMP sample SP2-3 (Plant $2 / 3$ Area, 20 31 inch horizon). The upper spectrum was obtained at ambient temperature using defocused ( $\sim 2 \mathrm{~mm}$ beam waist) $364 \mathrm{~nm}$ excitation from a continuous-wave Art laser. The lower spectrum was obtained using $425 \mathrm{~nm}$ excitation from a xenon arc lamp with the sample cooled to $\sim 10 \mathrm{~K}$. 


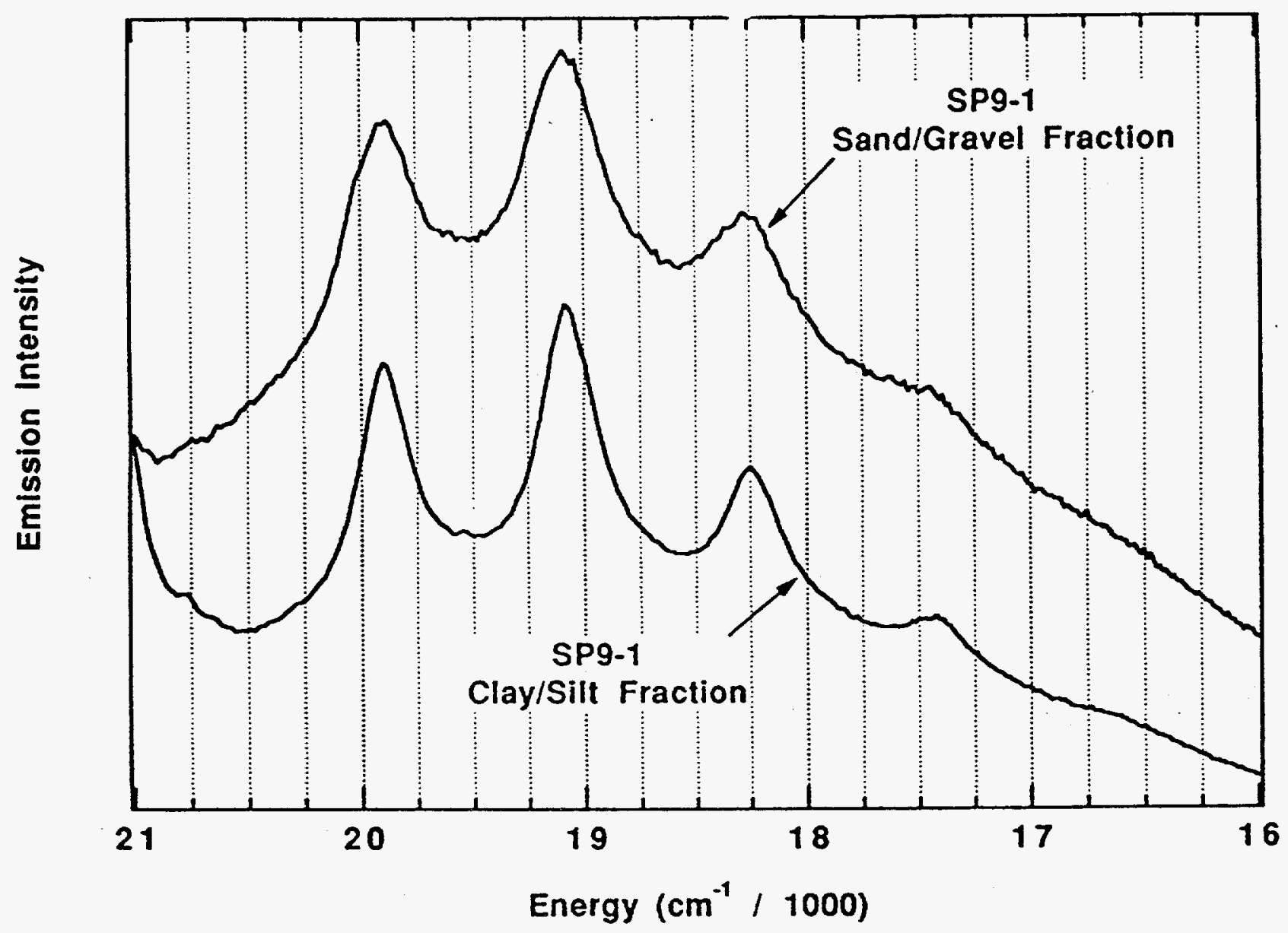

Figure 5.10. Comparison of the uranyl luminescence spectra versus size fraction for the FEMP sample sP9-1 (Incinerator Area). Both spectra were obtained at ambient temperature using $422 \mathrm{~nm}$ excitation from a xenon arc lamp. 


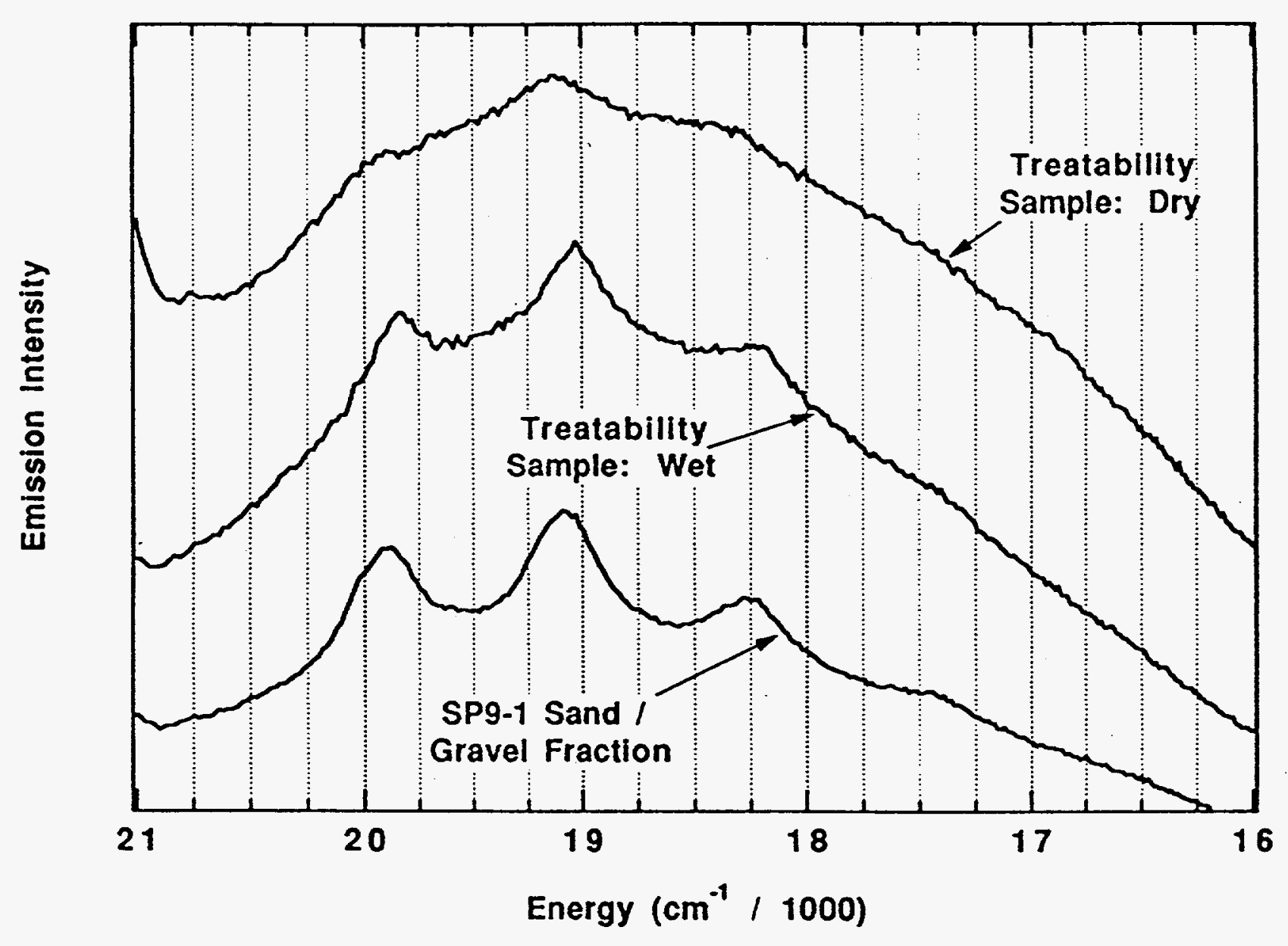

Figure 5.11. Comparison of the uranyl luminescence spectra obtained for the Treatability samples from the Incinerator Area (wet as received and following air drying) with the spectrum of Incinerator Area core sample SP9-1. All spectra were obtained at ambient temperature using $422 \mathrm{~nm}$ excitation from a xenon arc lamp. 


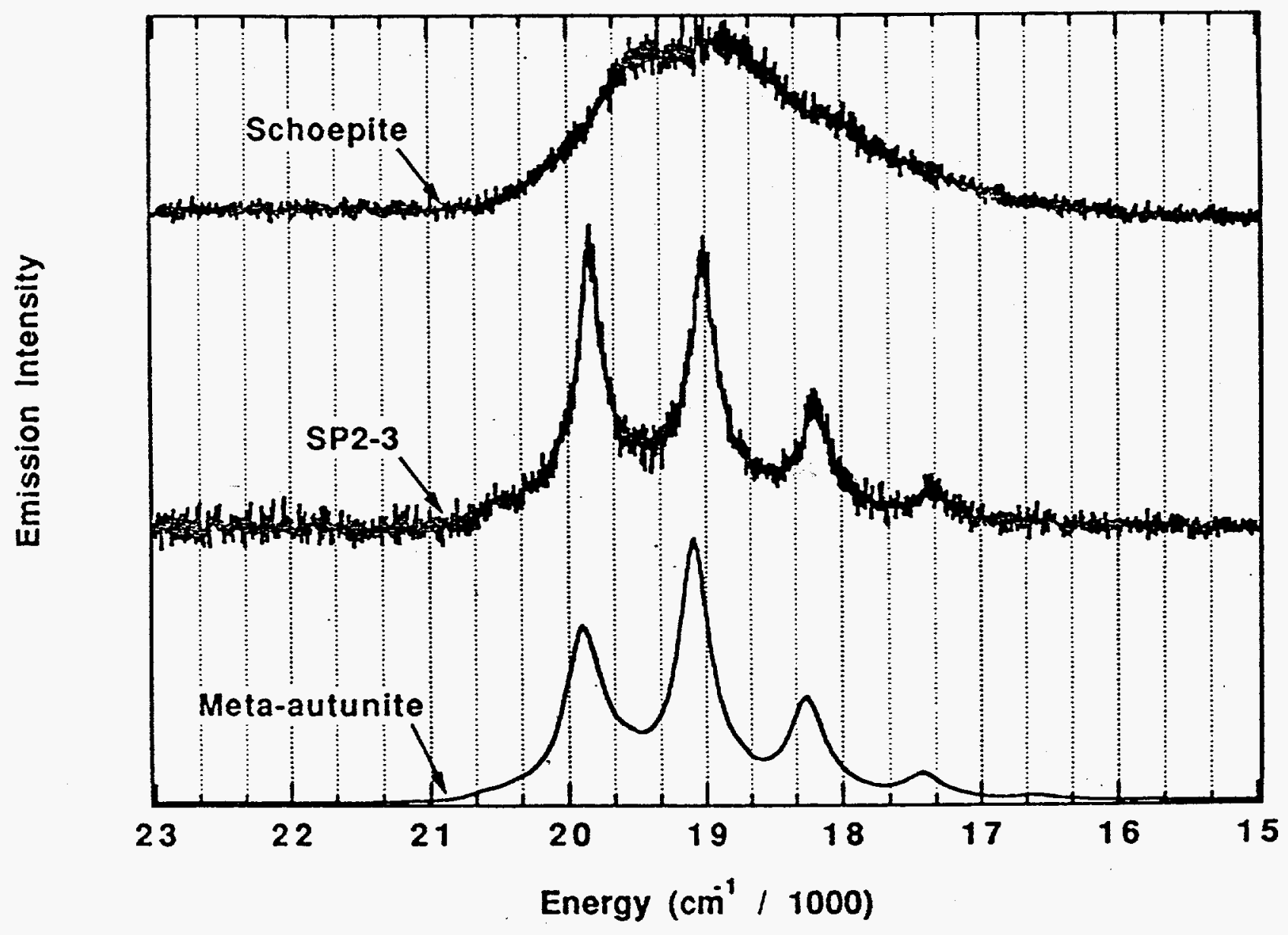

Figure 5.12. Fingerprinting comparison of the luminescence spectra of Schoepite (a uranyl hydroxide mineral) and Metaautunite (a uranyl phosphate mineral) with the spectrum of the FEMP Plant $2 / 3$ Area sample SP2-3. All spectra were obtained at ambient temperature with $364 \mathrm{~nm}$ excitation from a continuous-wave Art laser. 


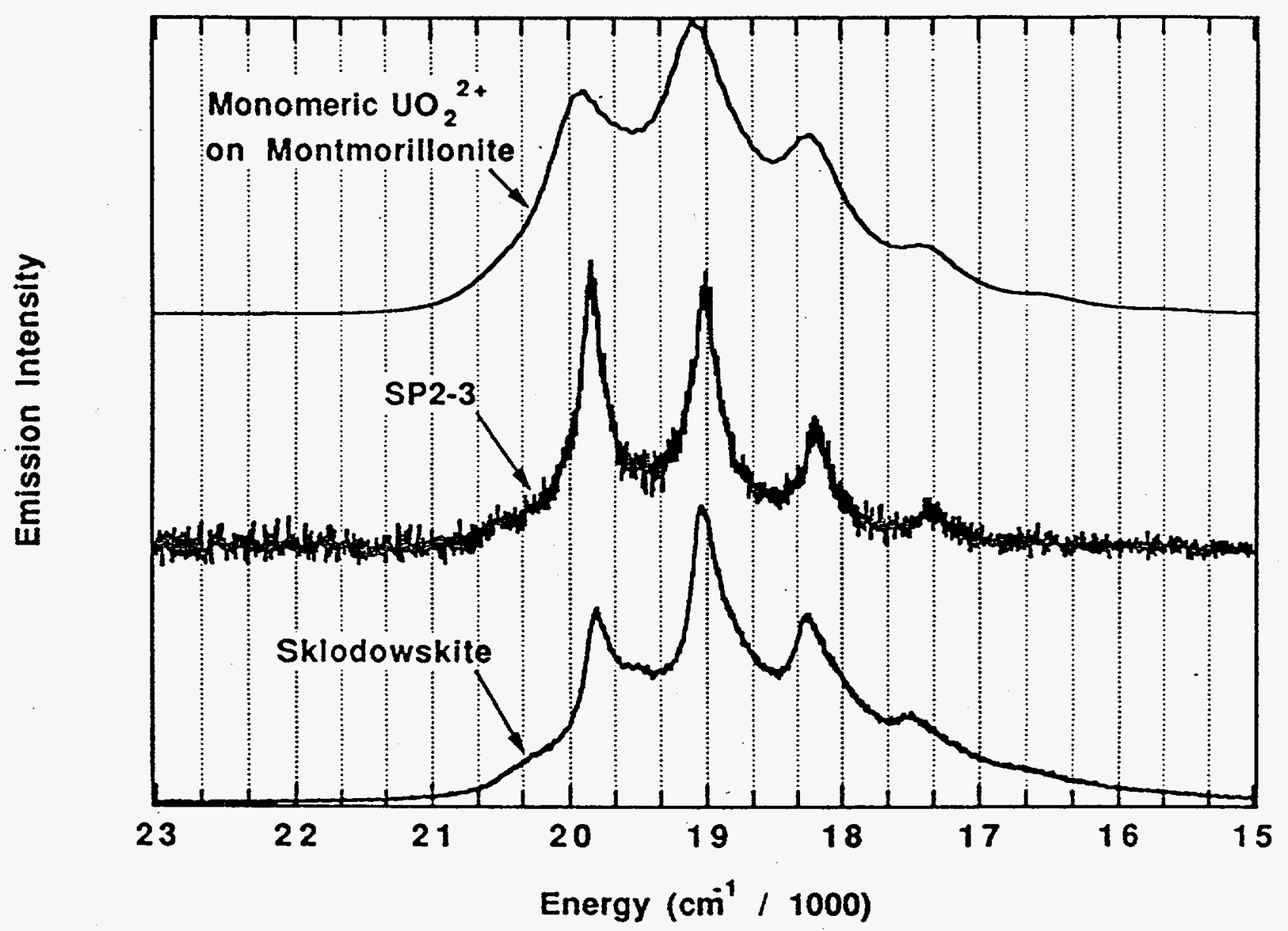

Figure 5.13. Fingerprinting comparison of the luminescence spectra of uranyl-laden Montmorillonite (a 2:1 layered silicate clay mineral) and sklodowskite (a uranyl silicate mineral containing a uranyl impurity) with the spectrum of the FEMP Plant 2 / 3 Area sample SP2-3. All spectra were obtained at ambient temperature with $364 \mathrm{~nm}$ excitation from a continuous-wave Art laser. 
bottom) does have this broad, structureless appearance common to uranyl hydroxides.

It might also be expected that the soils in the vicinity of Plant 2 / 3 would have elevated levels of phosphates $\left(\mathrm{PO}_{4}{ }^{-}\right.$) as a result of hydrolysis of tributylphosphate from the PUREX process. Many stable uranyl phosphate minerals exist, but they all seem to have the same emission spectral signature as that shown in Fig. 5.12 for meta-autunite $\left[\mathrm{Ca}\left(\mathrm{UO}_{2}\right)^{2}\left(\mathrm{PO}_{4}\right) \cdot 2 \mathrm{nH}_{2} \mathrm{O}\right]$. (This is not surprising, since they are all isostructural.) Note that, compared to the spectrum of Sample SP2-3, the spectrum for the phosphate mineral has all peaks shifted in energy, and the relative intensity pattern is different. Thus, it appears that the species giving rise to the SP2-3 spectrum is not a uranyl phosphate solid.

The soils in and around the the FEMP are known to contain appreciable quantities of $1: 1$ and $2: 1$ clay minerals. clay minerals have a good affinity for uranyl species, and they have been shown to take up uranyl into surface and interlayer sites by several different mechanisms. However, our previous work with uranyl / clay systems suggests that the emission spectra are usually only poorly resolved as shown in Fig. 5.13 (top) for a calcium montmorillonite laden with uranyl species from an acidic, aqueous solution. The high degree of resolution seen in the spectrum of the SP2-3 sample is, therefore, inconsistent with this uranyl species being associated directly with a clay. Note however that we cannot rule out the possibility of surface precipitation of uranyl on clay particles, because our uranyl / clay work has never probed conditions under which surface precipitation is expected.

A reasonable match to the SP2-3 spectrum is provided by the uranyl silicate mineral sklodowskite $\left[\mathrm{Mg}\left(\mathrm{UO}_{2}\right) 2\left(\mathrm{SiO}_{3}\right) 2(\mathrm{OH})_{2} \cdot 5 \mathrm{H}_{2} \mathrm{O}\right]$ shown in Fig. 5.13 (bottom). This sklodowskite sample is impure and contains additional uranyl species that are responsible for the shoulders filling in the intensity between each prominent vibronic band. If one considers only these prominent vibronic bands due to sklodowskite, then the match with the SP2-3 spectrum is good with respect to the position of the bands and the degree of vibronic resolution. The relative intensity pattern appears to differ from that of the SP2-3 species, but this may be skewed as a result of the spectrum from the emissive uranyl impurity. The presence of a uranyl silicate mineral in the plant $2 / 3$ soils is reasonable because the waste stream was highly acidic, and silicates in the soil (e.g., from the clays) can dissolve readily in aqueous acidic solutions.

At this time we do not have sufficient evidence to suggest definitively that the species responsible for the emission spectrum in SP2-3 is a uranyl silicate mineral. However, we do feel confident based on the high degree of vibronic resolution that the species responsible for the structured emission is some uranyl mineral or salt other than a simple hydroxide. close 
inspection of the structured spectra, particularly from the Plant 2 / 3 Area, suggest the presence of a weak, broad, and structureless emission band underlying the highly structured spectrum. This second band may be attributable to simple uranyl hydroxide species. We can also rule out a number of uranyl minerals containing heavy metals (e.g., beta-uranophane, kasolite, and cuprosklodowskite), because we have shown that the luminescence is strongly quenched for these materials. We are now in the process of obtaining library spectra for other candidate minerals for fingerprinting purposes. Uranyl carbonates (e.g., rutherfordine, sharpite) in particular are candidate species given the overburden of limestone gravel used throughout the the FEMP.

\section{Fingerprinting Using X-ray Powder Diffraction Data}

$X$-ray powder diffraction data have been obtained on several of the bulk samples obtained from ORNL and on the Treatability Sample from the Plant $1 /$ storage Pad Area. Here, too, the samples were ground to a fine powder prior to data collection. In general, the diffraction patterns are dominated by peaks from quartz in the soils. Surprisingly, clay minerals appeared to constitute only a small fraction of the soils. Trace lines have been identified in most of the powder patterns that can be correlated with hexavalent uranium minerals. To improve the signal-to-noise ratio for diffraction from the particulate uranyl in the samples, a manual dry concentration step (see Experimental section for details) was undertaken for sample SP2-3. The concentrated sample yielded the diffraction pattern shown in $\mathrm{Fig}$. 5.14. The lines that increased in intensity relative to the patterns for the bulk samples are labeled. A constrained search of the Joint Committee on Powder Diffraction Standards database for uranium solid phases resulted in four candidate uranyl minerals that may be responsible for the observed diffraction patterns. These are schoepite (a uranyl hydroxide), compreignacite (a potassium uranyl hydroxide), becquerelite (a calcium uranyl hydroxide), and sharpite (a calcium uranyl hydroxy-carbonate). In addition, a reasonable match was found with bassetite (an iron uranyl phosphate) and metatorbernite (a copper uranyl phosphate). As indicated in Fig. 5.14, these minerals have overlapping or near-overlapping diffraction lines in many cases. Thus, absolute identification will require a combination of $x$-ray diffraction data and luminescence data. These efforts are currently underway. Based on probable source terms for the contamination, only the metatorbernite (because it is a copper-bearing mineral) seems improbable as a candidate form of uranyl in the soils.

\section{Preliminary Investigations of Treated Samples}

We have also undertaken some simple leaching experiments to determine our capabilities to track uranium speciation in the soil samples following the types of leach treatments that will be 


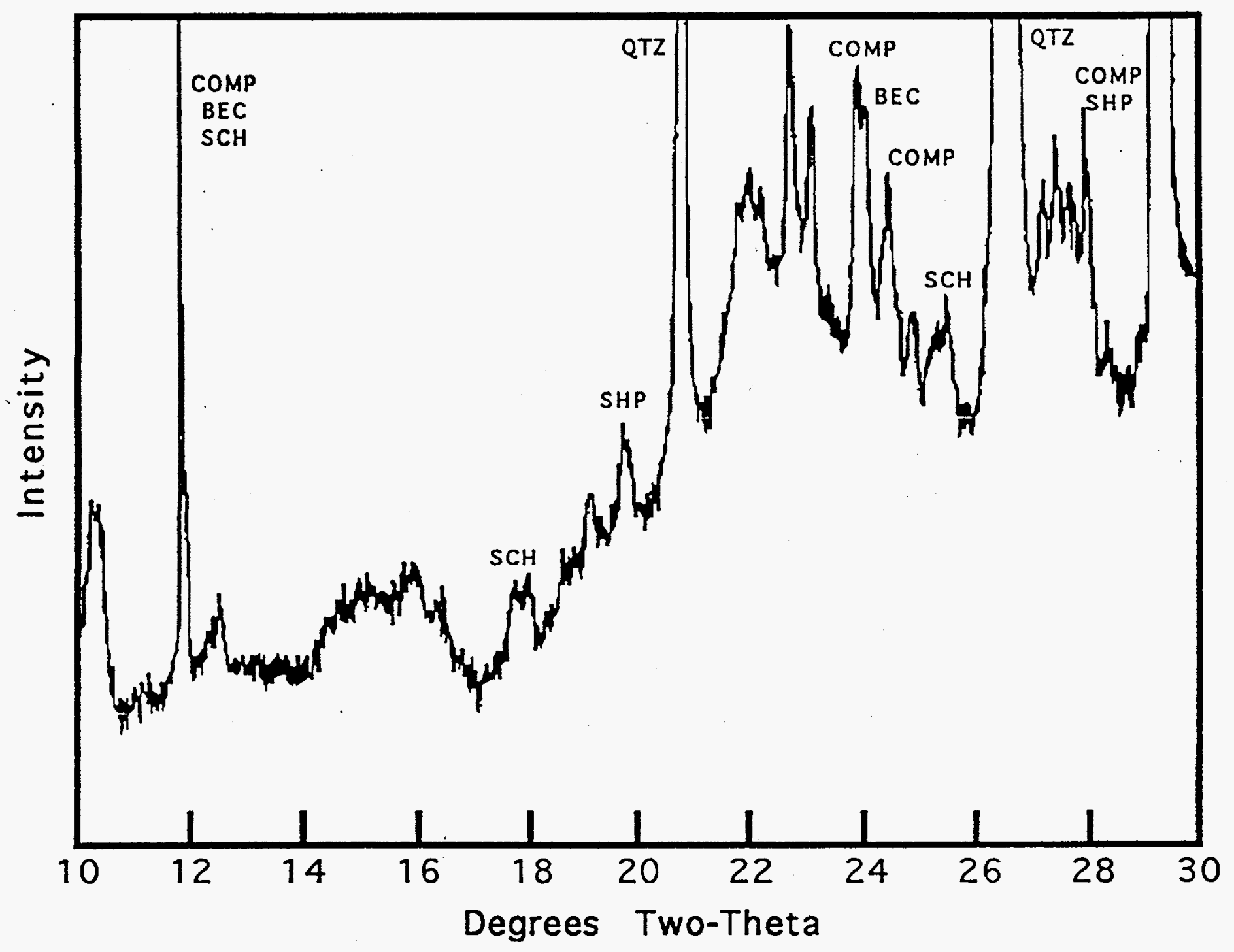

Figure 5.14. X-ray powder diffraction pattern of the FEMP sample SP2-3 following concentration of luminescent uranyl particulates. Possible assignments of the observed Iines are indicated. BEC = becquerelite. $\mathrm{COMP}=$ compreignacite. $\mathrm{QTZ}=$ quartz. $\mathrm{SCH}=$ schoepite. SHP = sharpite. 
carried out by the Decontamination Task Team. In our experiments, two samples (SP2-2 and SP9-1) were washed with dilute nitric acid solution. The washing began with $0.01 \mathrm{M}$ acid and proceeded to $0.1 \mathrm{M}$ acid solution. The final equilibrium $\mathrm{pH}$ values attained were 2.8 for $S P 2-2$ and 3.8 for SP9-1. Copious quantities of acid were consumed to reach these $\mathrm{pH}$ values suggesting that the soil samples contain large quantities of calcite or other acid-consuming minerals. No quantitative mass balance of uranium was attempted. However, assay of the resulting leachate solutions did indicate that this procedure removed significant quantities of uranium in the case of SP2-2 ( $25 \%$ based on an assumed $5000 \mathrm{ppm}$ concentration in the untreated soil sample), and relatively little in the sp9-1 sample. The treated SP2-2 sample was examined by $x$-ray absorption spectroscopy. Reasonable signal-to-noise was achieved in the spectrum, indicating that the treated soil still contained significant amounts of uranium. More notable was the fact that the spectrum still had all the characteristics of those seen for uranyl species. Unfortunately, the data quality was insufficient to draw specific conclusion regarding changes in the equatorial coordination sphere. However, the implication is that acid washing may selectively remove some, but not all, uranyl species.

\subsection{Implications with Respect to Remediation}

The single most significant finding from our speciation characterization work thus far is the prevalence of the hexavalent oxidation state in the uranium species in the contaminated soils. This is a beneficial result from the standpoint of remediation, because U(VI) species are more soluble in general than uranium species in the tetravalent oxidation state. Thus, powerful oxidizing / complexing agents and their commonly disadvantageous secondary waste streams should not be required. Instead, remediation strategies that employ relatively simple aqueous complexants should enjoy some high level of success. However, there is a possible drawback to the dominance of hexavalent uranium; namely, the existing contamination is more mobile in the soils, and the extent of contaminant migration and the timeliness with which it is remediated become important issues.

Our results also demonstrate that, even within the relatively small subset of contaminated soils we have sampled, the uranium speciation varies substantially. This is true from site to site (e.g., SP9-1 vs SP4-1), within horizons at the same site (e.g., SP2-2 vs SP2-3), and within size fractions in the same horizon at the same site (e.g., sP9-1 coarse vs fine fractions). It is reasonable to expect some variability in the solubility of these many different uranyl species, so it is prudent at this time to continue to develop and investigate several potentially useful soil washing chemistries. Further speciation investigations of the "treated" soil samples will then 
enable us to identify any intransigent forms of uranium, and propose alternate / additional remediation strategies.

Several specific results merit further comment here. The first concerns the speciation changes observed with depth for the Plant 2 / 3 Area samples. The simplest interpretation of the observed behavior is that the uranyl species is weathering as episodic influx of rain transports the uranium down into the soil. This would make sense in terms of the proposed increase in the degree of crystallinity of the uranyl species, because continual dissolution and reprecipitation can frequently have this effect. However, we cannot rule out the possibility that these two spectra (Fig. 5.8) derive from two entirely different uranyl species. This latter possibility would imply that the soil chemistry itself is changing in the horizons. In this case, it might be necessary to devise different remediation strategies for each horizon. The possible influence of changes in soil chemistry in the different horizons on uranium speciation should be a target for investigation in the Conceptual Model task of the Characterization Task Team. Finally, there is some evidence based on vibronic linewidths, particularly for portions of Samples SP9-1 and SP2-3, that the uranyl contamination is intimately (chemically) associated with the substrate, rather than present as particulates and/or surface precipitates. If this is true, this material may require more rigorous conditions for remediation, because the sorptive interactions with the metal oxides and clay minerals in these soils can be quite strong. 


\section{GEOCHEMICAL MODELLING}

\subsection{Introduction}

An integral part of site characterization is the use of environmental and other data to gain understanding of the properties of the uranium waste form and the processes that may cause migration of uranium in the subsurface. The stability of the uranium waste form and the potential for migration of uranium dissolved in subsurface water are influenced significantly by the chemical behavior of uranium aqueous solution, in minerals, and in phases adsorbed at mineral surfaces. Chemical modelling uses field and laboratory data, coupled with thermodynamic and chemical principles, to estimate the distribution of uranium among possible phases and chemical species.

\subsection{Approach}

The geochemical modelling process brings together three principal components: (1) the environmental data base, consisting of chemical analyses of water and soil samples; the thermodynamic data base, consisting of standard free energies of formation of aqueous species and solids containing chemical elements found in the chemical analyses; and (3) a computer program that uses the two data bases and an appropriate aqueous solution model to compute concentrations of aqueous chemical species and solid phases. This approach is illustrated by its application to analytical data from six wells at the FEMP site.

\section{Data from FEMP site Wells}

Chemical analyses from six well waters were used for geochemical modelling. These wells were chosen because they are among the seven wells whose waters showed the highest reported values of dissolved uranium. (The seventh well water was not analyzed completely, and could not be used for modelling.) Elemental concentrations, $\mathrm{pH}$, and sampling data for each well are shown in Table 6.1. Three wells $(1019,1021$, and 1022) are located in the Waste storage Area at the FEMP, one well (1085) is located in the northeast quadrant of the Production Area near the Decontamination Pad, and two wells (1113 and 1173) are located in the southeast quadrant of the Production Area near the Garage and Engine House. 
Table 6.1. Chemical Analyses of Waters from Six FEMP Wells (concentrations in mole/ $\mathrm{dm}^{3}$ )

\begin{tabular}{|l|c|c|c|c|c|c|}
\hline Well No. & 1019 & 1021 & 1022 & 1085 & 1113 & 1173 \\
\hline $\mathrm{Na}$ & $4.0 \times 10^{-3}$ & $1.1 \times 10^{-3}$ & $9.0 \times 10^{-4}$ & $1.6 \times 10^{-3}$ & $3.0 \times 10^{-3}$ & $4.4 \times 10^{-3}$ \\
\hline $\mathrm{Ca}$ & $2.7 \times 10^{-3}$ & $3.0 \times 10^{-3}$ & $3.4 \times 10^{-3}$ & $2.3 \times 10^{-3}$ & $3.0 \times 10^{-3}$ & $6.5 \times 10^{-3}$ \\
\hline $\mathrm{Mg}$ & $2.0 \times 10^{-3}$ & $1.5 \times 10^{-3}$ & $2.8 \times 10^{-3}$ & $2.1 \times 10^{-3}$ & $2.2 \times 10^{-3}$ & $3.1 \times 10^{-3}$ \\
\hline $\mathrm{Cl}$ & $1.8 \times 10^{-3}$ & $3.4 \times 10^{-4}$ & $8.5 \times 10^{-5}$ & $3.9 \times 10^{-4}$ & $1.9 \times 10^{-3}$ & $2.5 \times 10^{-3}$ \\
\hline total $\mathrm{CO}_{3}$ & $4.3 \times 10^{-3}$ & $4.9 \times 10^{-3}$ & $4.4 \times 10^{-3}$ & $3.8 \times 10^{-3}$ & $3.5 \times 10^{-3}$ & $5.3 \times 10^{-3}$ \\
\hline total $\mathrm{PO}_{4}$ & $3.2 \times 10^{-6}$ & $1.0 \times 10^{-4}$ & $4.5 \times 10^{-6}$ & $3.6 \times 10^{-6}$ & $1.9 \times 10^{-5}$ & $7.7 \times 10^{-5}$ \\
\hline total $\mathrm{SO}_{4}$ & $5.2 \times 10^{-3}$ & $6.6 \times 10^{-4}$ & $5.9 \times 10^{-5}$ & $2.9 \times 10^{-3}$ & $7.5 \times 10^{-4}$ & $2.2 \times 10^{-3}$ \\
\hline total U & $4.4 \times 10^{-6}$ & $1.2 \times 10^{-5}$ & $5.2 \times 10^{-5}$ & $1.8 \times 10^{-5}$ & $7.0 \times 10^{-6}$ & $4.1 \times 10^{-6}$ \\
\hline $\mathrm{pH}$ & 6.8 & 6.6 & 6.9 & 7.5 & 7.2 & 7.0 \\
\hline date & $3 / 23 / 90$ & $3 / 23 / 90$ & $3 / 23 / 90$ & $6 / 15 / 90$ & $6 / 25 / 90$ & $6 / 25 / 90$ \\
\hline
\end{tabular}

\section{Thermodynamic Data Base}

The thermodynamic data base used in this work is the "EQ3/6" data base maintained by the U. S. Department of Energy's Yucca Mountain Site Characterization Project. The data base was supplied as electronic data file DATAOCOM.R14 by Dr. James Johnson, EQ3/6 Data Base Administrator, Lawrence Livermore National Laboratory.

\section{Computer Program}

The computations were performed by the computer program STATEQ, developed by C. L. Carnahan, Lawrence Berkeley Laboratory. STATEQ assumes that all chemical reactions are at equilibrium. Activity coefficients are estimated by an extended form of the Debye-Huckel equation. The STATEQ program calculates equilibrium concentrations of aqueous species and activity products of species formed by dissolution of hypothetical minerals. The computed ion activity product (IAP) for a mineral is compared to the theoretical solubility product $\left(\mathrm{K}_{\mathrm{sp}}\right)$ for the same mineral by computing the "saturation index" (SI) from:

$$
S I=\log \left(I A P / K_{S p}\right)
$$

If $\mathrm{SI}>0$, the solution is supersaturated with respect to the mineral.

It is noted that no values of dissolved silica were reported in the chemical analyses shown in Table 6.1. For 
purposes of the computations, it was assumed that dissolved silica was present in each water at the concentration in equilibrium with quartz at $25^{\circ} \mathrm{C}, 1.00 \times 10^{-4} \mathrm{~mole} / \mathrm{dm}^{3}$.

The following aqueous species and minerals were included in the computations:

$$
\begin{aligned}
& \text { aqueous species: } \mathrm{H}+, \mathrm{Na}+, \mathrm{Ca} 2+, \mathrm{Mg}^{2}+, \mathrm{Cl}^{-}, \mathrm{CO}_{3}^{2-}, \mathrm{HCO}_{3}^{-} \text {, } \\
& \mathrm{CO}_{2}(\mathrm{aq}), \mathrm{HPO}_{4}^{2-}, \mathrm{H}_{2} \mathrm{PO}, \mathrm{SO}_{4}^{2-}, \mathrm{SiO}_{2}(\mathrm{aq}), \mathrm{NaHCO}_{3}^{0}, \mathrm{NaHPO}_{4}^{-} \text {, } \\
& \mathrm{CaHCO}_{3}^{+}, \mathrm{CaOH}^{+}, \mathrm{CaH}_{2} \mathrm{PO}_{4}^{+}, \mathrm{MgHCO}_{3}^{+}, \mathrm{MgH}_{2} \mathrm{PO}_{4}^{+}, \mathrm{UO}_{2}^{2+}, \mathrm{UO}_{2} \mathrm{CO}_{3}^{0} \text {, } \\
& \left.\mathrm{UO}_{2}(\mathrm{CO})_{3}\right)_{2}^{2-}, \mathrm{UO}_{2}\left(\mathrm{CO}_{3}\right)_{3}^{4-}, \mathrm{UO}_{2} \mathrm{Cl}^{+}, \mathrm{UO}_{2} \mathrm{OH}^{+}, \mathrm{UO}_{2} \mathrm{HPO}_{4}^{0}, \mathrm{UO}_{2} \mathrm{H}_{2} \mathrm{PO}_{4}^{+} \text {, } \\
& \mathrm{UO}_{2}\left(\mathrm{H}_{2} \mathrm{PO}_{4}\right)_{2}^{0}, \mathrm{UO}_{2} \mathrm{SO}_{4}^{0},\left(\mathrm{UO}_{2}\right)_{2} \mathrm{CO}_{3}(\mathrm{OH})_{3}^{-} \text {; } \\
& \text { minerals: } \mathrm{UO}_{2} \mathrm{CO}_{3}, \mathrm{UO}_{3}(\alpha), \mathrm{UO}_{2}(\mathrm{OH})_{2} \cdot \mathrm{H}_{2} \mathrm{O}, \mathrm{UO}_{2} \mathrm{SO}_{4} \cdot \mathrm{H}_{2} \mathrm{O}, \mathrm{CaUO}_{4} \text {, } \\
& \left.\mathrm{MgUO}_{4}, \mathrm{UO}_{2} \mathrm{HPO}_{4}, \mathrm{UO}_{2} \mathrm{HPO}_{4} \cdot 4 \mathrm{H}_{2} \mathrm{O},\left(\mathrm{UO}_{2}\right)_{3}\left(\mathrm{PO}_{4}\right)_{2} \cdot 4 \mathrm{H}_{2} \mathrm{O}\right) \text {, } \\
& \left(\mathrm{UO}_{2}\right)_{2} \mathrm{H}_{2}\left(\mathrm{PO}_{4}\right)_{2},\left(\mathrm{UO}_{2}\right)_{2}-\mathrm{Mg}\left(\mathrm{PO}_{4}\right)_{2},\left(\mathrm{UO}_{2}\right)_{2} \mathrm{SiO}_{4} \cdot 2 \mathrm{H}_{2} \mathrm{O} \text {, } \\
& \mathrm{Ca}\left(\mathrm{UO}_{2}\right)_{2} \mathrm{Si}_{2} \mathrm{O}_{6}(\mathrm{OH})_{2}, \mathrm{Ca}\left(\mathrm{UO}_{2}\right)_{2} \mathrm{Si}_{6} \mathrm{O}_{15} \cdot 5 \mathrm{H}_{2} \mathrm{O} \text {. }
\end{aligned}
$$

\subsection{Results And Discussion}

The computed concentrations of aqueous species of uranium in the six waters are shown in Table 6.2. For each water, these concentrations were normalized to the reported total uranium concentration to provide fractional uranium contents of each aqueous species. The fractions derived this way for the five most abundant aqueous species are shown graphically in Figure 6.1. The results indicate that the generally most dominant aqueous species of uranium in the six waters was $\mathrm{UO}_{2}\left(\mathrm{CO}_{3}\right)_{2}^{2-}$, which constituted $48-78 \%$ of the total uranium contents. However, in the well (1085) with the highest pH $(7.5)$, the abundance of the bis-carbonato complex (48\%) was slightly exceeded by that (50\%) of the tris-carbonato complex, $\mathrm{UO}_{2}\left(\mathrm{CO}_{3}\right)_{3}^{4-}$. In the well (1021) with the highest reported total phosphate concentration, the species $\mathrm{UO}_{2} \mathrm{HPO}_{4}^{0}$ reached an abundance of $17 \%$. The highest reported total uranium concentration occurred in well 1022, and in this well uranium contained in the binuclear species $\left(\mathrm{UO}_{2}\right)_{2} \mathrm{CO}_{3}(\mathrm{OH})_{3}^{-}$reached its highest abundance, $10 \%$. It is noteworthy that the most abundant species of uranium in the six waters are predicted to be negatively charged complexes; these species could be expected to be highly mobile due to their very low propensity to participate in ion exchange and surface complexation reactions at mineral surfaces. 
Table 6.2. Computed Concentrations (mole/ $\mathrm{dm}^{3}$ ) of Uranium Aqueous Species

\begin{tabular}{|l|c|c|c|}
\hline Well No. & 1019 & 1021 & 1022 \\
\hline $\mathrm{UO}_{2}^{2+}$ & $5.6 \times 10^{-11}$ & $2.4 \times 10^{-10}$ & $4.2 \times 10^{-10}$ \\
\hline $\mathrm{UO}_{2} \mathrm{CO}_{3}^{0}$ & $1.0 \times 10^{-7}$ & $3.7 \times 10^{-7}$ & $8.7 \times 10^{-7}$ \\
\hline $\mathrm{UO}_{2}\left(\mathrm{CO}_{3}\right)_{2}^{2-}$ & $3.4 \times 10^{-6}$ & $8.1 \times 10^{-6}$ & $3.6 \times 10^{-5}$ \\
\hline $\mathrm{UO}_{2}\left(\mathrm{CO}_{3}\right)_{3}^{4-}$ & $7.9 \times 10^{-7}$ & $8.5 \times 10^{-7}$ & $1.0 \times 10^{-5}$ \\
\hline$\left.\left(\mathrm{UO}_{2}\right)_{2} \mathrm{CO}_{3} \mathrm{OH}\right)_{3}^{-}$ & $2.7 \times 10^{-8}$ & $1.7 \times 10^{-14}$ & $2.5 \times 10^{-6}$ \\
\hline $\mathrm{UO}_{2} \mathrm{Cl}^{+}$ & $7.7 \times 10^{-14}$ & $7.2 \times 10^{-14}$ & $2.6 \times 10^{-14}$ \\
\hline $\mathrm{UO}_{2} \mathrm{OH}^{+}$ & $1.4 \times 10^{-9}$ & $4.6 \times 10^{-9}$ & $1.1 \times 10^{-8}$ \\
\hline $\mathrm{UO}_{2} \mathrm{HPO}_{4}^{0}$ & $1.6 \times 10^{-8}$ & $2.0 \times 10^{-6}$ & $1.7 \times 10^{-7}$ \\
\hline $\mathrm{UO}_{2} \mathrm{H}_{2} \mathrm{PO}_{4}^{+}$ & $1.7 \times 10^{-12}$ & $3.0 \times 10^{-10}$ & $1.6 \times 10^{-11}$ \\
\hline $\mathrm{UO}_{2}\left(\mathrm{H}_{2} \mathrm{PO}_{4}\right)_{2}^{0}$ & $3.0 \times 10^{-15}$ & $2.0 \times 10^{-11}$ & $3.6 \times 10^{-14}$ \\
\hline $\mathrm{UO}_{2} \mathrm{SO}_{4}$ & $9.7 \times 10^{-11}$ & $7.2 \times 10^{-11}$ & $7.9 \times 10^{-10}$ \\
\hline & & & \\
\hline $\mathrm{Well} \mathrm{No}$ & 1085 & 1113 & 1173 \\
\hline $\mathrm{UO}_{2}^{2+}+$ & $4.0 \times 10^{-12}$ & $1.3 \times 10^{-11}$ & $1.0 \times 10^{-11}$ \\
\hline $\mathrm{UO}_{2} \mathrm{CO}_{3}^{0}$ & $4.6 \times 10^{-8}$ & $6.3 \times 10^{-8}$ & $3.5 \times 10^{-8}$ \\
\hline $\mathrm{UO}_{2}\left(\mathrm{CO}_{3}\right)_{2}^{2-}$ & $8.4 \times 10^{-6}$ & $4.8 \times 10^{-6}$ & $2.5 \times 10^{-6}$ \\
\hline $\mathrm{UO}_{2}\left(\mathrm{CO}_{3}\right)_{3}^{4-}$ & $8.8 \times 10^{-6}$ & $1.9 \times 10^{-6}$ & $1.4 \times 10^{-6}$ \\
\hline$\left(\mathrm{UO}_{2}\right)_{2} \mathrm{CO}_{3}(\mathrm{OH})_{3}^{-}$ & $1.4 \times 10^{-7}$ & $7.1 \times 10^{-8}$ & $6.3 \times 10^{-9}$ \\
\hline $\mathrm{UO}_{2} \mathrm{Cl}^{+}$ & $1.3 \times 10^{-15}$ & $2.1 \times 10^{-14}$ & $1.8 \times 10^{-14}$ \\
\hline $\mathrm{UO}_{2} \mathrm{OH}^{+}$ & $5.5 \times 10^{-10}$ & $8.7 \times 10^{-10}$ & $3.7 \times 10^{-10}$ \\
\hline $\mathrm{UO}_{2} \mathrm{HPO}_{4}^{0}$ & $3.1 \times 10^{-9}$ & $4.2 \times 10^{-8}$ & $8.1 \times 10^{-8}$ \\
\hline $\mathrm{UO}_{2} \mathrm{H}_{2} \mathrm{PO}_{4}^{+}$ & $6.0 \times 10^{-14}$ & $1.7 \times 10^{-12}$ & $5.5 \times 10^{-12}$ \\
\hline $\mathrm{UO}_{2}\left(\mathrm{H}_{2} \mathrm{PO}_{4}\right)_{2}^{0}$ & $5.1 \times 10^{-17}$ & $1.3 \times 10^{-14}$ & $1.9 \times 10^{-13}$ \\
\hline $\mathrm{UO}_{2} \mathrm{SO}_{4}$ & $4.6 \times 10^{-12}$ & $4.0 \times 10^{-12}$ & $6.8 \times 10^{-12}$ \\
\hline
\end{tabular}

Saturation indexes for 14 uranium-containing minerals, computed from the predicted concentrations and activity coefficients in the six waters, are shown in Table 6.6. The highest saturation indexes for six minerals are presented graphically in Figure 6.2. These results indicate that al six waters should have been supersaturated with respect to $\left(\mathrm{UO}_{2}\right)_{2} \mathrm{SiO}_{4} \cdot 2 \mathrm{H}_{2} \mathrm{O}$ (soddyite), and four waters (1021, 1022, 1085, and 1113) should have been supersaturated (and the other two 


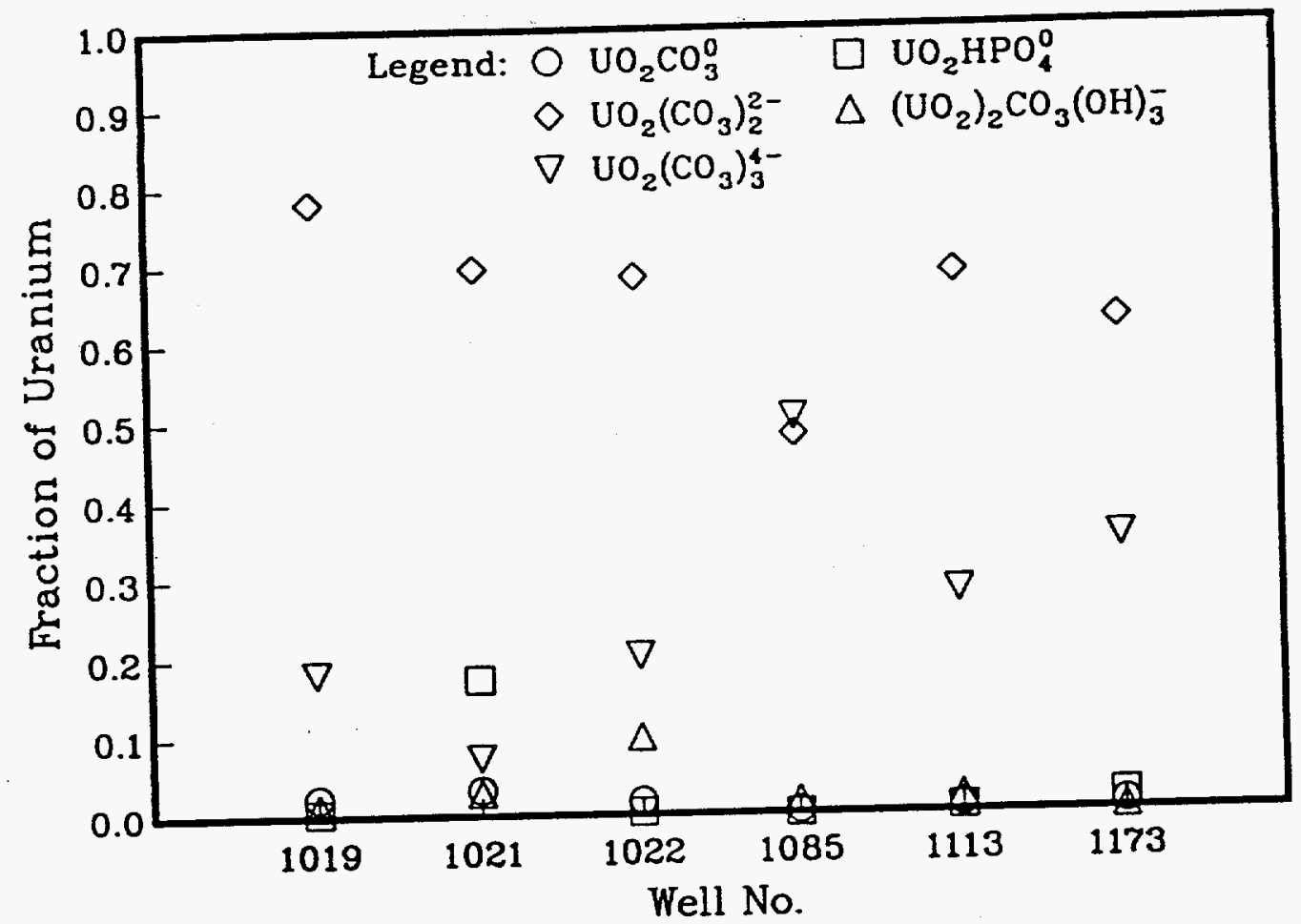

Figure 6.1. Fraction of dissolved uranium in dominant aqueous species.

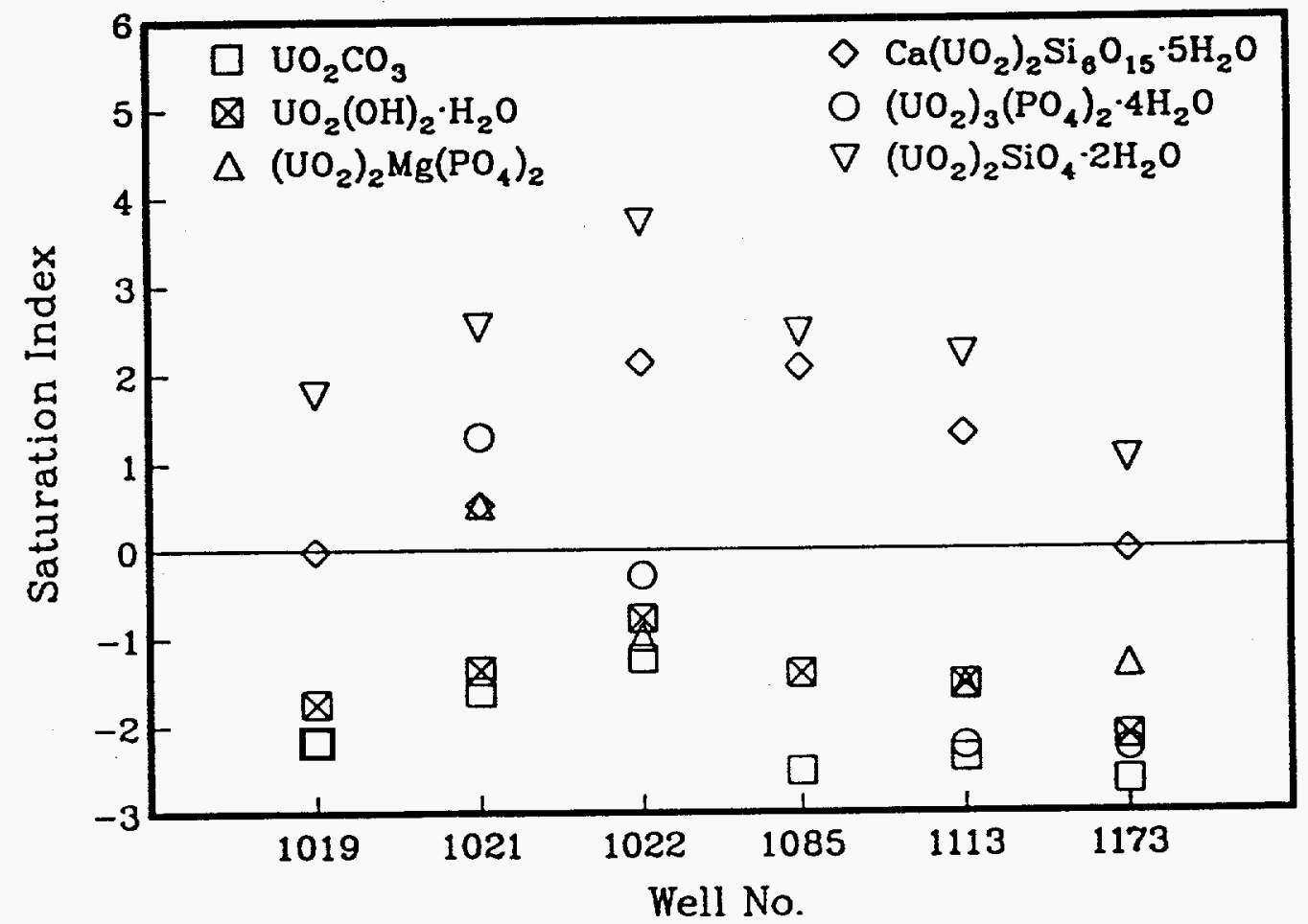

Figure 6.2. Saturation indexes for solids. 
waters almost saturated) with respect to $\mathrm{Ca}\left(\mathrm{UO}_{2}\right)_{2} \mathrm{Si}_{6} \mathrm{O}_{15} \cdot 5 \mathrm{H}_{2} \mathrm{O}$ (haiweeite). In addition, water from well 1021, which had the highest reported concentration of total phosphate, is indicated to have been supersaturated with respect to $\left(\mathrm{UO}_{2}\right)_{3}\left(\mathrm{PO}_{4}\right)_{2} \cdot 4 \mathrm{H}_{2} \mathrm{O}$ and $\left(\mathrm{UO}_{2}\right)_{2} \mathrm{Mg}\left(\mathrm{PO}_{4}\right)_{2}$ (saleeite). Other minerals whose solution components were apparently near saturation in these waters were $\mathrm{UO}_{2} \mathrm{CO}_{3}$ (rutherfordine) and $\mathrm{UO}_{2}(\mathrm{OH})_{2} \cdot \mathrm{H}_{2} \mathrm{O} \cdot$ (schoepite).

It is noted that the minerals soddyite and haiweeite both contain silica. The silica concentrations of all six waters were assumed to be $1.0 \times 10^{-4}$ mole $/ \mathrm{dm}^{3}$, in equilibrium with quartz. However, most natural waters appear to be near equilibrium with metastable amorphous silica, which has a solubility 20 times higher than that of quartz. The present calculations, using the lower quartz solubility, still predict supersaturation with respect to soddyite and haiweeite.

Evidently, the water compositions were highly metastable with respect to these solid phases, and achievement of equilibrium by precipitation was kinetically hindered. On the other hand, the real silica contents of the waters were not determined, and they might have been low enough that supersaturation did not exist in situ.

Table 6.3. Computed Saturation Indexes for Uranium-Containing Solids

\begin{tabular}{|l|l|l|l|l|l|l|}
\hline $\mathrm{Well} \mathrm{NO}$ & 1019 & 1021 & 1022 & 1085 & 1113 & 1173 \\
\hline $\mathrm{UO}_{2} \mathrm{CO}_{3}$ & -2.18 & -1.61 & -1.24 & -2.52 & -2.38 & -2.64 \\
\hline $\mathrm{UO}_{3}(\alpha)$ & -5.56 & -5.18 & -4.59 & -5.22 & -5.34 & -5.94 \\
\hline $\mathrm{UO}_{2}(\mathrm{OH})_{2} . \mathrm{H}_{2} \mathrm{O}$ & -1.75 & -1.37 & -0.78 & -1.41 & -1.54 & -2.13 \\
\hline $\mathrm{UO}_{2} \mathrm{SO}_{4} \cdot \mathrm{H}_{2} \mathrm{O}$ & -7.05 & -7.18 & -6.14 & -8.38 & -8.44 & -8.21 \\
\hline $\mathrm{CaUO}_{4}$ & -2.18 & -2.02 & -1.01 & -0.43 & -.1 .08 & -1.81 \\
\hline $\mathrm{MgUO}_{4}$ & -9.30 & -9.32 & -8.08 & -7.46 & -8.20 & -9.12 \\
\hline $\mathrm{UO}_{2} \mathrm{HPO}_{4}$ & -4.03 & -1.92 & -3.01 & -4.74 & -3.61 & -3.32 \\
\hline $\mathrm{UO}_{2} \mathrm{HPO}_{4} \cdot 4 \mathrm{H}_{2} \mathrm{O}$ & -3.69 & -1.58 & -2.66 & -4.40 & -3.27 & -2.98 \\
\hline$\left.\left(\mathrm{UO}_{2}\right)_{3}\left(\mathrm{PO}_{4}\right)_{2} \cdot 4 \mathrm{H}_{2} \mathrm{O}\right)$ & -3.31 & 1.29 & -0.29 & -4.39 & -2.24 & -2.27 \\
\hline$\left(\mathrm{UO}_{2}\right)_{2} \mathrm{H}_{2}\left(\mathrm{PO}_{4}\right)_{2}$ & -8.09 & -3.87 & -6.03 & -9.50 & -7.24 & -6.67 \\
\hline$\left(\mathrm{UO}_{2}\right)_{2} \mathrm{Mg}_{2}\left(\mathrm{PO}_{4}\right)_{2}$ & -3.29 & 0.52 & -0.99 & -3.21 & -1.56 & -1.32 \\
\hline$\left(\mathrm{UO}_{2}\right)_{2} \mathrm{SiO}_{4} .2 \mathrm{H}_{2} \mathrm{O}$ & 1.77 & 2.53 & 3.71 & 2.45 & 2.20 & 1.01 \\
\hline $\mathrm{Ca}\left(\mathrm{UO}_{2}\right)_{2} \mathrm{Si}_{2} \mathrm{O}_{6}(\mathrm{OH})_{2}$ & -8.34 & -7.80 & -6.20 & -625 & -7.02 & -8.35 \\
\hline $\mathrm{Ca}\left(\mathrm{UO}_{2}\right)_{2} \mathrm{Si}_{6} \mathrm{O}_{15}$ & -0.01 & 0.52 & 2.13 & 2.07 & 1.31 & -0.02 \\
$5 \mathrm{H}_{2} \mathrm{O}$ & & & & & & \\
\hline
\end{tabular}




\section{Summary of Results and Implications for the ID}

The two principal objectives of the Uranium in Soils Characterization Task group are (1) to demonstrate the innovative application of technologies and approaches applicable to the characterization of soils contaminated with uranium wastes, and (2) to provide site-characterization support to other task groups within this Integrated Demonstration. with respect to the characterization efforts described in this report, the first objective has been addressed by demonstrating the utility of state-of-the-science spectroscopy and microscopy techniques in conjunction with standard analytical methods to provide a quite precise description of uranium contamination in the soils at the FEMP site. We have also demonstrated the beneficial role that geochemical modeling can play in guiding and interpreting sitecharacterization activities. As discussed below, we have also amassed a significant body of data that serves to satisfy in part our second objective to support the activities of other task groups, most notably the Decontamination Task. In particular, our results can begin to be used to select appropriate remediation technologies (see below) and representative samples.

\subsection{Conclusions Regarding Innovative Application of Technologies and Characterization Approach}

A general conclusion regarding our results to date is that one of the principal reasons for our success is the strong integration and synergism of the various components in our approach. We have brought together conventional and advanced methods capable of microscopic to bulk, macroscopic scale investigation. The application of these advanced techniques represents an innovative application of the technologies since they have not been used prior to this remedial programs. In the process of demonstrating this suite of technologies, we have found clear evidence that no single technology would provide the depth and breadth of information that all the technologies, taken as a whole, provide. As an example, for samples taken from the Plant 1 area, soil mineralogy work (meso-scale) indicated that the uranium is primarily particulate, $x$-ray absorption studies (macro-scale) suggested that the particulate is mostly hexavalent uranium, TEM and Iuminescence studies (micro-scale) indicated that several different U(VI) mineral phases are present, and modeling studies confirmed that the existence of these U(VI) mineral phases is consistent with the site-specific groundwater composition. We believe that this integrated approach is crucial for the continued success of any characterization effort.

\subsection{Conclusions Regarding Physical Properties of Contaminated Soils}

Based on the mineralogical analyses and scanning electron microscopy of 10 different samples from five sites, we have 
determined that the uranium exists predominately in particulate form. The uranium is associated primarily with the sand and silt fractions of the soil, but some samples (the B-16 treatability sample, collected from the Plant 1 storage Pad Site, in particular) also have a significant amount of uranium associated with the clay fraction. In many cases, the uranium is found to be associated principally with the more dense fractions of the soil components. However, significant variations were also noted in the density fractions of the samples with which the uranium is associated. Because of these variabilities in particle-size and particle-density distributions, the Characterization Task group has strong reservations concerning the utility of density and/or size fractionation for soil-washing either as a stand-alone remediation technology or in conjunction with chemical treatment technologies.

\subsection{Conclusions Regarding Chemical Properties of Contaminated Soils}

Based on $x$-ray absorption analyses, the uranium in all samples examined thus far exists principally $(80-90 \%)$ in the hexavalent oxidation state. In general, hexavalent uranium has greater solubility than uranium in other oxidation states, thus strong oxidizing agents may not be necessary as part of a chemical remediation scheme. Note, however, that this result implies that the uranium is less stable is the soils than would be a tetravalent uranium species. Therefore, the extent of subsurface migration is expected to be greater for the hexavalent uranium species. In addition, because hexavalent uranium (as uranyl species) has a very small magnetic moment, remediation based on magnetic separation technologies will be of limited value unless the uranium is associated with some other paramagnetic phase (e.g., iron oxides).

Both microscopic (SEM and TEM) and spectroscopic (luminescence) techniques indicate that much of the particulate uranium exists in discrete, crystalline mineralogical phases, and these different techniques are in agreement with respect to the classes of minerals that are present. In contrast to the dominance of a single oxidation state, there is a wide variability in the speciation of the hexavalent uranium from site to site and in some cases with depth at a given site. TEM results further demonstrate that there is mineralogical heterogeneity even at the microscopic scale. While the full implications of these macro-scale and micro-scale heterogeneities are not clear as to their influences on remediation strategies, they indicate that a range of chemical treatment technologies will be required to effect complete remediation. Finally, the limestone gravel overburden appears to have played a significant role in defining the uranium speciation in the shallow subsurface as a result of increased $\mathrm{pH}$ and elevated carbonate concentration. 


\subsection{Conclusions Regarding Modeling Predictions}

Modeling results consistently predict the predominance of a small group of anionic uranium species in the groundwater. These include oxides, hydroxides, carbonates, silicic acids, and phosphates. As noted previously, the formation of the experimentally observed solids is consistent with the presence of these dissolved species in the groundwater and with the predicted solubility-controlling phases. It is noteworthy that the predominant dissolved species are predicted to be anionic, because this provides a ready explanation for the apparent lack of incorporation into clays (i.e., dominantly cation exchangers) and the apparent enhanced mobility of uranium at the site. The modeling studies also predict a high solubility for uranium in the groundwaters. This is consistent with the observed high uranium concentrations in the underlying perched water zones across the entire site. As such, the fate of uranium phases transported through the vadose zone (- 30 vertical feet) is called into question, and the time-scale for remediation of both the shallow subsurface and the groundwater become important. In addition, these results suggest that uranium should be found in the zones between the shallow subsurface and the perched water. The apparent absence of uranium in these zones warrants further exploration.

\subsection{Future Directions for Characterization Efforts}

In the coming year, our efforts will be concentrated on the following tasks:

* Coordinate with the Decontamination Task group to narrow the focus of work for both groups to one or two sites for characterization and treatability studies.

* Perform analyses similar to those described in this report on a limited number of additional samples obtained from the site(s) identified above.

* Perform analyses on the treated soil samples (in accordance with the strategy outlined in Fig. 1.1) to assist in remediation technology evaluation and optimization.

* Continue to use modeling to analyze the projected behavior of uranium at the selected site(s) and evaluate the utility of model calculations to guide in selection and assist in evaluation of chemical remediation technologies.

In addition, collaborative experiments within the Characterization Task group will be conducted on identical samples to explore the heterogeneity issue from the macro-scale to the micro-scale. 


\section{REFERENCES}

DOE, 1993, Integrated Demonstration, Site Characterization Demonstration Plan, Feed Materials Production Center, Fernald, Ohio. PL-3022, U.S. Department of Energy, Oak Ridge operations office, Oak Ridge, Tennessee.

DOE, 1990, Draft Remedial Investigation Report for operable Unit 3. Task 6 Report. Feed Materials Production Center, Fernald, Ohio. FMPC-0306-2 Draft, U.S. Department of Energy, Oak Ridge Operations Office, Oak Ridge, Tennessee.

R. Ewing, pers.com., University of New Mexico, (1992).

Jackson, M.L., 1975, Soil Chemical Analysis-Advanced Course, 2nd ed., Published by the author, University of Wisconsin-Madison, Wisconsin.

Kneff, D.W., G. Subbaraman, and R.J. Tuttle. 1992 . Homogeneity Evaluation of Fernald Soils Prepared For Treatability Studies. ETEC/GEN-ZR-0018. Energy Technology Engineering Center, Rocketdyne Division, Rockwell International, Los Angeles, CA.

Lee, S.Y., and J.D. Marsh, Jr., "Characterization of Uranium Contaminated Soils from DOE Fernald Environmental Management Project Site: Results of Phase II Characterization," ORNL/TM-11980, Oak Ridge National Laboratory (1992).

Perry, D.L., pers. Comm., LBNL (1992).

Soil Survey Staff, 1975, Soil Taxonomy: A basic system of soil classification for making and interpreting soil surveys, USDA-SCS Agric. Handbook 436, U.S. Government Printing office, Washington, D.C.

Tidwell, V.C., S.Y. Lee, D.E. Morris, D.L. Perry, C. Carnahan, J.C. Cunnane, S.D. Conradson, V. Gill, and M.D. Nickelson, 1992, "An Integrated Approach to the Characterization of Uranium-Contaminated Soils," In proceedings of SPECTRUM'92, Boise, ID, August 24-28, 1992.

Wade, J.W., F.F. Dyer, L. Robinson, N.A. Teasley, and J.R. Stokely. 1992. Neutron activation analysis of East Fork Poplar Creek samples. ORNL Analytical Chemistry Division, Document Number AC-MM-222002, Oak Ridge National Laboratory, Oak Ridge, TN. 


\section{URANIUM SOILS INTEGRATED DEMONSTRATION: SOIL CHARACTERIZATION PROJECT REPORT DISTRIBUTION}

George Allen, SNL

Anthony Armstrong, ORNL

Robert Bedick, METC

Sally M. Benson, LBL

James Berger, WHC

Jeanette Berry, MMES

Allison Blackman, DOE-SR

Wayne Bliss, REECO-NV

Jim Brainard, LANL

Taz Bramlette, SNL

Dave Brettschneider, FERMCO

Tom Brouns, PNL

Steve Brown, AL-EQS

Edgar Buck, ANL

Jim Buelt, PNL

Dennis Carr, FERMCO

Bob Carrington, Geotech

Vince $\mathrm{CeCi}$, BDM

David Chaiko, ANL

J. Todd Coleman, WSRC

Peter Colombo, BNL

James Corones, AMES

John Crockett, ORNL

Jim Cunnane, ANL (5)

Norman Cutshall, K-25 OR

Doug Davenport, MMES

Bill D'Marco, FERMCO

Karen Douglas, DOE-AL

Homer Dugger, KEH

Mike Eagle, EPA

Neal Egan, MSE

Mark Elliot, ORNL

William Ellis, DOE-SR

Dave Emilia, Geotech

Bruce Erdal, ET-AET

Les Fekete, PARSONS

John Ford, HAZWRAP

Chet Francis, ORNL

Doug Gerrick, FERMCO

Roger Gilchrist, WHC

Scott Grace, DOE-RF
Bimleshwar Gupta, NREL

Bill Haas, AMES

Joel Haugen, DOE-CH

James Helt, ANL

Helen Henson, K-25 OR

Don Herman, FERMCO

Ann Cochran Heywood, LLNL

Ned Hutchins, KEH

Roger Jacobson, DRI-NV

Sherri Johnson, DOE-SR

Dave Jordon, AS-KCP

Dawn Kaback, CCEM

Vince Kelly, MSE

Keith Kibbe, MMES

Kevin Kostelnik, EG\&G-ID

Michael Krstich, FERMCO

Roger Kuhl, EG\&G-ID

Bill Kuhn, PNL

Ed Lahoda, WSTC

Scott Larson, PPPL

S. Y. Lee, ORNL (5)

Alan J. Levy, LLNL

Anthony Malinauskas, MMES

Tom Malloy, MSE

Mike Malone, DOE-HO (5)

Lance Mamiya, DOE-RL

Wayne Martin, PNL

Cas Mason, LANL

John Mathur, DOE-HO

Gretchen Matthern, INEL

David Mclaughlin, WSTC

Lloyd McClure, WINCO-INEL

Katie McWilliam, DOE-NV

Ken Merrill, EG\&G-ID

Forrest Miller, WINCO-INEL

Johnny Moore, DOE-OR

Dave Morris, LANL (15)

Jennifer Nelson, SNL

Kim Nuhfer, FERMCO (25)

Karl Olson, LBL

Michael O'Rear, DOE-SR
Fred Penrod, DOE-NV

Dale Perry, LBL

Jerry Peterson, EG\&G-RF

Mary Peterson, PNL

Paul Pettit, FERMCO

Marilyn Quadrel, WHC

Leo Rogers, EG\&G-NV

Sherri Rudolph, DOE-RF

Bob Ryan

Don Sanning, EPA RREL

Pamela Saxman, DOE-AL

Richard Scott, DOE-SF

Mike Scriba, Fluor

Bill Sidle, DOE-FN

Steve Slate, PNL

Gary Staats, DOE-PETC

John Steele, WSRC

Steve Stein, PNL

Karen Stevenson, DOE-EML

John Stormont, SNL

Jim Stottlemyre, PNL

Ganesan Subbaraman, ETEC

John Suitlas, NUS

Jim Thompson, MMES

Vince Tidwell, SNL (5)

Mike Timpson, ORNL

Deborah Trader, DOE-RL

Bill Turney, LANL

Curtis Valle, AS-KCP

Paul Wang, AMES

Rod Warner, DOE-FN

Charley Watts, REECO-NV

Steve Webster, DOE-CH

Ted Wheelis, SNL

Thomas Williams, DOE-ID

Andrea Wollerman, SAIC

John C. Womack, WHC

James Wright, DOE-SR

Pete Yerace, DOE-FN

Don York, LANL

Charles Zeh, METC 


\section{Disclaimer}

This paper was prepared as an account of work sponsored by an agency of the United States government. Neither the United States government or any agency thereof, nor any of their employees, nor any of its contractors, subcontractors nor their employees makes any warranty, express or implied, or assumes any legal liability or responsibility for the accuracy, completeness, or usefulness of any information, apparatus, product, or process disclosed, or represents that its use would not infringe privately owned rights. Reference herein to any specific commercial product, process, or service by trade name, manufacturer or otherwise does not constitute or imply its endorsement, recommendation, or favoring by the United States government or any agency thereof. The views and opinions of authors expressed herein do not necessarily state or reflect those of the United States government or any agency thereof, or Fernald Environmental Restoration Management Corporation, its affiliates or its parent companies. 